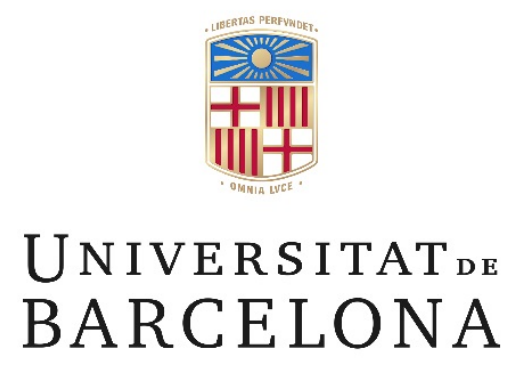

\title{
Patterns of Change and Their Relationship to Outcome and Follow-up in Group and Individual Psychotherapy for Depression
}

Danilo Orlando Moggia Narváez

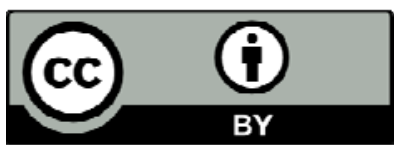

Aquesta tesi doctoral està subjecta a la llicència Reconeixement 4.0. Espanya de Creative Commons.

Esta tesis doctoral está sujeta a la licencia Reconocimiento 4.0. España de Creative Commons.

This doctoral thesis is licensed under the Creative Commons Attribution 4.0. Spain License. 


\title{
ENIVERSITAT IIIIIII BARCELONA
}

\author{
Facultat de Psicologia \\ Departament de Psicologia Clínica i Psicobiologia
}

Doctoral Programme in Brain, Behaviour, and Cognition

\author{
Dissertation
}
Patterns of Change and Their Relationship to Outcome and Follow-up in Group and Individual Psychotherapy for Depression

\author{
PhD Candidate
}

Danilo Orlando Moggia Narváez

Supervisor

Guillem Feixas Viaplana, $\mathrm{PhD}$

Barcelona, February of 2019 

A mis papás, Silvia y Orlando, por su entrega, dedicación, esfuerzo, aceptación y amor incondicional. Por llevarnos y apoyarnos (a mí y mi hermano Leo) siempre hacia adelante. Por entregarme todo lo necesario para llegar aquí y más... 

"Each person is a unique individual. Hence, psychotherapy should be formulated to meet the uniqueness of the individual's needs, rather than tailoring the person to fit the Procrustean bed of a hypothetical theory of human behaviour."

Milton H. Erickson 



\section{Acknowledgements}

First, I would like to express my sincere gratitude to my supervisor Guillem Feixas, for his continuous support during all these years of professional relationship. For his patience and devoted dedication to research and teaching. For all I have learned with and from him during all these years. With affection, thank you Guillem.

Second, I would like to thank Wolfgang Lutz for all his hospitality and support during my internship at the University of Trier. His guidance and encouragement helped me in carrying this project forward.

Third, I would like to express my gratitude to all the members of our team for his constant support during all these years. To my daily workmates: Joan Carles, Noelia, Ricardo, Helena, Alicia, Carmen, Miquel, and Víctor for the shared affection and the shared moments we have had in the last four years. To others members of our team and the department who also have supported my work indirectly or in the distance.

I would like to express my gratitude to all the members of the team of the University of Trier: Alice, Jessica, Sina, Brian, Anne-Katherina, Björn, Kaitlyn, Dirk, Birgit, Viola, Julian, thank you for sharing your valuable knowledge, your hospitality and support.

Additionally, I would like to thank Joan Guardia for giving me his opinion and advice on the statistical analysis, and to Leo McPartland for reviewing my English writing.

También quiero agradecer a mis amigos de Barcelona por todos los años de cariño y afecto compartidos, por apoyarnos mutuamente como la familia que hemos construido aquí. A mis amigos de Chile, por su cariño y apoyo incondicional, por el 
puntapié inicial que me permitió emprender esta aventura. Quiero agradecer especialmente a mi amigo Guido Del Solar por haber diseñado la portada.

Por último, a mis papas y a mi hermano, a quiénes este trabajo está dedicado, por su afecto constante y apoyo incondicional durante todos estos años. 


\section{Table of Contents}

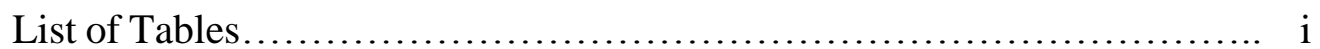

List of Figures.................................................. iii

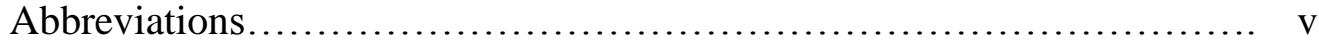

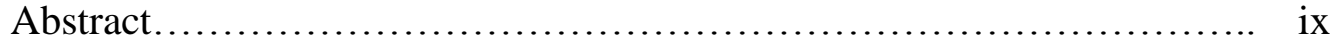

Resumen........................................................ xi

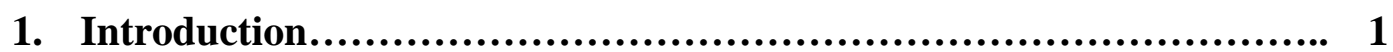

1.1 Psychotherapy Research and Depression......................... 2

1.2 Research Strategies to Enhance Psychotherapy for Depression.......... 9

1.2.1 Enhancing psychotherapy for depression by targeting factors related to psychopathology................................ 10

1.2.2 Enhancing psychotherapy for depression by targeting

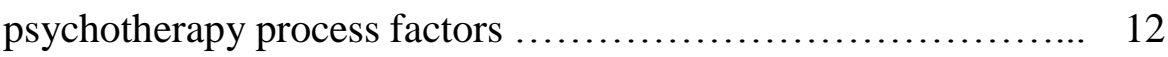

1.2.3 Dilemma-focused therapy as a way to enhance psychotherapy for depression by targeting a factor related to psychopathology: cognitive conflicts.

1.3 Patient-Focused Research and Treatment Personalisation.

1.3.1 Focusing on trajectories and patterns of change.

1.3.2 Focusing on early response .............................. 28

1.3.3 Treatment personalisation................................. 29

1.4 The Repertory Grid Technique as a Tool for Treatment Personalisation.. 33

2. Rationale..................................................................... 41

2.1 Justification.................................................... 43

2.2 Objectives............................................... 45

2.3 Hypothesis................................................... 45 


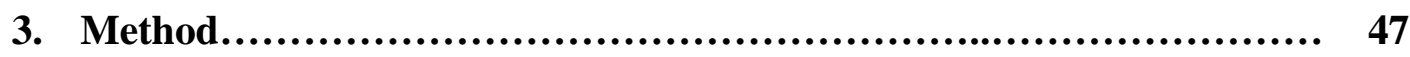

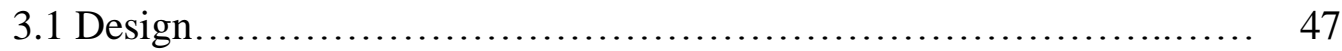

3.1.1 Design of the current research................................ 47

3.1.2 Design of the RCT study by Feixas et al. $(2013,2016,2018) \ldots \ldots .47$

3.2 Treatments............................................................ 48

3.2.1 Cognitive-behaviour group therapy (CBGT) ................. 48

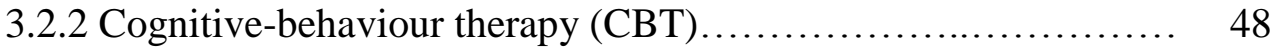

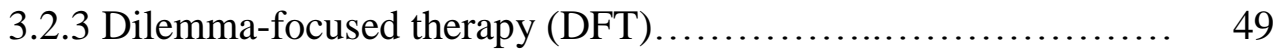

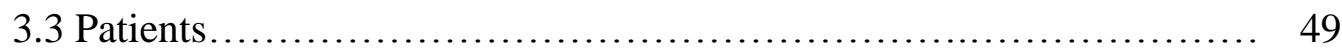

3.4 Instruments and Measures.......................................... 51

3.4.1 Structured Clinical Interview for DSM-IV Axis I Disorders

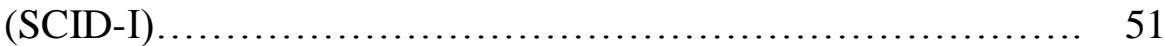

3.4.2 Beck Depression Inventory - II (BDI-II) ...................... 51

3.4.3 Global Assessment of Functioning (GAF) ...................... 52

3.4.4 Clinical Outcome in Routine Evaluation - Short Form B

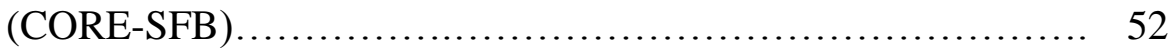

3.4.5 The Repertory Grid Technique (RGT) ........................ 53

3.4.5.1 Self-Ideal discrepancy................................. 53

3.4.5.2 Self-Others discrepancy............................... 53

3.4.5.3 Proportion of the Intensity of Constructs of Implicative

Dilemmas (PICID) .................................... 53

3.5 Data Analytical Strategy .............................................. 54

3.5.1 Patterns of change for group and individual therapy............... 54

3.5.2 Patients' characteristics within each pattern.................... 56

3.5.3 Patients' baseline characteristics as predictors of the patterns of 
change.

3.5.4 Patterns of change as predictors of treatment outcome at termination and follow-up

4. Results.

4.1 Patterns of Change for Group and Individual Therapy. 62

4.2 Patients' Characteristics within Each Pattern.... 60

4.3 Patients' Baseline Characteristics as Predictors of the Patterns of Change. 68

4.4 Patterns of Change as Predictors of Treatment Outcome at Termination and Follow-up.

5. Discussion

5.1 Limitations of the Study. 82

5.2 Proposals for Future Research. 85

6. Conclusions......................................................... 87

References..................................................... 89 



\section{List of Tables}

Table 1. Information criteria, $p$-value in bootstrapped likelihood ratio test (BLRT), and Lo-Mendel-Rubin likelihood ratio test (LRT) for models tested with growth mixture modelling (GMM)

Table 2. Parameters of the 3-class model obtained with GMM.

Table 3. Observed means, $(S D)$, [95\% CI], and effect sizes for CORE-SFB total score between classes comparisons

Table 4. Observed means, $(S D)$, [95\% CI], and effect sizes for BDI-II, GAF, Self-Ideal, Self-Others, and PICID between classes comparisons......

Table 5. Parameters for MLR predicting class membership from patients' baseline characteristics

Table 6. Parameters for MLR predicting class membership from patients' baseline characteristics and fibromyalgia diagnosis as predictor

Table 7. Parameters of sequential linear regression analysis to predict BDIII scores at termination, 3-months, and 1-year follow-up assessments.

Table 8. Percentage of recovered patients in each class 73 



\section{List of Figures}

Figure 1. Example of a repertory grid.

Figure 2. Schematic representation of an implicative dilemma and a dilemmatic construct.

Figure 3. CONSORT diagram of Feixas et al. (2018) RCT.

Figure 4. Path diagram of the model computed with GMM.

Figure 5. Estimated mean latent growth curves for the 3-class model with GMM

Figure 6. Observed means and $95 \%$ CI for CORE-SFB total score by classes at intake, last session of the group therapy phase, and post-treatment assessment

Figure 7. Observed means and 95\% CI for BDI-II total score and GAF by classes at intake, post-treatment, 3-months and 1-year follow-up assessment....

Figure 8. Observed means and $95 \%$ CI for Self-Ideal and Self-Others discrepancies, and PICID at intake and post-treatment assessments 



\begin{tabular}{|c|c|}
\hline & Abbreviations \\
\hline 1-year FU & 1 year follow-up \\
\hline 3-month FU & 3-month follow-up \\
\hline $95 \% \mathrm{CI}$ & $95 \%$ confidence intervals \\
\hline $\mathrm{ACT}$ & Acceptance and commitment therapy \\
\hline AIC & Akaike's information criterion \\
\hline ANOVA & Analysis of variance \\
\hline APA & American Psychological Association \\
\hline APA & American Psychiatric Association \\
\hline BA & Behavioural activation \\
\hline BDI-II & Beck Depression Inventory - II \\
\hline $\mathrm{BIC}$ & Bayesian information criterion \\
\hline BLRT & Bootstrapped likelihood ratio test \\
\hline CBGT & Cognitive-behaviour group therapy \\
\hline CBT & Cognitive-behaviour therapy \\
\hline $\mathrm{CCs}$ & Cognitive conflicts \\
\hline CONSORT & Consolidated Standards for Reporting Trials \\
\hline CORE & Clinical Outcome in Routine Evaluation \\
\hline CORE-OM & Clinical Outcome in Routine Evaluation - Outcome Measure \\
\hline CORE-SFB & Clinical Outcome in Routine Evaluation - Short Form B \\
\hline DALYs & Disability-Adjusted Life-Years \\
\hline DCs & Dilemmatic constructs \\
\hline DFT & Dilemma-focused therapy \\
\hline
\end{tabular}

DSM-5 Diagnostic and Statistical Manual of Mental Disorders, 5th Edition 
DSM-IV-TR Diagnostic and Statistical Manual of Mental Disorders, IV Edition, Text Revision

\begin{tabular}{|c|c|}
\hline EFT & Emotion-focused therapy \\
\hline ETR & Expected treatment response \\
\hline$F$ & Fisher's statistic \\
\hline FIT & Feedback-informed treatment \\
\hline$g$ & Hedges' $g$ effect size \\
\hline $\mathrm{G}_{\#}$ & Group therapy session number \\
\hline GAF & Global Assessment of Functioning \\
\hline GMM & Growth mixture modeling \\
\hline HAMD & Hamilton Depression Scale \\
\hline HLM & Hierarchical linear modeling \\
\hline $\mathrm{I}_{\#}$ & Individual therapy session number \\
\hline ICD-11 & International Classification of Diseases -11 th Edition \\
\hline IDs & Implicative dilemmas \\
\hline IHME & Institute for Health Metrics and Education \\
\hline IPT & Interpersonal therapy \\
\hline LRT & Lo-Mendel-Rubin likelihood ratio test \\
\hline$M$ & Mean \\
\hline MBCT & Mindfulness-based cognitive therapy \\
\hline MDD & Major depressive disorder \\
\hline MLM & Mixed linear modelling \\
\hline MLR & Multinomial logistic regression \\
\hline$N$ & Population size \\
\hline$n$ & Sample size \\
\hline
\end{tabular}


NICE National Institute for Clinical Excellence

NN Nearest neighbours

OECD The Organisation for Economic Co-operation and Development

ORS Outcome Rating Scale

$p \quad p$-value

PAI Personalised Advantage Index

PCPT Personal construct psychotherapy

PCT Personal construct theory

PICID Proportion of the intensity of constructs of implicative dilemmas

Post-TA Post-treatment assessment

$R^{2} \quad$ Proportion of explained variance

RCI Reliable change index

RCTs Randomised controlled trials

RGT Repertory grid technique

RM-ANOVA Repeated measures - analysis of variance

RMSEA Root mean square error of approximation

ROM Routine outcome monitoring

SCT Systemic couple therapy

SD Standard deviation

SE $\quad$ Standard error

SEM Structural equation modelling

TAU Treatment as usual

UN United Nations

VIF Variance inflation factor

WHO World Health Organisation 


$\begin{array}{ll}X^{2} & \mathrm{Chi}^{2} \\ z & \text { Standardised score }\end{array}$




\begin{abstract}
The study explored the presence of different patterns of change in a sample of patients who received cognitive therapy for depression in group and individual sequential formats. Our hypothesis was that some patients would respond better to group than to individual therapy, and that for others the opposite trend would be found. Objective: To identify differential patterns of response, to describe the differences in the patients' characteristics in each pattern, and to predict pattern membership from these characteristics. Also, we wanted to gauge the relationship between each pattern and treatment outcome at termination and follow-up. Method: 108 adults who met criteria for major depressive disorder and/or dysthymia completed the treatments included in a randomized controlled trial combining group and individual therapy. They were assessed with the Structured Clinical Interview for DSM-IV Axis I Disorders, the Beck Depression Inventory-II, the Clinical Outcome in Routine Evaluation, the Global Assessment of Functioning, and the Repertory Grid Technique. Growth mixture modeling was used to identify the patterns of change in each treatment phase. Mixed linear models and repeated measures analysis of variance were performed to compare patients' characteristics in each pattern. Multinomial logistic regression was used to compute predictive models for the patterns from patients' baseline characteristics. Finally, hierarchical linear regression was used to establish the power of each pattern to predict treatment outcome at termination and at 3-month and 1-year follow-up. Results: A 3-class solution was obtained: group therapy improvers, individual therapy improvers and non-improvers. Patients in each pattern differed in terms of initial symptom severity, psychological distress, functioning, self-ideal discrepancy, perception of social isolation, and conflictual construction of the self. Some of these variables also worked as predictors for pattern membership. More than half of the explained variance of the
\end{abstract}


outcome at termination and at 1-year follow-up was accounted for by initial depression scores and pattern of change. Conclusions: The results supported the hypothesis of differential patterns of response to cognitive therapy. Profiles of patients who obtained better results in group or individual therapy for depression could be identified as well.

Keywords: early response, trajectories, growth mixture modeling, personalised therapy, low- and high-intensity treatments 


\section{Resumen}

El estudio exploró la presencia de diferentes patrones de cambio en una muestra de pacientes que recibió terapia cognitiva para la depresión en dos formatos secuenciales: grupal e individual. Nuestra hipótesis fue que algunos pacientes responderían mejor a la terapia grupal que a la individual, y que para otros pacientes se encontraría el patrón opuesto. Objetivo: Identificar patrones diferenciales de respuesta, describir las diferencias entre las características de los pacientes en cada patrón y, desde estas características, predecir la pertenencia de los pacientes a cada patrón. También quisimos evaluar la relación entre cada patrón y el resultado de la terapia al final del tratamiento y al seguimiento. Método: 108 adultos que cumplieron criterios para el diagnóstico de trastorno depresivo mayor y/o distimia completaron los tratamientos como parte de un ensayo clínico aleatorizado que combinaba terapia grupal e individual. Los pacientes fueron evaluados con la Entrevista Clínica Estructurada para los Trastornos del Eje I del DSM-IV, el Inventario de Depresión de Beck - II, el Clinical Outcome in Routine Evaluation, la Escala de Evaluación de la Actividad Global, y la técnica de la rejilla. Se utilizaron modelos de crecimiento mixtos para identificar los patrones de cambio en cada fase de tratamiento. Se utilizaron modelos lineales mixtos y análisis de la varianza de medias repetidas para estimar las diferencias en las características de los pacientes entre cada patrón. A través de regresión logística multinomial se estimaron modelos predictivos de los patrones de cambio desde las características iniciales de los pacientes. Finalmente, a través de regresión lineal jerárquica se estimó el poder predictivo de cada patrón para explicar los resultados de la terapia al final del tratamiento, al seguimiento a los tres meses y al seguimiento a un año. Resultados: Se obtuvo una solución de tres clases: quienes mejoraron en terapia grupal, quienes mejoraron en terapia individual y quienes no mejoraron. Los pacientes 
pertenecientes a cada patrón se diferenciaron en el nivel inicial de sintomatología, malestar psicológico, funcionamiento, discrepancia yo-ideal, aislamiento social autopercibido y construcción conflictiva del sí-mismo. Algunas de estas variables también funcionaron como predictores de la pertenencia de los pacientes a cada patrón. Más de la mitad de la varianza explicada del resultado de la terapia al final del tratamiento y al seguimiento a un año fue representada por las puntuaciones iniciales de depresión y los patrones de cambio. Conclusiones: Los resultados tendieron a apoyar nuestra hipótesis acerca de patrones diferenciales de respuesta en terapia cognitiva. Los perfiles de los pacientes que obtuvieron mejores resultados en terapia grupal que en terapia individual para depresión pudieron ser identificados.

Palabras clave: respuesta temprana, trayectorias, modelos de crecimiento mixto, terapia personalizada, tratamientos de baja y alta intensidad 


\section{Introduction}

The current dissertation studied the patterns of change (trajectories) in a sample of patients that, in the context of a randomised controlled trial (RCT) for depression (Feixas et al., 2013, 2016, 2018), received two interventions sequentially: first, cognitive-behaviour group therapy (CBGT), regarded as low-intensity CBT (Söchting, Wilson, \& De Gagné, 2010), for all patients, and then, one of two types of cognitive individual therapy (high-intensity treatments) where patients were randomly allocated to either standard cognitive-behaviour therapy (CBT; Beck, Rush, Shaw, \& Emery, 1979) or dilemma-focused therapy (DFT; Feixas \& Compañ, 2016). Analyses of this RCT study both at end of therapy and follow up assessments (Feixas et al., 2016, 2018) showed that both conditions of treatment were equally efficacious.

Considering that patients received the treatments in two consecutive phases, and based on previous literature, we predicted the existence of distinct patient response patterns for each treatment phase. That is, we hypothesised that some patients would respond better to group therapy than to individual therapy, and that in other patients the opposite trend would be found.

The importance of identifying these patterns is the potential for establishing predictive models based on patients' characteristics belonging to each pattern cluster. That is, we want to identify the predictors of pattern cluster membership in order to use these models for treatment personalisation. From a cost-efficacy perspective, establishing “what works for whom?” (Paul, 1967) is particularly important, especially with patients who are likely to obtain greater benefits from a more economical therapeutic modality, such as group therapy (a low-intensity CBT), can be identified and also patients who do indeed need individual therapy (high-intensity CBT). 
In the study of Feixas et al. $(2013,2016,2018)$, a self-report measure of depression was used as primary outcome, and general functioning, psychological distress, and indexes from the repertory grid technique (RGT; Kelly, 1955/1991) — for assessing self-ideal discrepancy, perceived social isolation, and conflictual construction of the self - were used secondarily. In this study, the patterns are tracked in terms of psychological distress assessed session by session. From these patterns, differences in patients' characteristics belonging to each pattern cluster were compared. The patients' intake characteristics which predicted these patterns were established. Finally, the relationship between each pattern and treatment outcome at termination and follow-up was explored.

In the following sections, the theoretical background that guided this research will be outlined. First, a review of state of the art regarding psychotherapy research and depression is presented. Second, the attempts that have been made to improve psychotherapy for depression, and the research programme from which the study of Feixas et al. (2013, 2016, 2018) was designed, are explained. Third, recent paradigms in psychotherapy research and treatment personalisation, from which this dissertation was derived, are described. Finally, the contributions of one of the instruments used in the study of Feixas et al. $(2013,2016,2018)$, the RGT, and its potential utilisation for treatment personalisation are discussed.

\subsection{Psychotherapy Research and Depression}

Generally, the field of psychotherapy research can be summarised in three or four main lines of enquiry (depending on the authors doing the classification): psychotherapy outcome research, psychotherapy process research, process and outcome 
research, and common factors - for some authors this latter is a subtype of processoutcome research— (Gelo, Pritz, \& Rieken, 2015; Krause, 2005; Lambert, 2013a).

Psychotherapy outcome research aims to investigate whether a treatment produces the desired and expected clinical results (Gelo et al., 2015). In other words, psychotherapy outcome research deals with the question: does psychotherapy work (for ' $\mathrm{X}$ ' clinical condition)? Mostly quantitative studies based on pre-to-post comparisons can be found under this line of enquiry. These can be efficacy or effectiveness studies. The first type corresponds to designs where the conditions of the treatment are controlled (e.g., treatment manualisation, formal inclusion/exclusion systematised criteria), the effects of it are compared to a control group, and patients are randomly allocated to one of the tested conditions (Comer \& Kendall, 2013). These are the RCTs that support the paradigm of evidence-based practice. In contrast, effectiveness studies examine the results of treatments provided in natural clinical settings where the conditions of the treatment are under minimum control (Gold, 2015). These designs support the paradigm of practice-based evidence. These two paradigms are complementary because while efficacy studies obtain a high level of internal validity (and lower levels of external validity), effectiveness studies add to the opposite (Lambert, 2013b).

The second line of enquiry is psychotherapy process research, which deals with the question of how psychotherapy works (Hardy \& Llewelyn, 2015). Factors such as therapeutic alliance, therapist and patient behaviours during the sessions, therapeutic methods, clinical strategies and techniques, are studied with quantitative and qualitative designs. 
When the aforementioned factors are studied to see what effect they have on the outcome of therapy, we are talking about process-outcome research. Process-outcome research deals with the question: what is happening in the psychotherapy sessions that is helpful (or not)? In other words, what needs to happen during the sessions to obtain a specific outcome (Crits-Christoph, Connolly-Gibbons, \& Mukberjee, 2013; Gelo \& Manzo, 2015). Studies under this approach mostly use quantitative and mixed designs.

The common factors perspective can be classified as a process-outcome line of enquiry. Common factors (Cuijpers, Reijnders, \& Huibers, 2019; McAleavey \& Castonguay, 2015) emerged at the end of the 1970s when the first meta-analyses of psychotherapy outcome supported the general efficacy and effectiveness of psychotherapy, but not the superiority of any approach or school. "Everybody has won, all must have prizes" was the statement that summarised this equivalence conclusion known as "the dodo bird verdict" (Elliott, Barker, \& Hunsley, 2015). Common factors deal with the following question: if all "bona fide" approaches or schools of psychotherapy are equally efficacious and effective, what are the "common factors" that make psychotherapy work? Factors such as therapeutic alliance, empathy from the therapist, expectations of the patient, cultural adaptation of the therapy, and therapist individual differences have been studied regarding their contribution to treatment outcome (Wampold, 2015).

In the context of psychotherapy research, depression has been one of the most studied clinical conditions (Cuijpers, Karyotaki, Reijnders, \& Ebert, 2018; Wampold \& Imel, 2015). The probable reason is that depression is one of the most widespread mental health problems worldwide, being one of the leading causes of disability (World Health Organisation [WHO], 2018a). This led researchers and clinicians to access to the clinical population easily, and to prioritise the efforts to tackle this problem as a public 
health issue. In fact, the United Nations (UN) in their last World Happiness Report (Helliwell, Layard, \& Sachs, 2018), talks about depression as an "epidemic" due to the increase of its prevalence rates in the United States and other countries of the Organisation for Economic Co-operation and Development (OECD), not only in adults, but also in adolescents. According to the Institute for Health Metrics and Education (IHME), the estimated mean of Disability-Adjusted Life-Years (DALYs) for the world in 2016 was around 600 per 100,000 inhabitants (IHME, 2017). Furthermore, individuals with depression lost 5.6 hours of productive time at work per week compared to 1.6 hours in non-depressed workers, which results in 225 million of workdays lost per year (McLaughlin, 2011).

From current psychopathological nosologies (i.e., Diagnostic and Statistical Manual of Mental Disorders - 5 [DSM-5], American Psychiatric Association [APA], 2013; and International Classification of Diseases - 11 [ICD-11], WHO, 2018), depression is a term that refers to two different, but similar clinical conditions: major depressive disorder (MDD), and dysthymia (or persistent depressive disorder). In both, a number of symptoms such as low mood and sadness, apathy, anhedonia, hopelessness, tiredness, irritability, guilt, deteriorated image of the self (i.e., low self-esteem), alterations of the apetite and sleep must be present. According to the DSM-5 and ICD11 , the difference between these conditions is the chronicity and intensity of the symptoms. For MDD, five or more symptoms (including depressed mood and/or anhedonia) have to be present during the same two-week period; while for dysthymia, 
two or more symptoms (beyond depressed mood) should be present for at least two years. ${ }^{1}$

The outcome of psychotherapy for depression has been examined in more than 250 RCTs (Cuijpers et al., 2018). Diverse meta-analyses evaluating their efficacy or effectiveness have shown that effect sizes (in Hedges' $g$ ) go between .20 and 1.5 or higher in efficacy studies and between .20 and .80 or higher in effectiveness studies (Hunsley, Elliott, \& Therrien, 2014). Indeed, the efficay and effectiveness of psychotherapy for depression is well-established (Cuijpers, Ebert, Acarturk, Andersson, \& Cristea, 2016). The studies included approaches such as CBT, interpersonal therapy (IPT), problem-solving therapy, behavioural activation (BA), emotion-focused therapy (EFT), systemic couple therapy (SCT), mindfulness-based cognitive therapy (MBCT), psychodynamic therapies, acceptance and commitment therapy (ACT), low-intensity therapies (e.g., CBGT, telephone-delivered CBT and IPT, internet- and computerassisted therapy), among others (Parikh et al., 2016). Several RCTs comparing different types of psychotherapy have shown that there are no differences in effects among these therapies and, if any, it is minimal, concluding, therefore, with the "dodo verdict". In other words, they concluded that all bona fide therapies (i.e., delivered by trained therapists, based on psychological principles, and designed to be a viable treatmentParikh et al., 2016) seem to be equally efficacious or about equally efficacious in the treatment of depression (Cuijpers et al., 2016).

\footnotetext{
${ }^{1}$ In the study by Feixas et al. $(2013,2016,2018)$ RCT, patients were assessed conforming the criteria of Diagnostic and Statistical Manual of Mental Disorders - IV - Text Revision (DSM-IV-TR; APA, 2000) for MDD and dysthymia. These criteria did not change in DSM 5.
} 
Regarding process and process-outcome studies, the factors addressed by the researchers vary according to the theory of change they are assuming or the psychotherapeutic approach they are investigating. For instance, it is possible to find studies about the role of different process variables in treatment outcome of depression such as narrative markers of change or innovation (Fernández-Navarro et al., 2018; Gonçalves et al., 2016), emotional processing and task resolution (Greenberg \& Watson, 2010), narrative and emotional processing (Boritz, Bryntwick, Angus, Greenberg, \& Constantino, 2014), ambivalence toward change (Braga et al., 2018), assimilation of problematic experiences (Detert, Llewelyn, Hardy, Barkham, \& Stiles, 2006; Mendes et al., 2016; Ribeiro et al., 2016), just to name a few.

Assuming a common factors perspective, the American Psychological Association (APA) elaborated a task force on psychotherapy, called "Evidence-Based Therapy Relationships" (APA, 2012; Norcross \& Wampold, 2011; Norcross \& Lambert, 2018). In their lastest version, authors concluded that process factors such as alliance, collaboration, goal consensus, cohesion in group therapy, empathy, positive regard and affirmation, collecting and delivering patient feedback are "demonstrably effective" in terms of increasing the likelihood of psychotherapy success. Other factors such as congruence/genuineness, real relationship, emotional expression, cultivating positive expectations, promoting treatment credibility, repairing alliance ruptures, and managing countertransference are "probably effective"; and therapist self-disclosure and immediacy, are "promising but insufficient research to judge." These findings have been quoted in several clinical guidelines of depression as evidence-based therapy practices (Álvarez Ariza et al., 2014; Hunsley et al., 2014; Karyotaki et al., 2014; Parikh et al., 2016). 
Concerning therapy modality, meta-analyses (Cuijpers, van Straten, \& Warmerdam, 2008; Huntley, Araya, \& Salisbury, 2012; Okumura \& Ichikura, 2014) evaluating the efficacy and effectiveness of group vs. individual therapy for depression have concluded that group therapy is more effective than treatment as usual (TAU), but can be less effective than individual therapy at the end of treatment in more severe cases, while no differences were found at follow-up. Furthermore, group therapy showed higher dropout rates than individual therapy. However, the authors concluded that more research is needed to examine whether the difference between individual and group treatment is clinically relevant. Nevertheless, it is recommended considering other factors such as availability, costs, and patient preferences in choosing between group and individual therapy in clinical practice (Parikh et al., 2016).

To summarise, we agree upon the conclusions of Munder et al. (2018) after a reanalysis of treatments of depression in the context of a recent debate (Cuijpers et al., 2018) about Eysenck's (1952) original claim on psychotherapy ineffectiveness, as follows:

"Given these results, as well as a considerable corpus of evidence consistent with these results (Wampold \& Imel, 2015), we argue that the field should accept the general conclusion that psychotherapy is an effective practice and give our attention to ways that psychotherapy could be improved." (p. 6) 


\subsection{Research Strategies to Enhance Psychotherapy for Depression}

Considering the well-supported efficacy and effectiveness of psychotherapy for depression (as previously explained), psychological therapies (e.g., CBT) are recommended as first-line treatment by clinical guidelines (The National Institute for Health and Care Excellence [NICE], 2018). Nevertheless, responses remain approximately at 50\%, and recurrences and relapses are often (Buckman et al., 2018). Cuijpers et al. (2016) give us three interesting killer-facts. First, treatments for depression can reduce the burden of the symptoms by only about 33\% (Andrews, Issakidis, Sanderson, Corry, \& Lapsley, 2004). Second, more than $40 \%$ of the patients do not, or only partially, respond to treatment, and less than one third are wholly recovered after treatment (Hollon et al., 2002). Third, relapse rates are estimated at 54\% after two years and up to $85 \%$ within 15 years after recovery from an initial episode (Vittengl, Clark, Dunn, \& Jarrett, 2007). Additionally, 20 patients need to be treated with psychotherapy in order to avoid one case of deterioration (Cuijpers, Reijnders, Karyotaki, de Wit, \& Ebert, 2018), and dropout rates have been estimated around $17.5 \%$ and 20\% from individual psychotherapy (Cooper \& Conklin, 2015).

Under this scenario, researchers and clinicians have made many attempts to improve the response rates aimed at enhancing psychotherapies for depression. Three initiatives have been taken in order to achieve this goal: studying factors related to psychopathology, studying psychotherapy process factors, and treatment personalisation. In the following subsections, the first two initiatives will be discussed. Subsequently, DFT is outlined as an example of the first initiative. The third initiative, treatment personalisation, will be explained in the next section. 


\subsubsection{Enhancing psychotherapy for depression by targeting factors related}

\section{to psychopathology.}

Improving psychological therapies by studying factors related to psychopathology (e.g., behavioural inhibition, negative thoughts), implies to have a psychological theory and a model to explain depression, or counting on evidence which supports that ' $\mathrm{X}$ ' psychological variable is related to depression. That is, proposing a set of factors or variables which are causing, maintaining, and/or influencing the symptoms and the clinical condition. These variables should be operationalised in order to be measured and addressed in a specific treatment protocol. If the variable is properly modified during the treatment, symptoms must decrease in proportion. From this point of view, research designs (particularly RCTs) which dismantle components of treatment protocols or add components to them can be carried out. These designs aim to find specific effects on the treated condition by managing the target variable. That is, adding or removing the treatment component designed to treat that variable in the compared conditions (Wampold \& Imel, 2015). For instance, the first dismantling design was carried out by Jacobson et al. (1996). They tested the hypothesis that CBT for depression as formulated by Beck et al. (1979) would work better than BA and automatic thoughts restructuring components alone. At the same time, this latter would work better than BA alone. That was not the case; all three conditions resulted equally efficacious. In fact, later on these results were replicated in a study with similar design (Dimidjian et al., 2006).

Meta-analyses (Ahn \& Wampold, 2001; Bell, Marcus, \& Goodlad, 2013) evaluating the effects of dismantled or added components in several studies have found a modest effect on additive designs, and no effect on dismantling designs. However, it seems that the tiny effect found on additive designs was an artefact from the data 
analytic strategy utilised (Flückiger, Del Re, \& Wampold, 2015). In fact, in a recent meta-analyses of components studies (Cuijpers, Cristea, Karyotaki, Reijnders, \& Hollon, 2019) including publications from 1966 to 2016, the authors did not find sufficient statistical power to draw significant results. Therefore, they concluded that we do not know if the effect of psychotherapy for depression is due to specific components or common factors.

Another way of assessing the effect of addressing a specific factor related to psychopathology on treatment outcome is through mediation and moderation analyses (Kazdin, 2014). For example, evaluating the effect of automatic thoughts restructuring on CBT outcome. In these types of studies there is not a direct manipulation of the variables, but proper measurement of them and statistical analyses of their effects on treatment outcome.

Being CBT the most studied model of psychotherapy ever, several studies have been conducted to test the effect of mediators and moderators for this treatment of depression (Wampold \& Imel, 2015). They included change in negative attitudes and modification of automatic thoughts (Oei \& Free, 1995); BA, learning cognitive coping skills and modification of core dysfunctional schemas (Dimidjian et al., 2006; Jacobson et al., 1996); learning cognitive coping skills and problem resolution techniques (DeRubeis \& Feeley, 1990; Feeley, DeRubeis, \& Gelfand, 1999; Strunk, Cooper, Ryan, DeRubeis, \& Hollon, 2012; Tang \& DeRubeis, 1999); change of dysfunctional attitudes and negative emotions (Burns \& Spangler, 2001); acquisition of coping skills and change in implicitly maladaptive beliefs (Adler, Strunk, \& Fazio, 2015); among others. In none of these studies, a direct effect of the measured variables on treatment outcome could be isolated, resulting in an unresolved timeline problem (what was first, the change in the mediator or in the symptoms?, Kazdin, 2009). According to Longmore \& 
Worrell (2007), there is insufficient evidence to conclude that challenging thoughts is responsible for the benefits of CBT for depression. Furthermore, there is evidence that therapies are not specific to change the target variables they say to change according to their theory; thus change in a specific psychological variable may occur in different models of therapies (Castonguay, 2011). For instance, a change in distorted cognitions also occurs in IPT, pharmacotherapy, and BA alone (Dimidjian et al., 2006; Imber et al., 1990; Jacobson et al., 1996; Oei \& Free, 1995).

Considering the previous review, it is possible to conclude that, to date, there are not specific components regarding psychological factors related to psychopathology that can be specifically targeted to enhance the treatment of depression.

\subsubsection{Enhancing psychotherapy for depression by targeting psychotherapy}

\section{process factors.}

Studying psychotherapy process factors aimed at enhancing the treatment of depression, implies to control the conditions of the design by enhancing the targeted psychotherapy process factors (e.g., accomplishment of homework assignments, insights of the patients, repairing of alliance ruptures) in one of the tested conditions, or doing mediation and moderation analyses. It must be pointed out that this latter type of studies does not lead to a direct treatment improvement, but to establish what is the contribution of the studied factors to treatment outcome. Once these factors have been identified, they can be tested by enhancing them in one of a RCT's conditions, or in clinical practice through effectiveness studies.

Here we are talking about process factors which explain change processes and not psychopathology. These include process variables proposed by specific models of 
change and common factors. For instance, rates of homework assignments completion in CBT for depression resulted in a powerful predictor of patients' improvement (Burns \& Nolen-Hoeksema, 1991; Burns \& Spangler, 2000). These results were consistent with the study of Neimeyer and Feixas (2016), in which patients were randomly allocated to one of two conditions of a 10-week CBT programme for depression: with or without homework assignments. Allocation in the homework condition predicted more substantial improvement of the patients in depression symptoms at termination, but not at six-month follow-up. However, acquisition of cognitive restructuring skills predicted maintenance of treatment gains at follow-up in both conditions.

An observational study (Crits-Christoph, Gibbons, Temes, Elkin, \& Gallop, 2010) which compared how interpersonal issues were addressed by IPT and CBT therapists, found that the use of learning statements (defined as "any statement that helped the patient become aware of a thought, feeling, or behaviour" [p. 423], regarded as interpretation by psychodynamic approaches) was positively related to outcome in IPT for depression, but the opposite relation was found in CBT. Another study (McAleavey \& Castonguay, 2015) found that emotional deepening and exploration of the past (techniques associated with psychodynamic and humanistic therapies), not only can be identified in sessions conducted by CBT therapists, but also have been linked with outcome in CBT. Furthermore, patients with depression that were treated by CBT therapists specially trained in strategies for addressing alliance ruptures showed greater improvement and more clinically significant change than patients treated by standard CBT therapists in a RCT (Constantino et al., 2008).

Regarding the effect of the therapists in CBT for depression, adherence and competence rates on treatment outcome show contradictory results. One meta-analysis (Webb, DeRubeis, \& Barber, 2010) concluded that therapist adherence and competence 
play a little role in determining symptoms improvement. Later on, other authors (Webb et al., 2012) studying two different samples found that adherence to CBT techniques is strongly associated with patients' CBT skills and symptoms change in one sample. In the other sample, the therapeutic alliance was a stronger predictor than the factors mentioned. The authors concluded that interaction between depression symptoms severity at intake and $\mathrm{CBT}$ techniques might play a role in explaining the difference between the two samples.

Others studies found that adherence to behavioural methods and homework assignments were strong predictors of symptoms improvement (Sasso, Strunk, Braun, DeRubeis, \& Brotman, 2015). Finally, Socratic questioning predicted session to session symptoms improvement when the alliance was controlled (Braun, Strunk, Sasso, \& Cooper, 2015).

In terms of common factors, as was previously explained, APA's task force on psychotherapy relationships (acknowledged in clinical guidelines of depression), it was concluded that the best outcomes are likely to come from the use of evidence-based therapy relationships (see section 1.1). The therapeutic alliance has been identified as one of the main contributing factors to psychotherapy outcome, acting as the best predictor of treatment success (Ardito \& Rabellino, 2011; Flückiger, Del Re, Wampold, \& Horvath, 2018; Lambert \& Barley, 2001). In CBT for depression, the alliance factors of agreement between therapist and patient in tasks and methods, but not the affective bond between them, have been found strong predictors of treatment outcome. In contrast, both factors, when assessed in a late session, were significantly predicted by prior symptoms change (Webb et al., 2011). 
Almost every study reviewed fail in controlling the timeline of symptoms improvement and the role of the mediators analysed (Crits-Christoph et al., 2013). That is, it was not possible to say what was first, the role of the mediator in the change process or symptom improvement. Furthermore, only little empirical support for the respective theoretical models of change in psychotherapy for depression was reported in the studies (Lemmens et al., 2017). It is surprising that considering the number of outcome studies about CBT for depression that have been conducted to date, there is still a lack of studies about processes and mechanisms of change. Much more research is needed to determine whether specific processes and mechanisms are responsible for change, in order to enhance treatments for depression with this initiative.

\subsubsection{Dilemma-focused therapy as a way to enhance psychotherapy for} depression by targeting a factor related to psychopathology: cognitive conflicts.

One initiative aimed at improving the efficacy of psychotherapy for depression was the research project "Efficacy of a dilemma-focused intervention for unipolar depression" (Feixas et al., 2013, 2016, 2018). In this project, the initiative taken by the researchers was studying factors related to psychopathology (section 1.2.1), particularly cognitive conflicts (CCs).

A CC corresponds to an internal contradiction between two parts of the self that can play a role when a person is faced to a change process that compromises aspects of his or her identity (as in psychotherapy). One of these parts leads the person to change, enclosing the advantages of change. In contrast, the other part is led to maintain the continuity of the person's former identity, enclosing the disadvantages of change. 
The operationalisation of CCs has been carried out by means of the RGT (Feixas \& Saúl, 2004; Feixas, Saúl, \& Ávila-Espada, 2009). The RGT is derived from Kelly’s personal construct theory (PCT; Kelly 1955/1991), which assumes that each person constructs his or her own system of meanings to interpret his or her self, others and the world. The units with which this system of meanings is created are personal constructs: bipolar dimensions of meaning (e.g., black vs white, short vs tall, nervous vs calm, etc.) which people use to interpret the world, make decisions and act upon it. The RGT is a semi-structured interview that assesses the system of personal constructs people use to define themselves and their interpersonal world. In general terms, is a method for attempting to "stand in others" shoes," to see their world as they see it, and to understand their concerns (Fransella, Bell, \& Bannister, 2004). It begins by identifying a set of significant others (partner, family, friends) and self-elements (e.g., "self now", “ideal self”; see upper part of figure 1). Then, individuals are asked to find similarities and differences between them, using their own words to name these characteristics (their personal constructs; see left column of figure 1). Finally, individuals rate each element (self and others) according to each of the constructs elicited (usually on a 7point Likert scale). 
ELEMENTS

\begin{tabular}{|c|c|c|c|c|c|c|c|c|c|c|c|c|c|c|}
\hline \multicolumn{2}{|c|}{ CONSTRUCTS } & 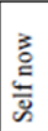 & $\begin{array}{l}\text { 苛 } \\
\frac{0}{2}\end{array}$ & 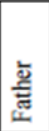 & 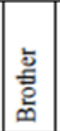 & 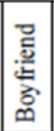 & 帝 & 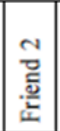 & 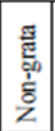 & 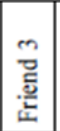 & 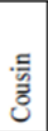 & 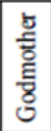 & 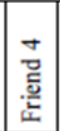 & 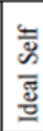 \\
\hline 1. Pessimistic & 1. Optimistic & 1 & 1 & 5 & 2 & 7 & 3 & 6 & 2 & 6 & 4 & 3 & 2 & 7 \\
\hline 2. Self-demanding & 2. Takes it easy & \begin{tabular}{|l|l|llll}
1 & & & \\
\end{tabular} & 6 & 6 & 2 & 2 & 5 & 6 & 3 & 5 & 6 & 4 & 5 & 4 \\
\hline 3. Fearful & 3. Enterprising & 2 & 2 & 6 & 2 & 4 & 5 & 6 & 5 & 2 & 3 & 4 & 5 & 5 \\
\hline 4. Lives to work & 4. Works to live & 5 & 1 & 2 & 2 & 6 & 6 & 6 & 1 & 6 & 7 & 6 & 6 & 7 \\
\hline 5. Imposes his/her wishes & 5. Tolerant with others & 6 & 2 & 1 & 1 & 4 & 3 & 6 & 1 & 7 & 3 & 4 & 2 & 7 \\
\hline 6. Teasing & 6. $\overline{\text { Touchy }}$ & 2 & 7 & 1 & 6 & 4 & 3 & 4 & 6 & 3 & 3 & 5 & 6 & 3 \\
\hline 7. Appreciates others & 7. Does not appreciate others & 2 & 6 & 6 & 6 & 1 & 5 & 4 & \begin{tabular}{|c|}
7 \\
\end{tabular} & 4 & 2 & 2 & 5 & 1 \\
\hline 8. Aggressive & 8. $\overline{\mathrm{Calm}}$ & 6 & 4 & 2 & 2 & 7 & 4 & 6 & 2 & 6 & 6 & 6 & 3 & 7 \\
\hline 9. Concerned about others & 9. $\overline{\text { Selfish }}$ & 2 & 2 & 6 & 7 & 2 & 3 & 5 & 7 & 3 & 3 & 2 & 2 & 2 \\
\hline 10. Avaricious & 10. Generous & 6 & 1 & 1 & 1 & 7 & 5 & 5 & 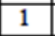 & 6 & 3 & 3 & 6 & 7 \\
\hline 11. Sensitive & 11. Materialistic, superficial & 1 & 5 & 7 & 7 & 1 & 4 & 5 & 7 & 1 & 4 & 3 & 4 & 1 \\
\hline 12. Cheeky & 12. Respectfiul & 6 & 6 & 5 & 4 & 6 & 6 & 6 & 1 & 6 & 5 & 6 & 5 & 7 \\
\hline 13. Hypocritical & 13. Sincere & 5 & 4 & 4 & 2 & 6 & 5 & 5 & \begin{tabular}{|l|l}
1 \\
\end{tabular} & 6 & 6 & 5 & 4 & 7 \\
\hline 14. Blackmailer & 14. Non blackmailer & 3 & 2 & 2 & 1 & 5 & 6 & 6 & 1 & 6 & 6 & 6 & 3 & 7 \\
\hline 15. Appears stronger than is & 15. Natural & 6 & 3 & 1 & 2 & 5 & 2 & 4 & 2 & 7 & 6 & 6 & 5 & 6 \\
\hline 16. Does not look after the friendship & 16. Looks after the friendship & 6 & 3 & 3 & 3 & 6 & 2 & 1 & 2 & 4 & 4 & 6 & 4 & 7 \\
\hline 17. Non Accessible & 17. Accessible & 5 & 2 & 2 & 1 & 4 & 2 & 4 & 1 & 6 & 3 & 5 & 2 & 7 \\
\hline 18. Introverted & 18. Extroverted & 1 & 2 & 6 & 2 & 4 & 5 & 7 & 5 & 2 & 6 & 6 & 5 & 5 \\
\hline 19. Gets depressed easily & 19. $\overline{\text { Does not get depressed easily }}$ & 1 & 2 & 6 & 3 & 6 & 3 & 7 & \begin{tabular}{|c|}
6 \\
\end{tabular} & 1 & 3 & 3 & 3 & 6 \\
\hline 20. Tries to find the good in things & 20. Sees only the negative & 6 & 6 & 4 & 6 & 1 & 5 & 2 & 7 & 6 & 3 & 3 & 5 & 1 \\
\hline
\end{tabular}

Figure 1. Example of a repertory grid. Note. Reproduced from Feixas et al. (April, 2012)

From the mathematical analysis of the resulting grid data matrix, several indexes about respondents' cognitive structure can be obtained, such as cognitive differentiation (uni/multidimensional thinking), polarised construing, self-ideal discrepancy, perception of social isolation, idealised perception of others, and conflictual construction of the self. Specialised software was developed to analyse repertory grid data and to detect CCs (Feixas \& Cornejo, 2002). Two types of CCs can be detected with the RGT: Implicative dilemmas (IDs), and dilemmatic constructs (DCs). To establish the presence of an ID, in the first step discrepant constructs (those in which the ideal self is different from the current self) and congruent constructs (in which the present self is similar to the ideal self) are detected. Then, the correlations between discrepant and congruent constructs are analysed in pairs; an ID is identified whenever the desirable pole of the discrepant construct correlates with the undesired pole of the congruent construct. Therefore, a desirable change in one construct implies an undesirable change in the 
other. In DCs, the "ideal self" is rated at the midpoint. This rating could imply that both poles of the construct comprise both desirable and undesirable characteristics for the person. Figure 2 shows the same repertory grid of the example in figure 1, representing an ID with their congruent and discrepant construct, and a DC.

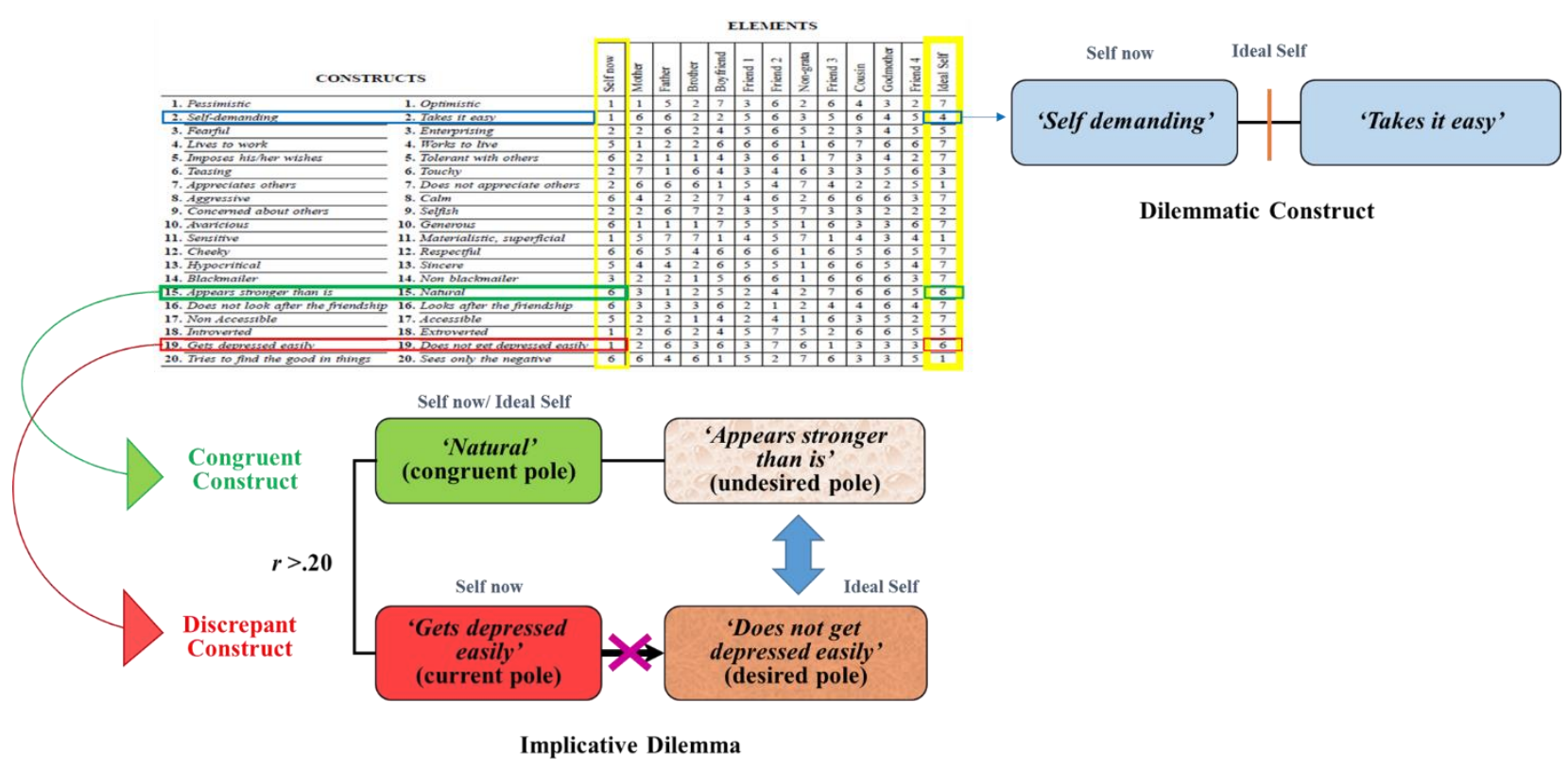

Figure 2. Schematic representation of an implicative dilemma and a dilemmatic construct. Note. Adapted from Feixas et al. (April, 2012)

Conceiving CCs as dilemmas, several studies have reported the value of IDs for understanding psychological distress in a variety of clinical conditions (Montesano, López-González, Saúl, \& Feixas, 2015). In particular, in people with depression, the presence of IDs was higher than in control groups (Feixas et al., 2014; Montesano et al., 2014), and depressed patients with IDs presented lower levels of global functioning and more frequent history of suicide attempts. Moreover, IDs together with large self-ideal discrepancy explained around $32-43 \%$ of the variance of symptom severity in patients with depression (Montesano, Feixas, Caspar, \& Winter, 2017). Regarding the effects of 
psychotherapy on IDs, it has been found that patients who presented IDs at baseline tended to resolve them by the end of the treatment independently of the psychotherapy approach (Feixas, Saúl, Winter, \& Watson, 2008). Moreover, in cases who did not resolve these conflicts, there was fewer symptoms improvement. This background jointly with the relevance of these dilemmas for the understanding of depressive symptoms led Feixas and Compañ $(2015,2016)$ to design DFT as a specific intervention, targeted to resolve these conflicts.

Before explaining how DFT works, it should be pointed out that, by no means, CCs are conceived as a causal variable or as the only maintenance factor of depression, but as a cognitive structure that may hinder the process of change (Feixas, 2013). In this sense, we are not talking about a psychopathological variable, but about a psychological factor that has been related to psychopathology as we pointed out in section 1.2.1.

DFT is a treatment module that can be added to traditional CBT for depression (or even to other therapies) and aims to address CCs that might affect depressed patients by hindering their change process. In general terms, DFT begins with the analysis of the patient's complaints and how they are related to his/her CCs (previously identified with the RGT). For instance, one initial task is to reframe the problematic situation or symptoms in terms of one or more dilemmas. Once both patient and therapist agree on a dilemma to serve as a target for the therapy, its implications are explored across a range of intra- and interpersonal situations, and across the patient's personal history. The final sessions are oriented towards the resolution of the dilemma(s) and the formulation of prospects of a life without them. DFT techniques are based on constructivist therapies (Neimeyer, 2009; Neimeyer \& Mahoney, 1995), which are focused on the elaboration of personal meanings, and especially personal construct psychotherapy (PCPT; Kelly, 
1955/1991; Winter \& Viney, 2005). They also include an adaptation of the two-chair dialogue (Greenberg, Rice, \& Elliott, 1993).

The project led by Feixas et al. $(2013,2016,2018)$ was a multi-centre RCT that tested whether the efficacy of traditional CBT for depression could be enhanced with the addition of DFT. For this purpose, patients first received seven sessions of CBGT before being randomly allocated to one type of individual cognitive therapy (traditional CBT or DFT) of eight sessions each. Therefore, in one arm of the RCT patients continued with traditional CBT for depression, receiving CBGT and individual CBT, while in the other arm, patients continued with DFT after receiving CBGT. In this way, any putative enhanced effect of DFT on CBGT could be observed. Therefore, two conditions of treatment were compared: CBGT plus individual CBT vs CBGT plus individual DFT. In both treatment arms, a final session of CBGT focused on relapse prevention was carried out. The results showed that both conditions obtained comparable results to those in the literature. Thus, no differential effect of DFT as compared to standard CBT was demonstrated. Additionally, both treatment conditions resolved CCs in the same proportion. Hence, CCs resolution did not depend on treatment allocation. However, patients who resolved their CCs obtained greater improvement than those who did not (Paz, Montesano, Winter, \& Feixas, 2019).

In terms of efficacy, and being a superiority study, it had serious limitations. According to the literature on dose-effect (Baldwin, Berkeljon, Atkins, Olsen, \& Nielsen, 2009; Howard, Kopta, Krause, \& Orlinsky, 1986) and early response (Lutz, Stulz, \& Köck, 2009; Owen et al., 2015), the majority of patients experience the majority of change along the first eight sessions of therapy (Duncan, 2014). Therefore, it was expectable that in the first phase of the treatment ( 7 sessions of CBGT), patients obtained the greatest improvement, for then continuing to improve at a slower pace in 
the second phase ( 8 sessions of individual cognitive therapy). Hence, to find a tiny difference regarding effect size at the end of the second phase, a big sample size was required for a sufficiently powered analysis capable to detect differences between groups (Tamayo-Sarver, Albert, Tamayo-Sarver, \& Cydulka, 2005). That was not the case in this study.

Despite these limitations, the case of DFT is a believable reflection of the results obtained by other studies that took the initiative of studying factors related to psychopathology aimed at improving psychotherapy for depression. That is, a psychological factor that has demonstrated to be related to depression in clinical samples is addressed in a treatment component as the target of psychotherapy. In this sense, the results obtained go in line with previous studies, and with what was pointed out by Castonguay (2011), different approaches to psychotherapy are not specific to change the target variable they say to change according to their model. Accordingly, CCs have been resolved in successful cases of psychotherapy independently of the approach, and symptoms improvement seem to be related to CCs resolution. Therefore, seems that the dodo bird is saying again "everybody has won, all must have prizes".

\subsection{Patient-Focused Research and Treatment Personalisation}

Efficacy and effectiveness studies can be considered treatment-focused research (Lutz, 2002) because both designs deal with the question of outcome regarding a particular model of treatment for a specific clinical condition. The results of both types of studies can inform to clinicians that a particular treatment is likely to work for a group of patients, but not if the selected treatment is working or not for a particular patient (Lutz, 2003). Indeed, the application of an evidence-based treatment alone, 
which on average has shown to be efficacious and/or effective in RCTs and/or naturalistic studies, respectively, does not guarantee that the provided treatment is the appropriate for a particular case (Howard, Moras, Brill, Martinovich, \& Lutz, 1996; Rubel, Lutz, \& Schulte, 2015). Patient-focused research is concerned with the question: is this treatment working for this patient at this moment? Related to this question, are the questions stated by Gordon Paul (1967) more than fifty years ago: "what treatment, by whom, is most effective for this individual with that specific problem, and under which set of circumstances?" (p. 111). These are the questions that treatment personalisation strives to answer.

Traditional research in psychotherapy outcomes for depression is based on preto-post comparisons (Bortolotti, Menchetti, Bellini, Montaguti, \& Berardi, 2008). These designs assume a linear, straightforward pattern of change between the two-time points of assessment (with one additional follow-up assessment, or two in the case of Feixas et al, 2016, 2018). In terms of outcomes, what happens during the treatment remains as a "black box" that is not taken into account in the results; thus, meaningful differences in individual treatment courses, or change patterns, remain masked or hidden (Lutz et al., 2009). In this regard, similar effects of different treatments do not necessarily imply that there are no identifiable differences in effects on individuals or subpopulations within a sample (Cuijpers, van Lier, van Straten, \& Donker, 2005). Founded on the idea of identifying these differences, patient-focused research in psychotherapy is designed to predict, model and monitor individual treatment progress, providing the therapist and the patient with accurate feedback based on this information during the course of the treatment (Lambert, Hansen, \& Finch, 2001; Lutz, De Jong, \& Rubel, 2015).

Different phenomena concerning different patterns of change have been studied with diverse methodologies, proposing diverse models for studying change. For 
instance, in terms of continuous patterns of change, general trajectories have been studied. Regarding discontinuous patterns, early response, sudden gain and sudden losses are the phenomena more examined (Hayes, Laurenceau, Feldman, Strauss, \& Cardaciotto, 2007).

Early response corresponds to a significant decreasing in symptoms at early stages of treatment. Sudden gains and sudden losses represent a sudden shift of the trajectory that the patient is following over relatively short intervals during the treatment, resulting in a significant improvement (sudden gains) or deterioration (sudden losses) of the levels of symptoms (Lutz et al., 2013).

Considering that we are interested in analysing the differential response of patients of the study of Feixas et al. (2013) with respect to group and individual therapy, we will focus on general trajectories and early response.

\subsubsection{Focusing on trajectories and patterns of change.}

Trajectories of patient change have several decades of history in psychotherapy research (Owen et al., 2015). They were first studied through dose-effects models (Baldwin et al., 2009; Howard et al., 1986), which established a relationship between the log number of session (dose) and the probability of patient improvement (effect). An extension of these models was conceptualised as a phase model, where specific dimensions of outcome were assessed to study how they change sequentially along different phases of the treatment (i.e., remoralisation, enhancing of well-being; remediation, achievement of symptomatic relief; rehabilitation, improvement of functioning through the reduction of maladaptive psychological patterns, Howard, Lueger, Maling, \& Martinovich, 1993). A negatively accelerated curve was obtained by 
these models, which was explained as the increasing difficulty of achieving the treatment goals throughout therapy (Castonguay, Barkham, Lutz, \& McAleavey, 2013; Lutz, 2003). The problem with these models is that the trajectories studied are from the average of patients, while patterns of change for the individual can vary significantly from the average trend.

Founded on the idea of capturing the individuality of the patterns of change, models which estimate an expected trajectory of recovery for each patient from their baseline characteristics have been investigated. These are the models of expected treatment response (ETR). Indeed, through these models, patient-focused research was born (Howard et al., 1996). On this purpose, growth curves through hierarchical linear modelling (HLM; also called mixed linear models, MLM) have been implemented. The treatment outcome of the patient is modelled throughout therapy as a polynomic function (e.g., log-linear) of session number, and patient intake characteristics are used as predictors. Hence, an expected trajectory for each patient at the beginning of the treatment can be estimated (Castonguay et al., 2013). Therefore, the ongoing therapeutic effectiveness can be assessed for each patient, comparing the patient's actual progress with the expected trajectory. These models have been implemented in clinical practice with instruments for routine outcome monitoring (ROM; Boswell, Kraus, Miller, \& Lambert, 2015) such as the Outcome Questionnaire - 45 (OQ-45; Lambert et al., 1996), the Clinical Outcome in Routine Evaluation (CORE; Evans et al., 2000; Trujillo et al., 2016), and the Outcome Rating Scale (ORS; Miller, Duncan, Sparks, \& Claud, 2003; Moggia, Niño-Robles, Miller, \& Feixas, 2018). With these questionnaires, computerised feedback systems have been created to support clinical decision making, informing the clinician whether the treatment is working for a particular patient (Lambert et al., 2001). 
Growth curves through HLM have the limitation that they assume that all members of the sample come from the same population. In this sense, an estimated trajectory does not allow for heterogeneous subgroups to exist within a sample (Kilmer, 2017). To address this issue, Lutz et al. (2005) have used cluster analysis with the nearest neighbours (NN) algorithm. To compute a model from patient's intake characteristics, the most similar previous treated cases are selected from a sample with this procedure. Thus, similarity among patients is defined through Euclidean distances between the selected variables. When the subgroups of more similar patients are identified, the expected trajectory is computed. It has been demonstrated that, with this methodology, more accurate models than traditional ETR models are estimated, contributing to a better prediction of treatment success, failure and duration (Lutz, Lambert, et al., 2006; Lutz, Saunders, et al., 2006).

Certainly, heterogeneity may exist due to individual differences coming from different subpopulations within the sample. A method which may operate without assuming homogeneity of the sample is growth mixture modelling (GMM; Muthén, 2004). GMM is based on latent growth models (structural equation modelling [SEM] framework) where slopes and intercepts are estimated as latent variables in which values depend on the means of the time-point observations (Wickrama, Lee, O’Neal, \& Lorenz, 2016). GMM goes beyond, allowing the identification of multiple unobserved subpopulations in longitudinal data. In GMM an additional latent categorical variable is included that accounts for sample heterogeneity, capturing individual differences in intake scores (intercepts) and change parameters (slope) in terms of fixed and random effects (Ram \& Grimm, 2009). GMM allows researchers to test for an a priori unknown number of latent subpopulations (clusters or classes). Through the goodness of fit 
indexes, diverse models can be compared and, thus, the model with the number of classes that better fit with the data can be determined.

GMM has been used to analyse data from naturalistic psychotherapy studies (Stulz \& Lutz, 2007; Stulz, Lutz, Leach, Lucock, \& Barkham, 2007) and RCTs (Lutz et al., 2009; Muthén, Brown, Hunter, Cook, \& Leuchter, 2011). One of the advantages of this method is that allows to track not only general trajectories but also patterns of discontinuous change such as clusters of early and late improvers.

Several studies researching trajectories and patterns of change in treatments for depression have been published (Bogner, Morales, Reynolds, Cary, \& Bruce, 2012; Cui, Lyness, Tang, Tu, \& Conwell, 2008; Cuijpers et al., 2005; Dew et al., 1997, 2001; Gildengers et al., 2005; Kelley et al., 2018; Liang, Xu, Quiñones, Bennett, \& Ye, 2011; Lutz et al., 2017; Rubel et al., 2015; Sakurai et al., 2013; Schlagert \& Hiller, 2017; Stulz, Thase, Klein, Manber, \& Crits-Christoph, 2010; Thibodeau et al., 2015; Vittengl, Clark, Thase, \& Jarrett, 2013; Wardenaar, Conradi, \& de Jonge, 2014; for a comprehensive review including studies until 2015, see Kilmer, 2017). They used diverse statistical methodologies such as HLM, cluster analyses, and GMM. The samples were quite diverse. In the majority of studies, patients come from outpatient clinics, and samples were different in group age (e.g., teenagers, adults, and elderly patients). The treatments duration was between six and 16 weeks, and follow-up assessments were between six months and two years. The treatment approaches were different, mainly including, CBT, IPT, and pharmacotherapy. The outcome measures utilised in most of the studies were for depression symptom severity, while general symptoms and psychological distress were used in other studies as well. Taken together, the patterns found in these studies can be summarised in five clusters of patients: early responders, late responders, moderate or steady responders, non-responders, and 
worsening. These results are consistent with the idea that patients receiving psychotherapy for depression are not a homogenous group (Fried, 2017; LorenzoLuaces, 2018).

The previous studies have limitations regarding the replicability of the results, the ecological validity, and the comparisons we can make among them. This is because the diversity of statistical techniques utilised produce a wide variety of pattern clusters, differing in type and number of trajectories. Other limitations come from the specifications of the designs, which include, high controlled paradigms; inclusion of a single diagnosis of MDD excluding co-morbidities; high standardisation of treatment protocols; assessment of symptoms at different time-points; small samples sizes; and different criteria for the selection of predictors (Kilmer, 2017).

Beyond depression, a polemic pattern cluster that has been reported in some studies is "getting worse before getting better" (Foa, Zoellner, Feeny, Hembree, \& Alvarez-Conrad, 2002; Owen et al., 2015). These were patients who showed worsening at the beginning of therapy, for then starting to improve, obtaining a good outcome at the end of the treatment. This pattern has been found in exposure-based trauma treatment (Foa et al., 2002), and in a naturalistic sample of 10,854 patients with mixed diagnosis (Owen et al., 2015). In this latter study, the commented pattern represented the $5.4 \%$ of the sample against "early and late changers" $(75.3 \%)$, and "slow and steady changers" (19.3\%). Patients of the group "getting worse before getting better", showed the lowest initial psychological functioning compared to others groups. Considering the design, no other distinctive characteristic was found for these patients. Altogether, according to the literature reviewed for this dissertation, to date, this pattern has not been reported in treatments for depression. 
In summary, the results of the previous studies support for the idea that patients receiving psychotherapy for depression are not a homogenous group. Moreover, some patients benefit more than others, whose profile can be identified in early stages of treatment.

\subsubsection{Focusing on early response.}

Based on the idea of improving the models used to predict trajectories, patterns of change, and treatment outcome, researchers have looked at patterns of early response, which are related to different final outcomes (Lambert, 2005; Lutz et al., 2017; Schlagert \& Hiller, 2017; Van et al., 2008). Early response in psychotherapy has been studied from different perspectives and with diverse methodologies, and there is no current consensus on the definition of the phenomenon (Rubel et al., 2014). For instance, some authors (Ilardi \& Craighead, 1994) defined it as a significant drop of symptoms by the fourth session, followed by a flat linear trajectory. Others (Stewart et al., 1998) conceived it as psychopathology being absent or minimal after two weeks of treatment, or as a minimum percentage of improvement across a pre-defined number of sessions at the beginning of treatment (Hayes, Feldman, et al., 2007). Furthermore, early response can be studied with rationally- (e.g., Jacobson and Truax's, 1991, reliable and clinically significant change criteria) or empirically- (e.g., ETR, NN, GMM) derived methods.

Regardless of the operationalised definition and the method used, most patients who show substantial improvement early in treatment obtain better outcomes at termination and follow-up than later improvers. In other words, early responders need fewer sessions to achieve steady improvement and are, therefore, more likely to 
terminate treatment earlier (Haas, Hill, Lambert, \& Morrell, 2002). Indeed, this results have been obtained with different samples in terms of age (e.g. teenagers, adults, and elderly patients; Gunlicks-Stoessel \& Mufson, 2011; Kok, van Baarsen, Nolen, \& Heeren, 2009), diagnosis (e.g. depression, anxiety, and eating disorders; Aderka, Nickerson, Bøe, \& Hofmann, 2012; Bradford et al., 2011; Nazar et al., 2017; Van et al., 2008), and psychotherapy modality (e.g. low and high intensity treatments; Lutz et al., 2017; National Collaborating Centre for Mental Health, 2011).

Indeed, early response has shown to be a powerful predictor of treatment outcome, supporting the value of identifying patients at risk of treatment failure at an early stage in treatment. The study of early patterns of change provides the therapist with feedback on the patient's trajectory, especially when at risk of not improving, deteriorating, or dropping out. Certainly, the identification of different patterns of change in the treatment of depression may provide valuable information about the course that different subpopulations of patients follow, their characteristics, and the stages of treatment that involve the greatest risk of failure (Delgadillo, Moreea, \& Lutz, 2016). In the context of personalised medicine, the study of early response constitutes a valuable grounding for supporting clinical decisions and interventions tailored to the individual patient, based on their predicted response or risk.

\subsubsection{Treatment personalisation.}

All the research described in this section so far aims not only to study patterns of change to acquire more knowledge about psychotherapy but to treatment personalisation. Thus, tailoring the interventions to the idiosyncratic characteristics of 
the patient, with the goal of offering the most effective treatment as possible according to the patient's characteristics.

In the field of health sciences, the term of personalised medicine or precision medicine has received considerable attention, and in the field of mental health, in particular, personalised care or tailored mental health (Müller et al., 2018). These terms define a health model that aims to identify the optimal treatment for each individual, taking into account her or his singularity, and the viability of adapting the therapeutic strategy along the course of treatment. It does not necessarily mean the creation of treatments that are unique to an individualised patient, but the ability to classify individuals into subpopulations that differ in their susceptibility, prognosis and response to a specific treatment (National Research Council, 2011).

The statistical models used for treatment personalisation incorporate different variables as predictors. These are of two kinds: prescriptive or prognostic (Cohen \& DeRubeis, 2018). Prescriptive variables influence the direction or strength of the difference in outcome between two or more treatments. They are also known as moderators. Alternatively, prognostic variables influence the course of a given treatment, predicting the response in a single treatment or irrespective of the treatment condition. Depending on the research context, the same variable can work as prescriptive or prognostic. As was stated before, most studies of treatment outcome for depression come from pre-to-post comparisons. For these studies, strategies aimed to decide which one of two or more treatments work better for a patient using prescriptive variables are implemented (e.g., Personalised Advantage Index, PAI; Cohen, Kim, Van, Dekker, \& Driessen, 2019; DeRubeis et al., 2014; ). These methods have been applied to data generated by previous studies with post-hoc analyses. A research design testing the efficacy of these methods in a prospective study has not been conducted yet (Müller 
et al., 2018). On the other hand, models that predict trajectories or patterns of change use prognostic variables (e.g., models based on ETR or NN). The application of these models in efficacy and effectiveness studies is described hereafter.

Several criteria to select predictors have been investigated with a variety of methods. For instance, some researchers used the analysis of covariance or correlations between the candidate variables, statistical differences between predefined clusters of patients in these variables, cluster analyses, or even artificial intelligence and machine learning algorithms (e.g., Lee et al., 2018). Cohen and DeRubeis (2018) have systematised a series of recommendations for building treatment selection models for depression. They pointed out that variables indicated by previous research as predictors of treatment outcome should be included in the tested models. Variables also should not have significant missing data and must exhibit sufficient variability ensuring low collinearity. Furthermore, they recommended centring variables to avoid inferential errors and to increase the stability of the models when dealing with regression-based approaches.

The most used variables to predict treatment outcome and patterns of change in psychotherapy for depression (Bogner et al., 2012; Bryan et al., 2012; Callahan \& Hynan, 2005; Cui et al., 2008; Cuijpers et al., 2005; Dew et al., 1997; Gildengers et al., 2005; Gude \& Havik, 2000; Howard et al., 1986; Ilardi \& Craighead, 1994; Liang et al., 2011; Lutz et al., 2009; Stulz \& Lutz, 2007; Stulz et al., 2010; Thase et al., 1997; Thibodeau et al., 2015; Wardenaar et al., 2014) are demographic variables such as age, ethnicity, socioeconomic status, marital status; social and relational factors such as social support and family functioning; variables related to personality such as introversion, emotional stability, self-esteem; physical health status, stress, and medical burden; mental health history such as pre-treatment hospitalisations; and clinical 
condition (baseline depression symptoms severity, comorbidity, and history of depression). Altogether, information about patterns of change (trajectories) in treatments for depression and factors predicting varying courses of treatment are sparse and further research is required.

In clinical practice, it has been reported (Ægisdóttir et al., 2006; Bar-Kalifa et al., 2016; Hannan et al., 2005) that psychotherapists are not good on identifying patients' prognosis and, patients that are not improving, deteriorating or in risk of dropping out along the course of treatment. In this respect, systems of feedback using ETR or NN models have been designed and implemented to provide information about each patient's progress, giving to the clinician the opportunity to correct the course of the treatment in case of risk. Studies about the added efficacy of implementing feedback systems in clinical practice (feedback informed treatment, FIT; Prescott, Maeschalck, \& Miller, 2017; or ROM-assisted psychotherapy; Boswell et al., 2015; Carlier et al., 2012; Delgadillo et al., 2017; Janse, De Jong, Van Dijk, Hutschemaekers, \& Verbraak, 2017; Kendrick et al., 2016; Knaup, Koesters, Schoefer, Becker, \& Puschner, 2009; Lambert, Whipple, \& Kleinstäuber, 2018; Miller, Duncan, \& Sorrell, 2006; Reese, Norsworthy, \& Rowlands, 2009; Shimokawa, Lambert, \& Smart, 2010) have shown that providing this feedback does not increase the effect for patients who already respond, but for patients who are in risk ("not on track" patients) the treatment become more efficacious, effective, and efficient (patients achieve improvements early in treatment). For depression, studies testing the efficacy and effectiveness of FIT (Connolly Gibbons et al., 2015; Delgadillo et al., 2018) showed that not on track patients had less severe symptoms after treatment and responded early compared to patients that received psychotherapy without a feedback system. 
Based on the previous information, it seems that treatment personalisation, particularly FIT, is a good strategy for increasing the efficacy, effectiveness and efficiency of psychotherapy for depression, especially for patients who are in risk of not responding to treatment.

Altogether, models for treatment personalisation of depression there are still showing small to medium effect sizes in the contribution of their predictors. In fact, in a meta-analysis, Cuijpers et al. (2016) estimated that it would take another 326 years to have sufficient statistical power for showing an effect size of $g=.50$ of the variables analysed (sociodemographic characteristics, comorbidity, symptoms, and treatment characteristics) and 1,372 years to show an effect size of .24. Under this background, it seems that there is still room for improving the predictive models utilised. In this respect, it has been argued that predictive models not only should consider symptom measures but measures about psychological processes underlying symptoms (Andrews \& Williams, 2014). In this regard, as the RGT was used in the study by Feixas et al. $(2016,2018) \mathrm{RCT}$, and considering that some of their indexes have been related to psychological processes underlying depression (Feixas et al., 2014; Montesano et al., 2014, 2017), we considered that the RGT has promising potential for treatment personalisation.

\subsection{The Repertory Grid Technique as a Tool for Treatment Personalisation}

The theoretical foundations of the RGT and how it is applied have been explained already (see section 1.2.3). Broadly speaking, is a constructivist assessment methodology (Neimeyer, 1993) which allows the exploration of the construct system of the person. Constructivist approaches to psychology and psychotherapy share a 
common principle: humans do not have direct access to a stable, singular, and entirely knowable external reality. On the contrary, our access to reality is limited by our knowledge structures, embedded in context, and relationally constructed. We as human beings are continuously and actively construing reality through our personal meanings. In this respect, constructivist assessment methodologies are oriented to study how the subject interprets reality according to his/her own personal meanings.

Traditionally, constructivist approaches in concordance with their assumptions, have privileged idiosyncratic assessment methods $(n=1)$. However, scientific enterprise works constructing nomothetic knowledge. In fact, idiosyncratic vs. nomothetic is an old controversy in psychology which has polarised the discipline in more than one occasion. For Feixas and Villegas (2000), PCT resolved this issue postulating general processes of construction for all human beings, while the content of such processes is idiosyncratic and unique for each individual. Regarding their methods, PCT has developed a general methodology that allows the systematic study of a single case. Thus, as a theory of processes of knowledge construction for all human beings, PCT is perfectly designed for capturing the contents of a person in particular. In this sense, the RGT is an assessment tool designed to capture idiosyncratic individual contents settled in nomothetic cognitive processes and structures. From this point of view, it seems that the RGT fits with the agenda of personalised medicine; that is, offering a series of indexes that are based on the individualised characteristics of the patient, which can be further utilised to identify subgroups of subpopulations based on their common cognitive processes and structures.

Traditionally, the RGT has been used for case formulation (Feixas, De La Fuente, \& Soldevila, 2003) as a way of "seeing the world through clients' eyes" (Winter \& Procter, 2014). In this respect, the RGT allows the clinician to understand how 
patients define and construct themselves and their significant others, whether they construct their interpersonal world in a polarised or loose way, how rich and differentiated is their way of construing, and which are their CCs, which could be hindering their change process, if any. Based on this information, the therapist can develop a case formulation to select and adapt the treatment to the psychological distinctiveness of each patient.

Many studies have been published using the RGT as a psychotherapy research measure (for a detailed review see Winter, 2003). Some of these studies have used the indexes of the RGT as predictors for treatment outcome, setting the bases for further research on treatment personalisation based on the RGT.

Moreover, the most studied patients' characteristics assessed with the RGT that have been used as predictors for treatment outcome are cognitive differentiation (particularly, tight or unidimensional construing), implications of symptomatic constructions, construction of the self (e.g., self-ideal discrepancy, differences between the construing of the past and the present self), construction of others (e.g., self-others dissimilarity, construction of the partner, tight or loose construing of others, similarity between client and therapist constructions), and CCs.

For instance, several studies have found that low cognitive differentiation (tight or unidimensional construing) acted as a predictor of poor treatment outcome in group therapy for alcohol abuse (Orford, 1974; low cognitive differentiation predicted dropout), behavioural therapy for agoraphobia (Winter \& Gournay, 1987), psychotherapy for inpatients with anorexia (Button, 1983), group (Winter, 1983) and individual analytic therapy (Carr, 1974), and PCPT (Morris, 1977). Nevertheless, one study found that a 
tight construing predicted bad outcome in group analytic therapy, but good outcome in behavioural therapy (Winter, 1983).

In terms of implications of symptomatic constructions, patients for whom their constructs concerning the symptoms had fewer implications improved more during group analytic therapy than patients who had more implications. The opposite was found in behavioural therapy (Winter, 1983). This difference was explained arguing that patients construing their symptoms as central for their identity were only likely to find meaningful, and respond to, a therapeutic approach focused on their symptoms (e.g., behavioural therapy). The work of Fransella (1972) on stuttering suggests that the higher the implications of losing symptoms, the more likely patients are to respond to treatment. The same was found on anorexia (Fransella \& Button, 1983). Similarly, in long-stay psychiatric inpatients, the more highly elaborated were their construing of their life outside hospital, the more likely patients were able to conduct their life successfully after being discharged from long-term hospitalisation (Winter, Goggins, Baker, \& Metcalfe, 1996). In behavioural therapy for social anxiety, it have been found that cases which the construction of symptom cessation implied little change on their other constructs, were more likely to improve (McKain, Glass, Arnkoff, SydnorGreenberg, \& Shea, 1988). More important than the number of implications is the nature of them, because it has been found that if symptoms have positive implications for patients, they were less likely to respond to treatment (Leitner \& Grant, 1982; Winter, 1988).

A positive self-construing and a low self-others discrepancy have showed to predict good outcome in individual (Carr \& Whittenbaugh, 1969) and group (Caine, Wijesinghe, \& Winter, 1981) therapy. However, other studies in group (Caine et al., 1981; Landfield, 1977) and biofeedback therapy (Large, 1985) reported that patients 
who constructed themselves more negatively, were the most responsive patients. In this regard, the authors have speculated that these patients were thus most motivated to change. Studies in both anorexia (Button, 1983) and agoraphobia (Winter \& Gournay, 1987) found that a good predictor for treatment outcome was the difference between the construing of the past and the present self, particularly a positive construction of the past self. The authors concluded that patients were more able to improve if they had a positive alternative construction of the self, based on a symptom-free past experience than an idealistic fantasy of a symptom-free life. In agoraphobia again (Winter \& Gournay, 1987), it was found that therapeutic improvement was predicted also by a positive construction of their partners.

Regarding the construction of others, in group therapy for incest survivors, the construction of other group members in a non-polarised way, and the identification with other group members, including the therapists, were predictive of good outcome (Neimeyer, Harter, \& Alexander, 1991). Additionally, patients who had similar constructs to their therapist tended to respond better to psychotherapy than those who did not (Landfield, 1971).

In cognitive-constructivist psychotherapy in primary care (Pucurull, 2015), it has been found that patients who begin the treatment with low cognitive differentiation tended to increase it by the end of therapy (they acquired a multidimensional way of construing). The opposite trend was found for patients who started therapy with high cognitive differentiation (at the end of therapy their way of construing tended to be unidimensional). These changes in cognitive differentiation were associated with decreasing in the levels of symptoms for both cases. Additionally, polarisation (tendency to a black-or-white way of construing) tended to decrease by the end of therapy associated with symptoms improvement also. Furthermore, patients who had 
one or more IDs at intake and resolved them by treatment termination, obtained higher effect sizes in symptoms improvement than patients who did not resolve them, or those who did not present them at the beginning of therapy.

Finally, in depression, patients who resolved their CCs after psychotherapy acquired greater benefits with regard to reduction of depressive symptoms and psychological distress than those who maintained them (Paz et al., 2019). Indeed, the resolution of CCs after treatment predicted symptoms improvement (especially at 3month follow-up), and not the other way around (Paz, 2016).

The studies using the indexes of the RGT for predicting treatment outcome have limitations regarding their design and statistical power. Most of them correspond to effectiveness studies where the treatment conditions were not manualised. The administration protocol of the RGT vary from one study to another, producing grids with different types of elements and constructs; therefore, the indexes are not comparable because they are capturing different aspects of the cognitive structure and the construing processes of the subjects. These two flaws produce problems regarding replicability. Furthermore, the majority of the studies have small sample sizes producing limitations concerning the statistical power and the generalisation of the results. The exception to these limitations come from the work of Feixas et al. (2009) in which the administration protocol of the RGT has been systematised and formalised, producing replicable results, especially concerning the detection of IDs. It is from this seminal work that all research commented so far about CCs and DFT has been produced.

While it is true that the studies using the indexes of the RGT for predicting treatment outcome have some limitations, we consider that the RGT has good potential for providing measures for treatment personalisation. This is not just because, 
theoretically, it is an assessment method designed for such purpose, but also because, empirically, their indexes have been related to psychological processes and structures that may be associated to symptoms and, also, have been utilised for predicting treatment outcome with promising results, although they require further investigation. 



\section{Rationale}

The previous chapter can be summarised in the following statements that work as rationale for the research conducted:

- Depression is one of the most important mental health problems worldwide and is one of the leading causes of disability.

- Several studies have demonstrated that psychotherapy is an effective and efficacious treatment for depression.

- Despite their contrasted effectiveness and efficacy, responses remain approximately at 50\%, and recurrences and relapses are often.

- Comparing group and individual therapy for depression, it has been found that group therapy is more effective than TAU but can be less effective than individual therapy at the end of treatment for more severe patients, while no differences were found at follow-up.

- Several attempts have been made to increase the efficacy and effectiveness of psychotherapy for depression. Addressing factors related to psychopathology, enhancing psychotherapy process factors, patient-focused research and treatment personalisation are the main initiatives taken by the researchers.

- DFT is a treatment module that can be added to traditional CBT for depression. It was designed under the initiative of addressing factors related to psychopathology, particularly CCs.

- Research on CCs, particularly IDs, have related the presence of CCs to psychological distress in several clinical conditions. In depression, the presence of IDs was higher than in control groups, and patients with IDs presented lower levels of global functioning and more frequent history of suicide attempts. IDs 
together with low levels of self-esteem explained around $32-43 \%$ of the variance of symptom severity in patients with depression.

- The added efficacy of DFT to CBGT for depression was tested in a RCT. Two conditions of treatment were compared, CBGT plus individual CBT vs CBGT plus individual DFT. The results showed that both conditions obtained equivalent results, thus both resulted equally efficacious. Additionally, both treatment conditions resolved CCs in the same proportion. Hence, CCs resolution did not depend on treatment allocation. However, patients who resolved their CCs obtained greater improvement than those who did not.

- In the previous study, a measure of depression was used as primary outcome, and general functioning, psychological distress, and indexes from the RGT were used secondarily.

- Patient-focused research and treatment personalisation aim to identify if a particular treatment is working or not for a particular patient, and to identify factors from patient's characteristics that allow to predict treatment effectiveness for a patient in particular.

- While other initiatives tended to fail, it seems that patient-focused research and treatment personalisation is a promising strategy to enhance psychotherapy for depression.

- General trajectories of change and early response are the change patterns most studied to classify patients regarding their response, to monitor and predict treatment outcome.

- Different methods have been employed to select predictors from patients' pretreatment characteristics. 
- The most used predictors are sociodemographic and clinical characteristics, and symptom measures at intake. While predictive models for treatment personalisation are promising, there is still room for improvement.

- To consider measures of processes underlying symptoms has been suggested in order to enhance predictive models.

- The RGT is an assessment method that has promising potential for treatment personalisation because its indexes have been associated to psychological processes underlying symptoms of depression, and to different treatment outcomes.

\subsection{Justification}

As was previously explained, the current research was aimed at studying the patterns of change followed by the patients in the study by Feixas et al. $(2013,2016$, 2018). The relevance of studying these patterns in terms of trajectories relies on the fact that pre-to-post comparisons (or with one or two additional follow-up assessments) can mask what happened in between, during the treatment, regarding outcome. Along with the contributions of patient-focused research, tracking the patterns of change permits the identification of different clinical subpopulations and individual differences in terms of change patterns. This contribution not only increases our knowledge about the course different patients follow in psychotherapy, but also provides researchers and clinicians with information for predicting, modelling and monitoring individual treatment progress during an ongoing course of treatment. With feedback systems which incorporate this information, the trajectories that patients might follow could be predicted, and clinicians can monitor the patient's progress by comparing the observed and the predicted 
response, thus having the opportunity to correct the course of the treatment in cases of failure risk. With these innovations, psychotherapy for depression can be enhanced by increasing its effectiveness for patients who do not respond or tend to deteriorate as research on FIT has shown.

Being depression a worldwide spread problem with a prevalence which has been increasing in the last decade, to count on more effective treatments becomes a priority. Traditional initiatives taken by researchers (studying factors related to psychopathology and enhancing psychotherapy process factors) to achieve this goal tended to fail. However, patient-focused research and treatment personalisation have shown promising results. Altogether, more research is still needed to enhance the predictive models and personalisation strategies. The current study aims to contribute in this direction.

Considering that in the study by Feixas et al. (2013) patients received treatment in two phases (low and high intensity, respectively), and assuming a cost-efficacy perspective, treatment personalisation aimed to identify "what works for whom?" (Paul, 1967) becomes highly relevant. Thus, patients obtaining greater improvements from a more economical therapeutic modality, like group therapy (low-intensity CBT), can be identified, but also patients who really need individual therapy (high-intensity cognitive therapy) to obtain improvements.

Additionally, as in the study by Feixas et al. $(2013,2016,2018)$ the RGT was used as a secondary measure. This is not a typical symptom measure but rather their indexes may reflect psychological processes which have been related to depression. Therefore, indexes can be examined as predictors of outcome and, thus, be used in the future for treatment personalisation based on putatively enhanced predictive models. 
Altogether, this dissertation aims to contribute to the study of different patterns of change that patients in group and individual psychotherapy for depression can follow, their early identification for treatment personalisation, and therefore, contributing to better outcomes in the psychotherapy for depression to benefit more patients and save care costs.

\subsection{Objectives}

1. To explore if there are clusters of different patterns of change across the group and individual therapy phases regarding psychological distress.

2. If different clusters can be identified, to identify the characteristics of the patients included in each one in terms of sociodemographic variables, clinical condition, psychological distress, depression symptom severity, general functioning, self-ideal discrepancy, perceived social isolation, and conflictual construction of the self.

3. To determine which of these patients' baseline characteristics predict these differential patterns of change.

4. To establish if the patterns of change are predictive of treatment outcome at termination and follow-up in terms of depression symptom severity.

\subsection{Hypothesis}

Considering that early response is a frequent pattern reported in the literature of treatments for depression, and that group therapy tended to be less effective than individual therapy in some cases, we hypothesised that a differential pattern of early response and other pattern of response to individual therapy could be identified. If that 
is the case, then there would be a group of patients who responded better to group than to individual therapy, and that in another group the opposite trend would be found. In other words, we would be able to assume that there were patients that needed individual therapy after group therapy to obtain improvements while that was not significant for others. 


\section{Method}

\subsection{Design}

\subsubsection{Design of the current research.}

The current research is a quantitative exploratory study based on a post-hoc analysis of longitudinal data of previous study (Feixas et al., 2013, 2016, 2018) with an experimental design (RCT). Methodologically, it is an exploratory repeated measures design in which the same participants were assessed before treatment, in several occasions over the course of treatment, at termination, and at follow-up.

\subsubsection{Design of the RCT study by Feixas et al. (2013, 2016, 2018).}

Feixas et al (2013)'s RCT aimed to test the hypothesis that the treatment condition including a specific module (DFT) focusing on the resolution of cognitive conflicts (CCs) or dilemmas identified for each patient in particular (Feixas et al., 2009) would prove more effective, thus increasing the efficacy of CBT for depression. To do this, all patients received a treatment structured in two phases. The first one consisted of seven sessions of CBGT for all patients (low-intensity CBT). In the second phase, patients were randomized to one of two individual therapy conditions (of eight sessions each), CBT or DFT (high-intensity cognitive therapies). DFT (Feixas \& Compañ, 2015, 2016) is a treatment module that can be added to traditional CBT for depression and is aimed at addressing and solving CCs, as was explained in section 1.2.3. Before the group phase, each patient was interviewed by the therapists to explore his or her particular complaints and treatment motivation. This interview was designed to start building the therapeutic alliance, as is recommended by general group therapy guidelines regardless the theoretical orientation (Burlingame, Strauss, \& Joyce, 2013; 
Yalom \& Leszcz, 2005). After the second phase, one final CBGT session including relapse prevention closed the treatment. From the first interview with the therapists, sessions were scheduled at one-week intervals. Seven centres in and around Barcelona, Spain, participated in the trial. In total, 22 groups were formed with between four and nine patients each. Patients were treated at their usual health care centres by therapists $(N=44)$ in training from the University of Barcelona. The first phase was conducted by two therapists who also conducted the later individual phase, one applying CBT and the other DFT. Therapists were selected for each treatment condition according to their training and experience. They also received additional training in the use of each manual, and supervision was provided for each condition by senior therapists.

\subsection{Treatments}

\subsubsection{Cognitive-behaviour group therapy (CBGT).}

A manual was designed to adapt the guidelines of cognitive therapy for depression (Beck et al., 1979) to a seven-session group intervention. In this part, psychoeducation, behavioural activation, and identification of automatic thoughts were covered through group discussions and homework assignments.

\subsubsection{Cognitive-behaviour therapy (CBT).}

Patients allocated to this condition also received CBT in this phase in accordance with a manual designed for the trial. In this part, patients continued the identification of automatic thoughts, but cognitive restructuring and behavioural 
experiments were more prominent. The main goal was the identification and revision of underlying assumptions and core beliefs.

\subsubsection{Dilemma-focused therapy (DFT).}

A manual for this condition was also written in both English (Feixas \& Compañ, 2016) and Spanish (Feixas \& Compañ, 2015).

Since both therapeutic approaches tested were equally efficacious and since both can be broadly regarded as varieties of cognitive therapy, we analysed the pooled sample of patients regardless of their treatment allocation.

\subsection{Patients}

To be eligible, patients had to meet the following criteria: age between 18 and 70 years old; score of 20 or above on the Beck Depression Inventory - II (BDI-II); diagnostic criteria for MDD or dysthymia assessed with the Structured Clinical Interview for DSM-IV Axis I Disorders (SCID- I; First, Spitzer, Gibbon, \& Williams, 1996) and at least one CC, as detected by the RGT. Exclusion criteria were the presence of psychotic symptoms, manic or hypomanic episodes in the past, substance abuse, organic brain dysfunction, acute suicidal ideation, and mental retardation. Patients who were already receiving psychological treatment had substantial visual, hearing, and cognitive deficits, or lacked the linguistic competence to communicate in Spanish or Catalan were also excluded. Of 197 eligible patients, 141 started the group therapy; 128 finished the first phase and were randomly assigned to one of the two individual therapy conditions (see figure 3 for CONSORT diagram and more details). One hundred and 
eight patients completed the second phase ( $n=54$ in CBT, and $n=54$ in DFT), and 106 agreed to participate in post-treatment assessments (completers). The present study included the 108 patients $\left(n=84\right.$ [77.8\%] women; $\left.M_{\text {age }}=49.28, S D=10.98\right)$ who had completed the two phases of treatment, because we were interested in tracking the patients' patterns of change (trajectories) over the two phases. Ninety-five patients were assessed at the 3-month follow-up, and 77 at one year.

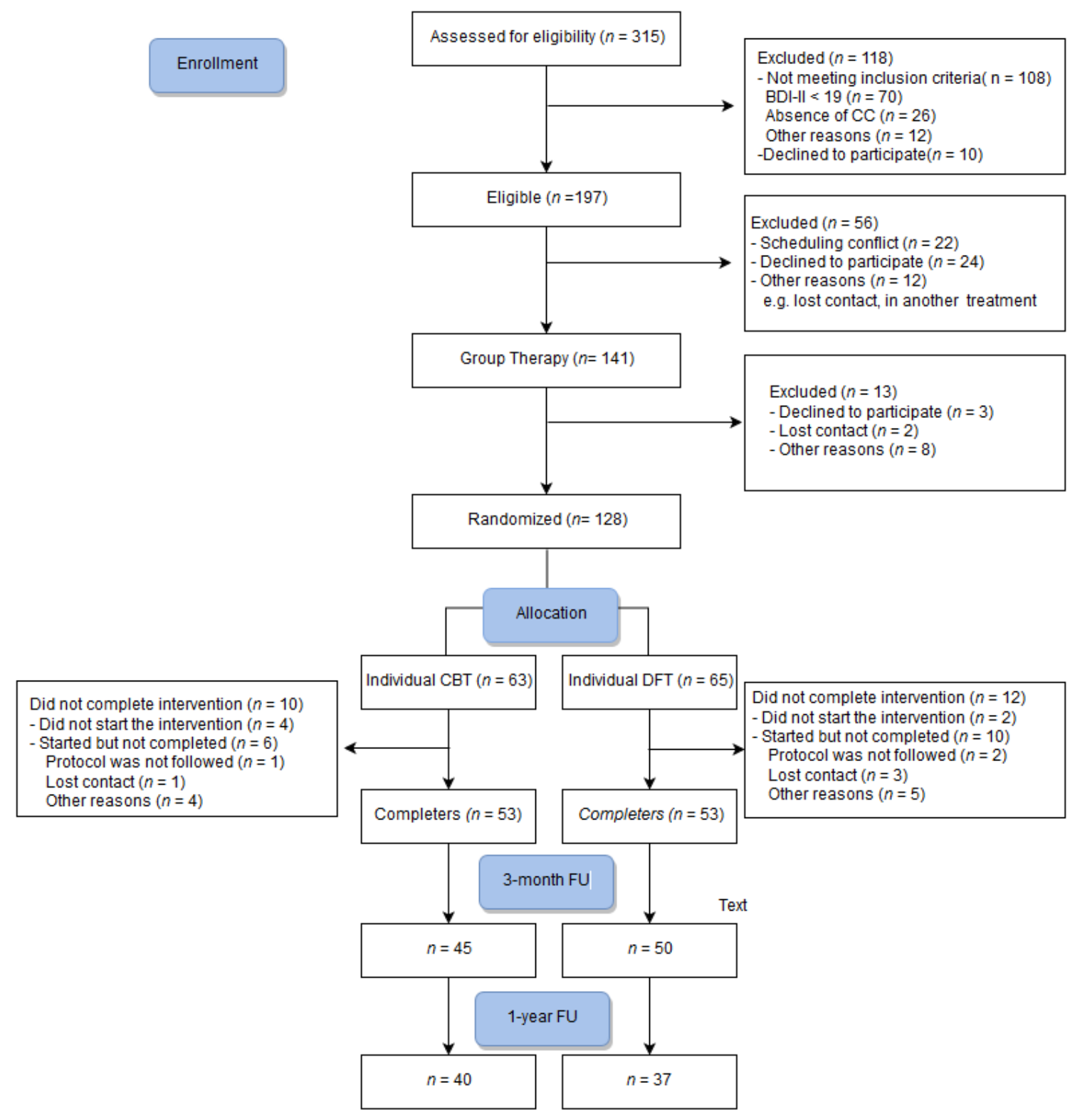

Figure 3. CONSORT diagram by Feixas et al. (2018) RCT. 


\subsection{Instruments and Measures}

Patients were assessed on a battery of instruments before treatment, at termination, and at 3-month and 1-year follow up. Brief outcome measures were applied in each session during both phases of treatment. For the current study, the following instruments and measures were considered:

\subsubsection{Structured Clinical Interview for DSM-IV Axis I Disorders (SCID- I;}

\section{First, Spitzer, Gibbon, \& Williams, 1996)}

The SCID-I is a structured clinical interview designed to verify the accomplishment of diagnostic criteria for mental disorders according to the DSM-IVTR axis I. With the SCID-I, information such as socio-demographic data, psychotropic drug consumption, medical history, and treatments received was also collected. The Spanish version of the SCID-I was applied at pre- and post-treatment assessment.

\subsubsection{Beck Depression Inventory - II (BDI-II; Beck, Steer, \& Brown, 1996).}

The BDI-II is a self-reported questionnaire composed of 21 items answered on a Likert scale that goes from 0 to 3 . It covers two factors related to the DSM-IV diagnostic criteria for dysthymia and MDD: a physical or motivational factor, and a cognitive or affective factor. The total score ranges from 0 to 63 and is calculated by summing all items. The Spanish version of the BDI-II (Sanz, 2013) was applied at pretreatment and post-treatment assessments and at 3-month and 1-year follow-up. The BDI-II was the primary outcome measure of Feixas et al. $(2016,2018)$ study. 


\subsubsection{Global Assessment of Functioning (GAF; APA, 2000; First et al.,} 1996).

The GAF is a heteroapplied scale that assesses functioning in daily-life activities. It is part of the diagnosis the clinician should typify for the Axis V of the DSM-IV-TR. The scale goes from 1 to 100 in ranges of 10, where the 1-10 range represents minimal functioning due to the danger of hurting oneself or others, and the 91-100 range represents the absence of symptoms and no impaired functioning. The Spanish version of the GAF was applied at the pre-treatment, post-treatment, and 1-year follow-up assessments.

\subsubsection{Clinical Outcome in Routine Evaluation - Short Form B (CORE-SFB;}

Evans et al., 2000).

The CORE-SFB is a short psychotherapy-outcome measure based on the 34item Clinical Outcome in Routine Evaluation - Outcome Measure (CORE-OM). It assesses the same four factors as the CORE-OM using 18 items: well-being (4 items), problems or symptoms (6 items), general functioning (6 items) and risk of self-harm and harm to others ( 2 items). In this questionnaire, the respondent answers each item on a 5-point Likert scale that goes from "never" to "always". The direct score varies from 0 to 72 . To estimate the global score, the direct score (sum of all items) is divided by the total number of items, obtaining a score between 0 and 4 , with higher scores representing high levels of psychological distress. The Spanish version (Feixas et al., 2012; Trujillo et al., 2016) was applied at pre-treatment and post-treatment assessments, in the interview with the therapists, and in each treatment session. 
3.4.5 Repertory Grid Technique (RGT; Feixas \& Cornejo, 2002a; Fransella et al., 2004; Kelly, 1955/1991).

The RGT is a semi-structured interview designed to assess the system of personal constructs that patients use to define themselves and their interpersonal world. Several indexes can be obtained for each patient with the mathematical analysis of the repertory grid data matrix. We used the software GRIDCOR 4.0 (Feixas \& Cornejo, $2002 b)$ to obtain the indexes for this study, which were:

3.4.5.1 Self-ideal discrepancy. This is based on the Euclidean distance between the ratings to the "self now" element and those of the "ideal self" (how she/he would like to be). It can be considered an indicator of self-esteem (the higher the distance, the lower the self-esteem). According to Spanish normative data (Trujillo, 2016), the mean of this score for the general population is .23 $(S D=.09)$.

3.4.5.2 Self-others discrepancy. This is based on the Euclidean distance between the ratings to the "self now" element and those of the "others" (averaging scores of all other elements) and describes how similar the patient views him/herself to significant others. High scores on this index correspond to a greater perception of social isolation. According to the normative data, the mean of this score for the Spanish population is $.21(S D=.06)$.

\subsubsection{Proportion of the intensity of constructs of implicative dilemmas}

(PICID). This measures both the number and intensity of the IDs appearing in the repertory grid of a subject with respect to the maximum possible conflictual relationships between the constructs of that person (see Rouco, Paz, Winter, \& Feixas, 2018, for more details). The higher the index, the higher the level of internal conflicts. Correlations of .20 between the constructs that are part of the ID have been considered. 
The RGT was applied at pre-treatment and post-treatment assessments.

\subsection{Data Analytical Strategy}

First, to analyse whether patterns of change can be tracked along the two phases of treatment, we used GMM techniques. CORE-SFB scores at pre-treatment assessment, pre-treatment interview, each therapy session, and post-treatment assessment were included in the models (19 time-points in total). Second, differences in patients' baseline and outcome characteristics were explored in relation to the patterns found using MLM (or HLM), repeated measures analysis of variance (RM-ANOVA), and chi-square $\left(X^{2}\right)$ test. Third, multinomial logistic regression (MLR) models were computed to identify patient's baseline characteristics that predicted pattern membership. Fourth, using sequential linear regression analysis, patients' baseline characteristics and patterns of change were examined as predictors of BDI-II total score at post-treatment and follow-up assessments. This procedure made it possible to test whether the fact of belonging to a specific pattern could be used to predict outcome. Finally, with $X^{2}$ test, we explored the differences in the proportion of recovered patients (according to Jacobson and Truax's criteria, 1991) for each class at termination, at 3month and 1-year follow up assessments.

\subsubsection{Patterns of change for group and individual therapy.}

As was explained in section 1.3.1, GMM is a method based on latent growth models which allows the identification of multiple unobserved subpopulations in longitudinal data. 
In the current study, models were estimated with a piecewise function (Kohli, Harring, \& Hancock, 2013). Moreover, two slopes and two intercepts were computed, one for each phase of the treatment. Using a conventional latent growth model, we tested the polynomic function with the best fit for the data. Models were compared through the $X^{2}$ test, root mean square error of approximation (RMSEA), Bayesian information criterion (BIC), and Akaike's information criterion (AIC). We followed the criterion of the lower the value, the better the model (Byrne, 2012). Once resolved, GMM was implemented starting with a one-class model. Several models with progressive numbers of classes were tested until we found a solution that met the criteria of the lowest value in BIC and AIC, and statistical significance $(p<.05)$ on the bootstrapped likelihood ratio test (BLRT) and Lo-Mendel-Rubin likelihood ratio test (LRT), which checked whether the implementation of an additional latent class could result in a significant improvement of the model (Kim, 2014; Koffmann, 2017). Entropy scores were also taken into account for model comparisons (a measure of classification quality that goes from 0 to 1 , where 1 corresponds to the case where all individuals have probability 1 for one class and 0 for the others; Nylund, Asparouhov, \& Muthén, 2007). Variances around the class-specific slopes were fixed to zero, whereas intercept variances were freely estimated. Therefore, differences in change patterns had to be captured by the difference in mean slope and initial scores at each phase of the treatment (Muthén, Brown, Hunter, Cook, \& Leuchter, 2011). Figure 4 shows the path diagram of the model performed. 


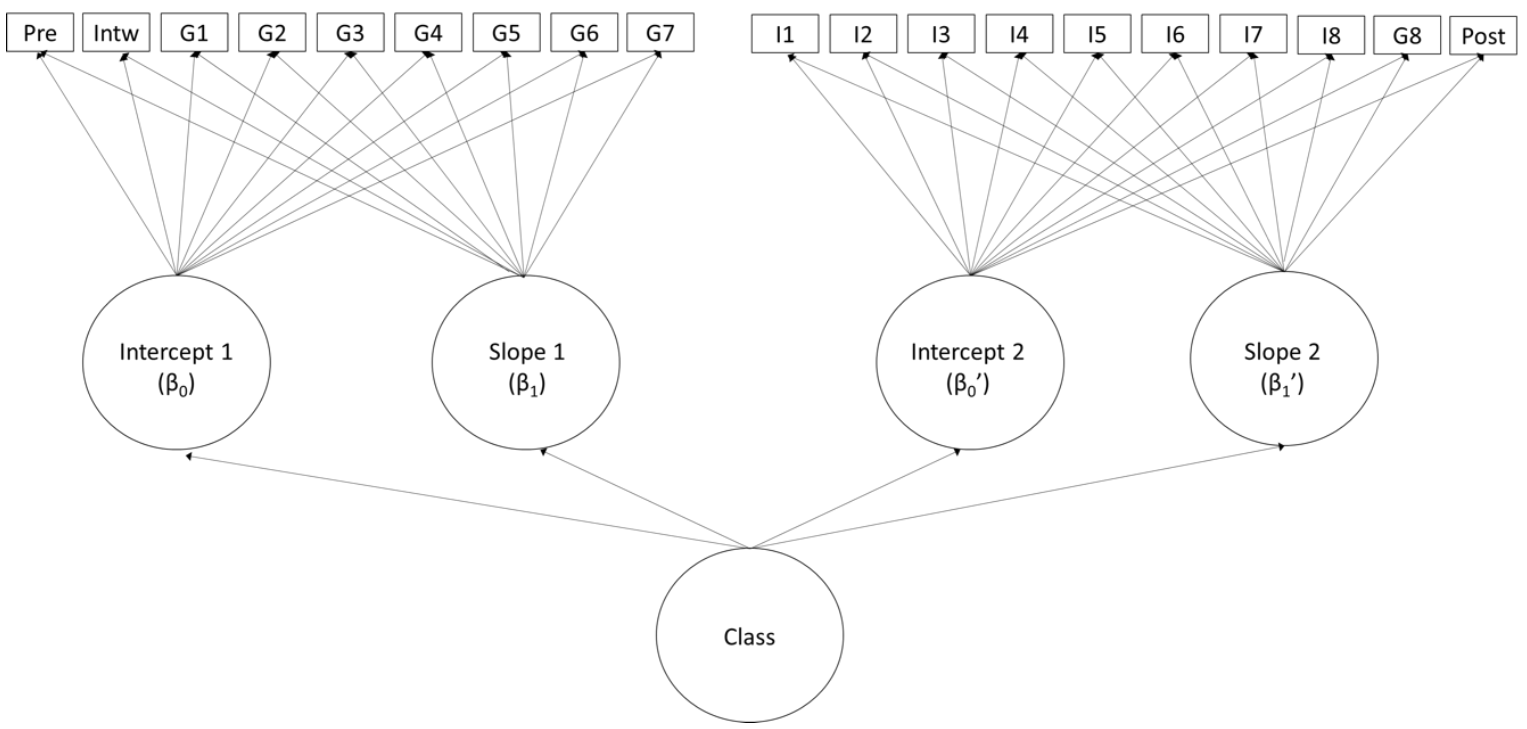

Figure 4. Path diagram of the model computed with GMM. Note. Pre $=$ pre-treatment assessment; Intw $=$ pre-treatment interview; $\mathrm{G}_{\#}=$ number of group therapy session; $\mathrm{I}_{\#}=$ number of individual therapy session; Post $=$ post-treatment assessment.

\subsubsection{Patients' characteristics within each pattern.}

Once the patterns were identified, patients were categorized accordingly into classes. Differences in patients' characteristics between classes at baseline, termination, and follow-up were explored using MLM for continuous variables with more than twotime point assessments. For continuous variables with only two-time point assessments (i.e., RGT indexes assessed only pre- and post-therapy), RM-ANOVA was performed. Contrasts between classes at each time point were examined through ANOVA applying Bonferroni correction. Effect sizes were also computed as Hedges' g. Differences between classes in categorical variables at baseline were explored using the $X^{2}$ test. 


\subsubsection{Patients' baseline characteristics as predictors of the patterns of} change.

Based on the previous results, variables at baseline were selected as predictors for class membership through MLR (backward stepwise method). AIC, BIC, and $X^{2}$ tests were used for model comparison. Furthermore, all predictors were centred following the guidelines of Kraemer and Blasey (2004), whereby continuous variables were mean-centred, ordinal variables were median-centred, dichotomous variables were coded at $1 / 2$ and $-1 / 2$, and categorical variables were dummy coded at $1 / n$, and $-1 / n(n$ being the number of categories).

\subsubsection{Patterns of change as predictors of treatment outcome at termination} and follow-up.

Through multiple linear regression (stepwise method), predictive models for the outcome at termination and follow-up were computed. The effect of class membership (dummy coded) was added to these models through a sequential analysis. Variables were also centred according to the guidelines of Kraemer and Blasey (2004). Finally, differences in the percentage of patients in each class with a reliable change in BDI-II and a score under the clinical cut-off (recovered patients, according to Jacobson and Truax, 1991) $)^{2}$ at termination and at 3-month and 1-year follow up were explored using the $X^{2}$ test.

\footnotetext{
${ }^{2}$ The reliable change index (RCI) for BDI-II in Feixas et al.'s (2016) RCT was 7.76, and the cut-off score was 17.53 (Paz et al., 2019). Both were computed using normative data for Spanish population (Sanz, 2013).
} 
Latent growth models and GMM were computed with Mplus 7 (Muthén \& Muthén, 1998-2012), and the other analyses were carried out with IBM SPSS 25 (IBM Corp., 2017). 


\section{Results}

\subsection{Patterns of Change for Group and Individual Therapy}

Using latent growth models, we found that a linear function provided a better solution for our data, $X^{2}(176)=310.59, p<.001, \mathrm{RMSEA}=.084, \mathrm{BIC}=2111.76$, AIC $=2042.02$, than a log-linear function, $X^{2}(176)=323.29, p<.001, \mathrm{RMSEA}=.088, \mathrm{BIC}$ $=2121.18, \mathrm{AIC}=2051.45$. Solutions for models based on quadratic and cubic functions did not converge. Therefore, the linear function was chosen to perform GMM, and tests of goodness of fit suggested a three-class solution (see tables 1, 2 and figure 5).

Table 1

Information criteria, p-value in bootstrapped likelihood ratio test (BLRT), and LoMendel-Rubin likelihood ratio test (LRT) for models tested with growth mixture modelling (GMM)

\begin{tabular}{cccccc}
\hline $\begin{array}{c}\text { Num of } \\
\text { classes }\end{array}$ & BIC & AIC & $\begin{array}{c}\text { BLRT } \boldsymbol{p} \text { - } \\
\text { value }\end{array}$ & $\begin{array}{c}\text { LRT } \boldsymbol{p} \text { - } \\
\text { value }\end{array}$ & Entropy \\
\hline 1 & 2111.76 & 2042.03 & --- & --- & --- \\
2 & 2013.75 & 1930.61 & .329 & .316 & .86 \\
$\mathbf{3}$ & $\mathbf{1 9 8 1 . 4 3}$ & $\mathbf{1 8 8 4 . 8 7}$ & $\mathbf{. 0 0 0}$ & $\mathbf{. 0 2 9}$ & $\mathbf{. 8 8}$ \\
4 & 1961.13 & 1851.16 & .000 & .092 & .90 \\
5 & 1954.58 & 1831.20 & .000 & .345 & .88 \\
\hline
\end{tabular}

Note. BIC = Bayesian information criterion; AIC = Akaike's information criterion 


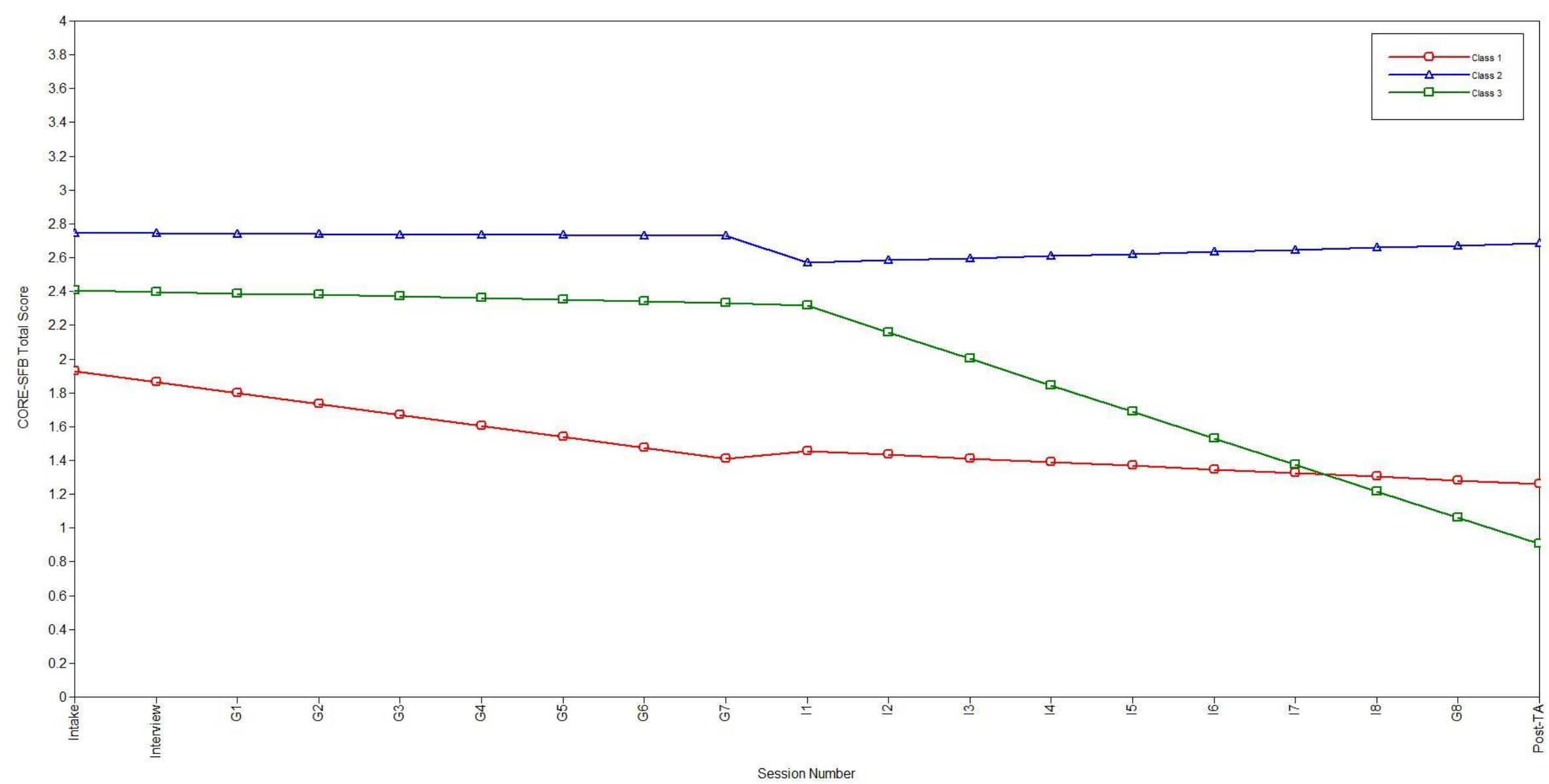

Figure 5. Estimated mean latent growth curves for the 3-class model with GMM. Note. $\mathrm{G}_{\#}=$ number of group therapy session; $\mathrm{I}_{\#}=$ number of individual therapy session; Post-TA = post-treatment assessment. 
Table 2

Parameters of the 3-class model obtained with GMM.

\begin{tabular}{|c|c|c|c|c|c|}
\hline & \multirow[b]{2}{*}{$n$} & \multicolumn{2}{|c|}{ Group Therapy Phase } & \multicolumn{2}{|c|}{$\begin{array}{c}\text { Individual Therapy } \\
\text { Phase }\end{array}$} \\
\hline & & $\begin{array}{c}\text { Intercept } \\
\beta_{0} \\
\end{array}$ & $\begin{array}{c}\text { Slope } \\
\beta_{1} \\
\end{array}$ & $\begin{array}{c}\text { Intercept } \\
\boldsymbol{\beta}_{0},\end{array}$ & $\begin{array}{c}\text { Slope } \\
\beta_{1},\end{array}$ \\
\hline Class 1 & $\begin{array}{c}63 \\
(58.3 \%)\end{array}$ & $1.93 * * *$ & $-.07 * * *$ & $1.65 * * *$ & $-.02 * *$ \\
\hline Class 2 & $\begin{array}{c}26 \\
(24.1 \%)\end{array}$ & $2.74 * * *$ & -.002 & $2.46 * * *$ & .012 \\
\hline Class 3 & $\begin{array}{c}19 \\
(17.6 \%)\end{array}$ & $2.41 * * *$ & -.01 & $3.73 * * *$ & $-.16^{* * *}$ \\
\hline
\end{tabular}

Considering the estimated means of the model (table 2), in figure 4 is possible to see that patients in the first class were characterized by medium-to-high distress severity at baseline (note that the mean for Spanish mental health outpatients for COREOM is $M=1.62$, Trujillo, et al., 2016). They presented rapid improvement during group therapy, but their improvement was slower in the individual therapy phase. This class was called group therapy improvers. The other two classes had a high average of symptom severity scores at baseline. Patients in class 3 started with lower severity distress than those in class 2, and hardly improved during the group therapy; however, when they started the individual therapy phase, they started to improve very rapidly. This class was called individual therapy improvers. Patients in class 2 were those with the highest level of distress at baseline; they did not improve at any phase in the treatment, and some even deteriorated. This class was called non-improvers. 


\subsection{Patients' Characteristics within Each Pattern}

Firstly, differences between classes in CORE-SFB total score at baseline, the last session of the group therapy phase (G7), and post-treatment assessment were estimated through MLM. The main effect of treatment in reducing the scores over time was significant, $F(2,108.70)=22.76, p<.001$. Post-hoc contrasts revealed significant differences between different time points within, $F(2,80.87)=22.76, p<.001$, and between classes $F(2,79.69)=91.92, p<.001$. At post-treatment assessment, classes 1 (group therapy improvers) and 3 (individual therapy improvers) tended to present similar scores. Figure 6 shows the trajectory of the three classes based on these comparisons, and table 3 gives the specific values and effect sizes of the mean differences.

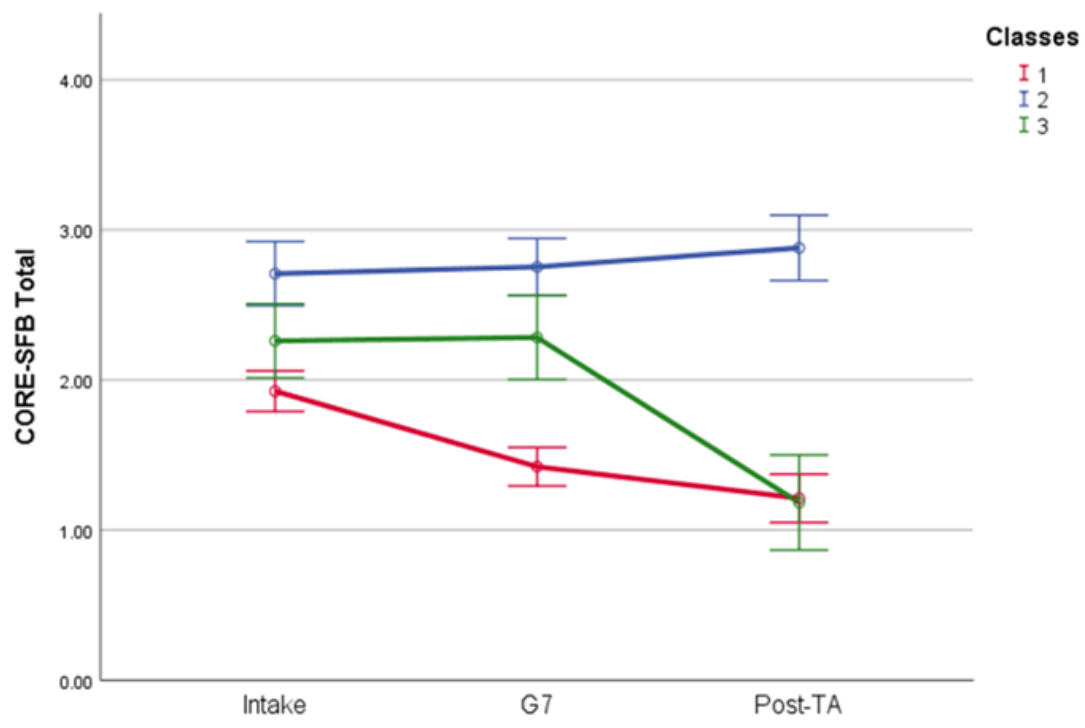

Figure 6. Observed means and 95\% CI for CORE-SFB total score by classes at intake, last session of the group therapy phase, and post-treatment assessment. Note. G7 = group therapy session number 7; Post-TA = post-treatment assessment. 
Table 3

Observed means, (SD), [95\% CI], and effect sizes for CORE-SFB total score between classes comparisons

\begin{tabular}{|c|c|c|c|c|c|c|}
\hline Class & Intake & G7 & Post-TA & $\begin{array}{c}\text { Effect Size } \\
\Delta \\
\text { Intake/G7 }\end{array}$ & $\begin{array}{c}\text { Effect Size } \\
\Delta \text { G7/Post- } \\
\text { TA }\end{array}$ & $\begin{array}{c}\text { Effect Size } \\
\Delta \\
\text { Intake/Post- } \\
\text { TA }\end{array}$ \\
\hline 1 & $\begin{array}{c}1.93(.50) \\
{[1.79,2.06]}\end{array}$ & $\begin{array}{c}1.42(.47) \\
{[1.30,1.55]}\end{array}$ & $\begin{array}{c}1.21(.54) \\
{[1.06,1.37]}\end{array}$ & $\begin{array}{c}1.04 * * \\
{[.64,1.44]}\end{array}$ & $\begin{array}{c}.41^{*} \\
{[.02, .81]}\end{array}$ & $\begin{array}{c}1.38 * * \\
{[.95,1.81]}\end{array}$ \\
\hline 2 & $\begin{array}{c}2.71(.49) \\
{[2.51,2.91]}\end{array}$ & $\begin{array}{c}2.75(.46) \\
{[2.57,2.93]}\end{array}$ & $\begin{array}{c}2.88(.39) \\
{[2.68,3.08]}\end{array}$ & $\begin{array}{c}-.08 \\
{[-.65, .48]}\end{array}$ & $\begin{array}{c}-.29 \\
{[-.94, .35]}\end{array}$ & $\begin{array}{c}-.37 \\
{[-1.02, .29]}\end{array}$ \\
\hline 3 & $\begin{array}{c}2.26(.49) \\
{[2.03,2.49]}\end{array}$ & $\begin{array}{c}2.28(.56) \\
{[2.02,2.54]}\end{array}$ & $\begin{array}{l}1.18(.50) \\
{[.90,1.47]}\end{array}$ & $\begin{array}{c}-.04 \\
{[-.69, .62]}\end{array}$ & $\begin{array}{c}1.99 * * \\
{[1.10,2.88]}\end{array}$ & $\begin{array}{c}2.13 * * \\
{[1.22,3.03]}\end{array}$ \\
\hline
\end{tabular}

Note. $\Delta=$ difference; G7 = group therapy session number 7; Post-TA = post-treatment assessment; $* * p<.001 ; * p<.01$

Similar analyses were performed for BDI-II, GAF, and RGT indexes. For BDIII, scores at baseline, post-treatment, 3-month and 1-year follow-up assessments were compared. The main effect of treatment on the reduction of BDI-II scores through time was significant, $F(3,71.01)=68.39, p<.001$. Classes added a significant effect to the model $F(2,5.42)=27.29, p=.001$, and post-hoc contrasts revealed significant differences $F(2,42.64)=37.41, p<.001$ between classes 1 (group therapy improvers) vs. 2 (non-improvers), and 2 vs. 3 (individual improvers) at each time point after baseline. For GAF, scores at baseline, post-treatment, and 1-year follow-up assessments were compared. The main effect of treatment on the increase of GAF scores over time was significant, $F(2,117.92)=67.40, p<.001$, as well as the effect of class membership, $F(2,35.58)=16.60, p<.001$. Post-hoc contrasts showed significant differences $F(2,40.21)=16.60, p<.001$ between classes 1 (group therapy improvers) 
vs. 2 (non-improvers), and 3 (individual therapy improvers) vs. 2 at post-treatment, and 1-year follow-up assessments. Figure 7 shows these comparisons for BDI-II and GAF based on observed means and 95\% CI.

RGT indexes at baseline and post-treatment were compared through RMANOVA. In all the models, the assumption of sphericity was accomplished according to the Greenhouse-Geisser estimation. The main effect of treatment on decreasing selfideal discrepancy was significant, $F(1,102)=32.74, p<.001$, and post-hoc contrasts revealed significant differences, $F(2,102)=8.72, p<.001$, between classes 1 ( group therapy improvers) vs. 2 (non-improvers) and between 2 vs. 3 (individual therapy improvers) at post-treatment assessment. Similar results were found for the self-others discrepancy and PICID. The main effect of treatment was significant for self-others discrepancy, $F(1,102)=25.69, p<.001$, and for PICID, $F(1,102)=17.05, p<.001$. Post-hoc contrasts between classes at post-treatment assessment for these two indexes were also significant, $F(2,102)=5.20, p<.01, F(2,102)=3.33, p<.05$ respectively. Table 4 gives the specific values and effect sizes of the mean differences. Figure 8 shows these comparisons for Self-Ideal and Self-Others discrepancies, and PICID based on observed means and $95 \% \mathrm{CI}$. 

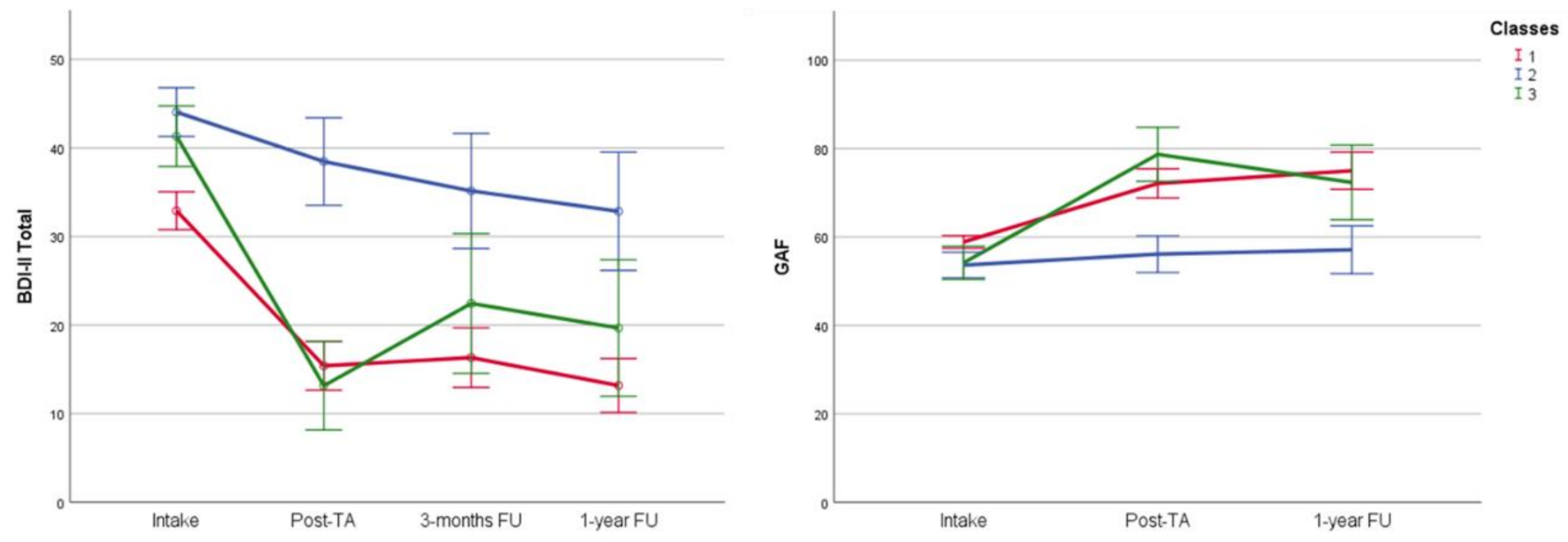

Figure 7. Observed means and 95\% CI for BDI-II total score and GAF by classes at intake, post-treatment, 3-months and 1-year follow-up assessment. Note. Post-TA $=$ post-treatment assessment; $\mathrm{FU}=$ follow-up. 

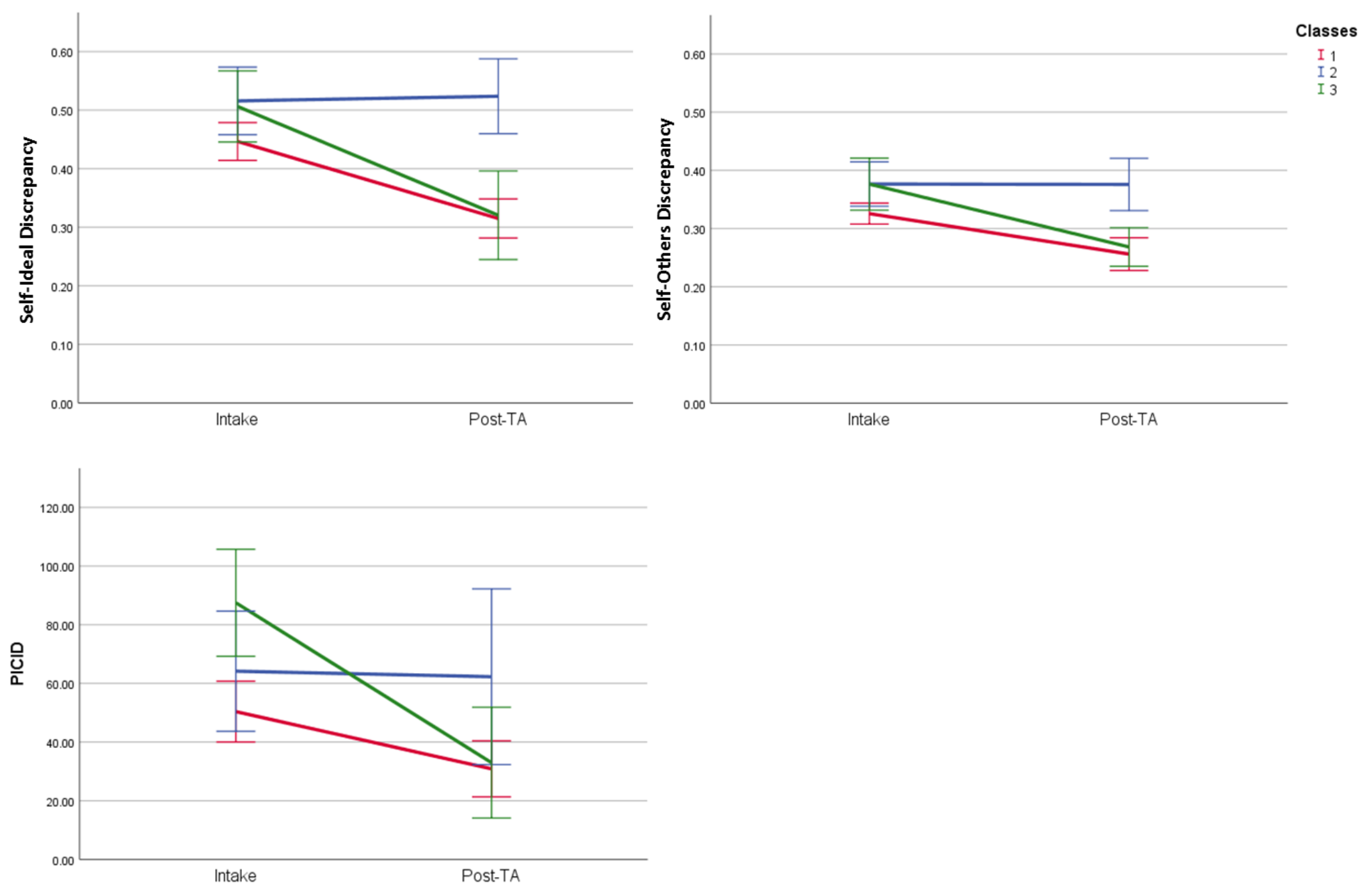

Figure 8. Observed means and 95\% CI for Self-Ideal and Self-Others discrepancies, and PICID at intake and post-treatment assessments. Note. Post-

$\mathrm{TA}=$ post-treatment assessment. 
Table 4. Observed means, (SD), [95\% CI], and effect sizes for BDI-II, GAF, Self-Ideal, Self-Others, and PICID between classes comparisons.

\begin{tabular}{|c|c|c|c|c|c|c|c|c|}
\hline & & Intake & Post-TA & 3-m FU & $1-y$ FU & $\begin{array}{c}\text { Effect Size } \Delta \\
\text { Intake/Post-TA }\end{array}$ & $\begin{array}{c}\text { Effect Size } \Delta \\
\text { Intake/3-m FU }\end{array}$ & $\begin{array}{c}\text { Effect Size } \Delta \\
\text { Intake/1-y FU }\end{array}$ \\
\hline \multirow{4}{*}{ BDI-II } & & {$[30.81,35.00]$} & {$[12.71,18.10]$} & {$[13.03,19.61]$} & {$[10.23,16.14]$} & {$[1.37,2.20]$} & {$[1.12,1.92]$} & {$[1.66,2.62]$} \\
\hline & Class 2 & $44.04(6.80)$ & $38.46(12.24)$ & $35.14(14.28)$ & $32.84(13.84)$ & $.56^{*}$ & $.81 * *$ & $1.06^{* *}$ \\
\hline & Class 3 & $41.32(7.10)$ & $13.16(10.39)$ & $22.44(14.80)$ & $19.67(13.90)$ & $3.10^{* * *}$ & $1.64 * * *$ & $1.99 * * *$ \\
\hline & & {$[38.13,44.51]$} & {$[8.49,17.83]$} & {$[15.19,29.69]$} & {$[12.63,26.70]$} & {$[2.16,4.04]$} & {$[.87,2.40]$} & {$[1.16,2.81]$} \\
\hline \multirow[t]{4}{*}{ GAF } & Class 1 & $58.87(5.72)$ & $72.11(12.07)$ & --- & $74.98(13.85)$ & $-1.43 * * *$ & --- & $-1.62 * * *$ \\
\hline & & {$[50.88,56.40]$} & {$[52.18,60.06]$} & & {$[52.06,62.15]$} & {$[-.84, .28]$} & & {$[-.98, .23]$} \\
\hline & Class 3 & $54.17(7.50)$ & $78.68(12.68)$ & --- & $72.33(15.22)$ & $-2.29 * * *$ & --- & $-1.52 * *$ \\
\hline & & {$[50.70,57.63]$} & {$[72.98,84.38]$} & & {$[64.63,80.04]$} & {$[-3.12,-1.46]$} & & {$[-2.30,-0.75]$} \\
\hline \multirow[t]{4}{*}{ Self-Ideal } & Class 1 & $.44(.13)$ & $.32(.13)$ & --- & --- & $.92 * * *$ & --- & -- \\
\hline & & {$[.41, .48]$} & {$[.28, .35]$} & & & {$[.55,1.29]$} & & \\
\hline & Class 2 & $.52(.15)$ & $.53(.15)$ & --- & --- & -.07 & --- & --- \\
\hline & & {$[.45, .58]$} & {$[.46, .59]$} & & & {$[-.62, .49]$} & & \\
\hline \multirow{3}{*}{$\begin{array}{c}\text { Self- } \\
\text { Others }\end{array}$} & & {$[.34, .42]$} & {$[.33, .42]$} & & & {$[-.46, .65]$} & & \\
\hline & Class 3 & $.38(.09)$ & $.27(.07)$ & --- & --- & $.13^{* *}$ & --- & --- \\
\hline & & {$[.34, .42]$} & {$[.24, .30]$} & & & {$[-.50, .77]$} & & \\
\hline \multirow[t]{6}{*}{ PICID } & Class 1 & $50.39(40.12)$ & $30.89(36.99)$ & --- & --- & $.50^{* *}$ & --- & --- \\
\hline & & {$[40.02,60.75]$} & {$[21.33,40.44]$} & & & {$[.14, .86]$} & & \\
\hline & Class 2 & $64.16(47.39)$ & $62.28(69.28)$ & --- & --- & .03 & --- & --- \\
\hline & & {$[43.67,84.65]$} & {$[32.32,92.24]$} & & & {$[-.53, .59]$} & & \\
\hline & Class 3 & $87.48(37.87)$ & $32.98(39.18)$ & --- & --- & $1.38^{* *}$ & --- & --- \\
\hline & & {$[69.23,105.73]$} & {$[14.10,51.87]$} & & & {$[.68,2.09]$} & & \\
\hline
\end{tabular}

Note. $\Delta$ = difference; Post-TA = Post-treatment assessment; 3-m FU = 3-months follow-up assessment; 1-y FU = 1-year follow-up assessment; *** $p<.001 ; * * p<.01 ; * p<.05$ 
No differences between classes were found in the age of the patients or in other RGT indexes. Regarding differences in categorical variables at baseline (explored with the $X^{2}$ test), no differences were found in sex, medication, marital, employment status or mental health diagnosis. In terms of medical diagnosis, we found that of the 26 nonimprovers (class 2) 14 (53.9\%) had a concurrent diagnosis of fibromyalgia syndrome (representing $70 \%$ of the 20 patients with this diagnosis in the study). The statistical contrast was significant, $X^{2}(2)=28.49, p<.001$, indicating the preponderance of these patients in this pattern (standardized residual, $z>1.96$ ).

\subsection{Patients' Baseline Characteristics as Predictors of the Pattern of Change}

Two MLR models for predicting class membership from patients' baseline characteristics were estimated with the backward stepwise method. On the basis of the previous results on patients' characteristics within each pattern, variables were selected as predictors for these models.

The assumptions of no multicollinearity between independent variables (tolerance values $>.10$ and variance inflation factor $[\mathrm{VIF}]<10$ ), and linear relationship between continuous independent variables and the logit of the dependent variable (no significant interaction between the dependent variables and the logit of themselves) were accomplished for both models. Equally, no indication of over/under dispersion was detected $(\Phi \approx 1)$.

The first model tested left out self-ideal and self-others discrepancies, and GAF because they did not contribute as significant predictors. Therefore, the variables entered the model were BDI-II, CORE-SFB, and PICID, $X^{2}(6)=49.26(\mathrm{AIC}=152.19$, $\mathrm{BIC}=172.71), p<.001$, pseudo $R^{2}=.40$ (Cox \& Snell), .47 (Nagelkerke), with a 
classification ratio of $61.5 \%$. Parameters of the model in table 5 show that CORE-SFB initial score contributed to discriminating between classes 1 (group therapy improvers) vs. 2 (non-improvers), and between 2 vs. 3 (individual therapy improvers; the higher the CORE-SFB score, the greater the likelihood of belonging to class 2), while BDI-II and PICID did so for class 1 vs. 3 (the higher the PICID and/or the BDI-II score, the greater the likelihood of belonging to class 3, individual therapy improvers). With the idea of increasing the predictive power of the model, a second analysis adding interactions was computed but the effect of interactions was not significant; therefore, they did not enter the model.

Table 5

Parameters for MLR predicting class membership from patients' baseline characteristics.

\begin{tabular}{|c|c|c|c|c|c|}
\hline Predictor & $B(S E)$ & $P$ & $\begin{array}{c}\text { Lower } \\
95 \% \text { CI }\end{array}$ & $\begin{array}{l}\text { Odds } \\
\text { Ratio } \\
\end{array}$ & $\begin{array}{c}\text { Upper } \\
95 \% \text { CI }\end{array}$ \\
\hline \multicolumn{6}{|c|}{ Class 1 (group therapy improvers) vs. 2 (non-improvers) } \\
\hline Intercept & $1.48(.40)$ & $<.001$ & & & \\
\hline BDI-II & $-.10(.05)$ & .05 & .83 & .91 & 1.00 \\
\hline CORE-SFB & $-2.55(.86)$ & $<.001$ & .01 & .08 & .42 \\
\hline PICID & $-.01(.01)$ & .07 & .97 & .99 & 1.00 \\
\hline \multicolumn{6}{|c|}{ Class 3 (individual therapy improvers) vs. 2 (non-improvers) } \\
\hline Intercept & $.26(.47)$ & .58 & & & \\
\hline BDI-II & $.02(.05)$ & 65 & .92 & 1.02 & 1.14 \\
\hline CORE-SFB & $-2.10(.91)$ & $<.05$ & 02 & .12 & .73 \\
\hline PICID & $.00(.01)$ & .45 & .99 & 1.00 & 1.02 \\
\hline \multicolumn{6}{|c|}{ Class 1 (group therapy improvers) vs. 3 (individual therapy improvers) } \\
\hline Intercept & $1.22(.34)$ & $<.001$ & & & \\
\hline BDI-II & $-.12(.05)$ & $<.05$ & .81 & .89 & .97 \\
\hline CORE-SFB & $-.44(.70)$ & .53 & .16 & .64 & 2.54 \\
\hline PICID & $-.02(.01)$ & $<.05$ & .97 & .98 & .99 \\
\hline
\end{tabular}

A second model was computed using the diagnosis of fibromyalgia syndrome (dichotomous variable) as predictor, $X^{2}(8)=57.19(\mathrm{AIC}=147.18, \mathrm{BIC}=172.72), p<$ 
.001 , pseudo $R^{2}=.45$ (Cox \& Snell), .53 (Nagelkerke), with a classification ratio of $68.4 \%$. In table 6 , the parameters of the model indicate that fibromyalgia acted as a predictor, increasing the likelihood of belonging to class 2 (non-improvers) compared to class 1 (group therapy improvers) in 7.14 times, and of belonging to class 2 compared to class 3 (individual therapy improvers) in 8.44 times. Note that in table 6 the predicted classes are 1 and 3, hence, to compute odds ratios for belonging to class 2,1 must be divided by the odds ratio reported.

Table 6

Parameters for MLR predicting class membership from patients' baseline characteristics and fibromyalgia diagnosis as predictor.

\begin{tabular}{|c|c|c|c|c|c|}
\hline Predictor & $B(S E)$ & $\boldsymbol{P}$ & $\begin{array}{c}\text { Lower } \\
95 \% \text { CI }\end{array}$ & Odds Ratio & $\begin{array}{c}\text { Upper } \\
95 \% \text { CI }\end{array}$ \\
\hline \multicolumn{6}{|c|}{ Class 1 (group therapy improvers) vs. 2 (non-improvers) } \\
\hline Intercept & $1.75(.44)$ & $<.001$ & & & \\
\hline Fibromyalgia & $-2.00(.90)$ & $<.05$ & .02 & .14 & .79 \\
\hline BDI-II & $-.08(.05)$ & .10 & .83 & .92 & 1.02 \\
\hline CORE-SFB & $-2.31(.86)$ & $<.05$ & .02 & .10 & .53 \\
\hline PICID & $-.01(.01)$ & .40 & .98 & .99 & 1.01 \\
\hline \multicolumn{6}{|c|}{ Class 3 (individual therapy improvers) vs. 2 (non-improvers) } \\
\hline Intercept & $.51(.51)$ & .31 & & & \\
\hline Fibromyalgia & $-2.10(1.01)$ & $<.05$ & .02 & .12 & .89 \\
\hline BDI-II & $.38(.58)$ & .51 & .93 & 1.04 & 1.16 \\
\hline CORE-SFB & $-1.80(.95)$ & .06 & .03 & .17 & 1.07 \\
\hline PICID & $.02(.01)$ & .10 & 1.00 & 1.02 & 1.03 \\
\hline \multicolumn{6}{|c|}{ Class 1 (group therapy improvers) vs. 3 (individual therapy improvers) } \\
\hline Intercept & $1.24(.36)$ & $<.001$ & & & \\
\hline Fibromyalgia & $.10(1.10)$ & .93 & .13 & 1.11 & 9.37 \\
\hline BDI-II & $-.12(.05)$ & $<.05$ & .81 & .89 & .97 \\
\hline CORE-SFB & $-.51(.73)$ & .48 & .15 & .60 & 2.49 \\
\hline PICID & $-.02(.01)$ & $<.05$ & .96 & .98 & .99 \\
\hline
\end{tabular}




\subsection{Patterns of Change as Predictors of Treatment Outcome at Termination and}

\section{Follow-up}

The predictive power of change patterns for the BDI-II total score at termination, 3-month and 1-year follow-up assessments was estimated using hierarchical linear regression analysis.

The assumptions of linear relationship between variables; normal distribution of continuous and ordinal variables (Shapiro-Wilk test, $p>.05$ ); no multicollinearity (tolerance values > .10 and VIF < 10); normality (visual inspection of Q-Q plot indicated normal distribution of residuals, and $M$ residuals $=0$ ), homocedasticity (Levene test, $p>.05$ ) and no auto-correlation of the residuals (Durbin-Watson statistic $<3$ and $>$ 1), were accomplished.

The BDI-II score at baseline was used as a default predictor to control their effect in the models. Baseline scores of the other variables (GAF, CORE-SFB, self-ideal discrepancy, self-others dicrepancy, and PICID) were tested as predictors using the stepwise method. The first analysis left these variables out of the model because they did not contribute to it as significant predictors. Therefore, only the BDI-II score at baseline entered as a predictor in the first step. In the second step, the dummy-coded class membership variables were added to the model (see table 7).

For instance, at termination, $27 \%$ of patients' depression levels depended on their initial score, and $28 \%$ on their pattern of change, amounting to $55 \%$ of the total explained variance. This value fell at 3-month follow-up, where the effect of the patterns seemed to play a less crucial role, and then increased again at 1-year follow-up. 
Table 7

Parameters of sequential linear regression analysis to predict BDI-II scores at termination, 3-months, and 1-year follow-up assessments.

\begin{tabular}{|c|c|c|c|c|c|c|}
\hline \multirow[b]{2}{*}{ Predictors } & \multicolumn{2}{|c|}{ Post-TA } & \multicolumn{2}{|c|}{ 3-m FU } & \multicolumn{2}{|c|}{ 1-y FU } \\
\hline & $B(S E)$ & $\begin{array}{l}\text { Increment } \\
\text { in } R^{2}\end{array}$ & $B(S E)$ & $\begin{array}{l}\text { Increment } \\
\text { in } R^{2}\end{array}$ & $B(S E)$ & $\begin{array}{l}\text { Increment } \\
\text { in } R^{2}\end{array}$ \\
\hline \multicolumn{7}{|c|}{ Step 1} \\
\hline Intercept & $2.50(1.25)^{* * *}$ & .27 & $21.70(1.43)^{* * *}$ & .18 & $19.53(1.48)^{* * *}$ & .17 \\
\hline BDI-II pre & $.84(1.25)^{* * *}$ & & $.69(.15) * * *$ & & $.64(.17)^{* * *}$ & \\
\hline \multicolumn{7}{|c|}{ Step 2} \\
\hline Intercept & $14.21(1.34)^{* * *}$ & .28 & $19.23(1.86)^{* * *}$ & .11 & $16.45(1.76)^{* * *}$ & .17 \\
\hline BDI-II pre & $.57(.13)^{* * *}$ & & $.41(.17)^{*}$ & & $.23(.19)^{*}$ & \\
\hline Class 1 & $-36.00(4.70)^{* * *}$ & & $-21.16(5.93)^{* *}$ & & $-25.58(5.97)^{* * *}$ & \\
\hline Class 3 & $-25.50(4.19)^{* * *}$ & & $-18.04(6.65)^{* *}$ & & $-19.52(6.17)^{* *}$ & \\
\hline$R^{2}$ & & .55 & & .29 & & .34 \\
\hline
\end{tabular}

Note. Post-TA = Post-treatment assessment; 3-m FU = 3-months follow-up assessment;

1-y FU = 1-year follow-up assessment; *** $p<.001 ; * * p<.01 ; * p<.05$

Finally, table 8 shows the percentage of patients in each class who achieved a reliable change in BDI-II and whose scores were under the clinical cut off (recovered patients) at termination, 3-month and 1-year follow up. $X^{2}$ tests found statistically significant differences between the proportion of classes at post-treatment assessment: $X^{2}(6)=34.90, p<.001 ; 3$-month follow-up, $X^{2}(6)=23.61, p<.01$; and 1-year followup, $X^{2}(6)=20.10, p<.01$. The proportion of recovered patients in class 2 (nonimprovers) was the lowest for each time point. 
Table 8

Percentage of recovered patients in each class.

\begin{tabular}{cccc}
\hline Classes & Post-TA & 3-m FU & 1-y FU \\
\hline 1 & $61.9 \%$ & $62.7 \%$ & $72.7 \%$ \\
2 & $3.8 \%^{*}$ & $9.5 \% *$ & $15.8 \% *$ \\
3 & $68.4 \%$ & $37.5 \%$ & $53.3 \%$
\end{tabular}

Note. Post-TA = Post-treatment assessment; 3-m FU = 3-months follow-up assessment;

1-y FU = 1-year follow-up assessment; * standardized residual, $z>1.96$ 



\section{Discussion}

The present research studied the patterns of change, in patients receiving group and individual psychotherapy for depression in the context of a RCT. Three types of patterns were found: group therapy improvers (class 1), individual therapy improvers (class 3), and non-improvers (class 2).

Consistent with our hypothesis, we found a differential pattern of early response (class 1) and other pattern of response to individual therapy (class 3). Thus, there was a group of patients who responded better to group than to individual therapy, and that in other group the opposite trend was found. In other words, there were patients that needed individual therapy after group therapy to obtain improvements.

Concerning the objective of exploring the patients' characteristics in each pattern (objective 2), group therapy improvers started the treatment with lower levels of symptoms of psychological distress and depression and higher levels of functioning than the other two groups. These results are consistent with the scores in the RGT indexes, in which they showed the lowest levels of self-ideal discrepancy (higher selfesteem), of self-others discrepancy (perception of higher similarity with others), and of conflicted construction of the self (PICID). These characteristics seemed to be signs of good prognosis for these patients, who were early responders to group therapy and improved very fast during this phase of the treatment. While it is true that they continued to improve during the individual therapy phase, the improvement was less marked than during the previous phase and also less marked than among the individual therapy improvers. In terms of the outcome at termination and follow-up assessments, these patients' BDI-II scores were, in most cases, at functional levels, and in the category of recovered. They continued to improve 3 months and 1 year after the 
treatment, showing that they were able to maintain the benefits of the treatment over time. These patients presented improvements in their construction of self and others as measured with the RGT.

Individual therapy improvers started at similar levels of depression to nonimprovers. As regards psychological distress, their initial levels were lower than nonimprovers, but higher than group therapy improvers. During the group therapy phase they showed no improvement at all, but when the individual therapy phase began, they responded promptly and started to improve very fast. By the end of treatment, they had reached the same levels of symptoms and functioning as the group therapy improvers, with a similar proportion of recovered patients. Three months after treatment they tended to show an increase in depression symptoms, but had partially recovered by the time of the one-year follow up. These results suggest that although some patients in this group had difficulties in maintaining treatment benefits, one year after treatment their scores on the BDI-II tended to be within the range of the general population (Sanz, 2013). In terms of functioning, they showed good levels at post-treatment assessment, which were practically maintained one year later. Again, as in the previous group, these results were consistent with the scores on the RGT indices. Individual therapy improvers started with similar levels of self-ideal discrepancy, perception of social isolation, and conflictual construction of the self to non-improvers, but presented improvements on all these indices after treatment. These results, along with the results obtained by the previous subgroup, showed that patients who improved in psychotherapy ended up with better self-esteem, perceived themselves as more similar to others, and tended to reduce their CCs after the treatment; these outcomes also mirror those of other psychotherapy studies (Feixas et al., 2008; Pucurull, 2015). 
Non-improvers started the treatment with the highest levels of psychological distress and depression, and their levels of functioning were lower than the group therapy improvers though similar to those of the individual therapy improvers. The same comparisons were observed for the RGT indices. These patients did not show patterns of response at any phase of the treatment; they did not improve over the course of treatment with regard to psychological distress, and in fact seemed to deteriorate; their BDI-II scores appeared to have fallen at treatment termination and at the follow-up assessments, but they presented more limited improvement than the other groups, and obtained the lowest effect sizes. In fact, their mean scores were not within functional ranges at any assessment point, and the number of recovered patients was small. The changes in their RGT indices were not significant; thus, they did not present improvements in their self-esteem or in their perception of social isolation, and their CCs did not resolve after treatment. We stress that the majority of patients in this cluster were diagnosed with fibromyalgia syndrome. This may explain the differences between CORE-SFB and BDI-II outcome scores; while these patients' depression symptoms seemed to improve, their levels of psychological distress did not, probably because of the persistence of their physical difficulties.

Models for predicting class membership from patients' baseline characteristics (objective 3) significantly discriminated group therapy improvers from non-improvers and individual therapy improvers. BDI-II, CORE-SFB, and PICID emerged as significant predictors for this purpose: higher BDI-II and PICID scores were associated with a higher likelihood of being an individual therapy improver than a group therapy improver, and higher baseline scores for CORE-SFB were related a higher likelihood of being a non-improver than a group therapy improver. Moreover, a diagnosis of fibromyalgia made it more likely that a patient would be a non-improver. 
What these results show is that the greater the initial impairment (in terms of depression symptom severity and psychological distress) and conflictual construction of the self, the more likely it is that patients will benefit from individual therapy than from group therapy. Although our first model was unable to discriminate well between individual therapy improvers and non-improvers, the results suggested that the greater the patients' impairment, the less likely they were to benefit from either group or individual therapy (i.e., the more likely they were to be non-improvers). This discrimination is clearer in the second model with the addition of fibromyalgia diagnosis.

These results can be assessed in the light of the profiles of patients proposed by DeRubeis, Gelfand, German, Fournier, and Forand (2014). These authors established a theoretical classification of patients according to their response to psychotherapy, based on the quality of the treatment received (in terms of the therapeutic alliance and the "fit" of the treatment plan to the characteristics of the patients), and the time-effect of patients' natural evolution (e.g., spontaneous remission). They define easy patients as the ones who would experience considerable improvement even without therapy, and would evidence maximal improvement if the quality of the therapy is at least good. Pliant patients are those whose response to therapy is excellent if excellent therapy is provided, poor if the therapy is poor, and so on. Challenging patients are those who experience no improvement unless therapy quality is at least good, and achieve less than maximal improvement even when optimal therapy is provided. Finally, intractable patients experience no improvement whatever the quality of therapy provided to them. In our case, group therapy improvers seem to correspond to the easy category (although we do not know whether they would have improved with individual therapy, or without therapy), individual therapy improvers to pliant and challenging, and non-improvers to 
challenging and intractable. While research has tended to show that patients with more severe levels at baseline may obtain at least as much clinical benefit from low-intensity interventions as less severely depressed patients (Bower et al., 2013; Driessen, Cuijpers, Hollon, \& Dekker, 2010), our results suggested the opposite: that is, that low-intensity treatment had little effect on more severely distressed patients, especially in the presence of somatic complaints (i.e., fibromyalgia).

The role of fibromyalgia comorbidity in patients' response is an interesting and relevant finding considering that a recent meta-analysis (which reviewed patient response profiles in treatments for depression; Cuijpers, Karyotaki, Reijnders, \& Huibers, 2018) found that the characteristic of comorbid general medical disorder was not related to better or worse outcome. Although the diagnosis of fibromyalgia acted as a predictor in our model, indicating the importance of this condition in non-improvers, the small sample size prevents us from drawing any firm conclusions; we merely report it as an observation that merits further research with studies designed to gauge the weight of concurrent fibromyalgia in efficacy studies of depression.

Patterns of change contributed to explaining BDI-II scores at termination and follow-up after controlling for baseline scores (objective 4). In fact, patterns of change doubled the variance accounted by the model. Therefore, the early identification of these patterns in clinical practice can contribute to adjust the treatment given to patients in risk (e.g., non-improvers) in an early stage, knowing that their pattern of change has been associated to a specific treatment outcome. Indeed, proportions of recovered patients were higher in the group and individual therapy improvers at each time-point of assessment after the treatment than in non-improvers. 
As regards the method used, GMM captured the variability of the patterns of change within the sample and was able to identify classes representing subpopulations. It was possible to identify patterns of change in the two phases of treatment, indicating the patients who responded better to group than individual therapy, and vice versa. GMM provided a sound classification of the patients for end-of therapy outcome (based on CORE-SFB) which was consistent across the 3-month and 1-year follow-up assessments in terms of depression symptoms (measured with BDI-II) and level of functioning (measured with GAF).

The RGT indices were also useful for establishing comparisons between groups with regard to variables other than symptoms. In this respect, Andrews and Williams (2014) state that "To personalize a treatment, it is essential that we look beyond the symptom level and consider the processes that subserve anxiety and depressive symptoms." Accordingly, the RGT indices used in this study referred to variables that have been associated with different cognitive processes underlying depressive symptoms (negative view of the self, perceived self-isolation, and CCs). Interestingly, although the three measures changed across the therapy process, only the PICID entered the model for predicting class membership. The relevance of IDs for depression was already highlighted by Montesano, Feixas, Caspar and Winter (2017). In their study of 161 patients with depression and 110 non-clinical controls, they showed that IDs might have an even more important role than the well-established influence of negative view of self. Overall, the RGT indices have a strong potential as predictors of treatment outcome in depression and promise to be particularly useful in the design of personalised treatments; therefore, they should be included in further research on the psychotherapy of depression. 
Our results corroborate those of previous research in so far as patterns of change, particularly early response, proved to be a sound predictor of treatment outcome at termination and follow-up. Nevertheless, this is the first study to examine patterns of change in combined group and individual therapy (low and high intensity treatments). In this respect, and considering patients' baseline characteristics, the results showed that easy patients (like our group therapy improvers) were patients with medium-to-low initial levels of impairment, who were able to benefit from a low-intensity treatment such as CBGT for depression, and that this treatment maintained its effects across time. In contrast, pliant and challenging patients like our individual therapy improvers were patients with medium-to-high initial levels of impairment who benefited from a highintensity treatment such as individual CBT or DFT; as other authors have suggested (Bower et al., 2013), they may be candidates for a stepped care model. Additionally, seeing that these patients could present certain levels of relapse at the 3-month followup assessment, may be convenient to provide them with booster sessions after treatment aimed to prevent relapse.

Our findings are relevant from a cost-efficacy perspective, because if patients are properly assessed at the beginning, they can be promptly assigned to the most suitable therapeutic modality, thus saving unnecessary care costs and multiple futile efforts (Meeuwissen et al., 2019). In stepped care models, low-intensity treatment is recommended for all patients, and those who do not improve in the first step are referred to a high-intensity treatment (Bower \& Gilbody, 2005; Silverstone et al., 2017; The National Institute for Health and Care Excellence - NICE, 2018). The results of this approach are likely to improve if patients who will not benefit from the low-intensity treatment, but may benefit from the high-intensity modality, can be identified at baseline (Lorenzo-Luaces, DeRubeis, van Straten, \& Tiemens, 2017). 
Moreover, our results can inform clinical decisions in the context of FIT to monitor patients' progress, prognosis, and risk factors for treatment failure (e.g., fibromyalgia). In this respect, these results potentially contribute to treatment personalisation as an option for improving treatments for depression. Nevertheless, some ethical considerations should be addressed. For instance, what happens if the predictive models suggest, as the better treatment for a particular patient, a treatment modality against patient's preferences? While literature shows mixed results about the predictive utility of patient's preferences for treatment response for depression (Dunlop et al., 2017; Swift \& Callahan, 2009; Winter \& Barber, 2013), further research is required not only for clearing out its role. More important, this can be seen as an ethical issue involving patients' rights. Another kind of conflict might occur if the recommended treatment is too costly for the patient or for the health care system.

\subsection{Limitations of the Study}

Regarding the limitations of our study, the sample size of completers was small for the kind of analyses applied, and this restricted the statistical power of the study. Similar analyses in larger samples should now be carried out in order to corroborate (or not) these results. The data obtained under the controlled conditions of RCTs have limitations regarding their external validity (although the fact that the patients were recruited and seen at their care centres minimized this limitation). Furthermore, these results are similar to those obtained in natural settings for the treatment of affective disorders (Bradford et al., 2011; Schlagert \& Hiller, 2015). Adopting a processesoutcome perspective and considering the sequential order of the interventions, conclusions can only be obtained about the effect of each treatment phase, and not about 
the possible interaction between first receiving group therapy and then receiving individual therapy, and vice versa. For instance, the effect of group therapy on individual therapy improvers cannot be established, because the previous group therapy may have "warmed up" these patients, who then started changing in the individual therapy phase. A design controlling the order of the interventions would overcome this difficulty. In the RCT on which this study is based (Feixas et al., 2013, 2016, 2018), the order was not reversed, for clinical reasons; it was assumed that more specific and individualized work should follow an intervention mostly based on non-specific factors and psychoeducational therapeutic interventions (such as those of low-intensity CBT), and not the other way around.

Additionally, there are several levels of variability present in the current study: therapist and group levels, services, and neighbourhoods (Saxon, Delgadillo, Barkham, \& Firth, 2018). In previous analyses (Paz et al., 2019), the effect of therapist nesting accounted for $11 \%$ of the variance, showing that there was a dependence in the change of patients treated by the same therapists (each therapist treated between two and three patients on average). In this regard, it should be considered that the classes found might be the product of an interaction between the therapist and the patient's characteristics (Johns, Barkham, Kellett, \& Saxon, 2019). Taking into account that there was a small sample size in each class, we considered that mixed models (i.e., HLM) accounting for the effects of the levels of variability before stated on the pattern clusters, would not have enough power to obtain reliable results and arrive at firm conclusions (Magnusson, Andersson, \& Carlbring, 2018; Schiefele et al., 2017).

Another limitation derives from the type of measures utilised in the analyses. They are self-reported questionnaires in which the answers of patients can be less reliable if they are compared with scales rated by clinicians. The inclusion of such 
measures (e.g., Hamilton Depression Scale, HAMD, Hamilton, 1960) in future studies would contribute to address this issue.

Regarding the regression models obtained, their predictive power is modest; therefore, prospective predictions based on these models need to be utilised with caution. Taking an interdisciplinary perspective, to consider predictors beyond social and psychological variables (e.g., neurobiological markers, microbiota-inflammation markers; Hahn et al., 2011; Inserra, Rogers, Licinio, \& Wong, 2018; Soriano-Mas et al., 2011; Wise et al., 2017) might contribute to increase the variance explained by the models, and to enhance the accuracy of the classification methods for the identification of patients' subpopulations. In this regard, Lee et al. (2018) stated:

"An integrative approach involving multiple forms and sources of data are needed to deconstruct and parse clinical heterogeneity in mood disorders, as opposed to identifying precise lists of baseline predictors in isolation. For example, sociodemographic characteristics (e.g., employment, socioeconomic, marital status; occupation type) and other phenomenological patient features (e.g., symptom profile, severity), as well as peripheral tissue biomarkers (e.g., tumour necrosis factor- $\alpha$, interleukin-6, interleukin-1 $\beta$, C-reactive protein, brainderived neuro- trophic factor), have been previously reported to significantly predict therapeutic outcomes in clinical populations with a mood disorder (Kessler et al., 2016; Mansur et al., 2016; McIntyre et al., 2017; Strawbridge et al., 2015)”( p. 530)

Considering the sociodemographic characteristics of the sample, the majority of patients were women and elderly people. While it is true that we did not find differences in gender and age between the patients belonging to each patterns (hence, they did not 
enter as predictors in the models), predictive models should be interpreted in the light of this sample characteristics. In fact, dynamics of group therapy for depression and the topics covered with young adults along therapy sessions can be quite different to group therapy with elderly people (Cuijpers, Karyotaki, Pot, Park, \& Reynolds, 2014; Fiske, Wetherell, \& Gatz, 2009).

Despite these limitations, our results are consistent with, and expand on, prior findings regarding the course of psychotherapy, suggesting that there is no one typical pattern of early change for all patients (Lutz et al., 2009), and no one treatment that works for all (Norcross \& Wampold, 2011b). Rather, similar patterns of early change seem to be specific for different groups of patients, and these patterns are connected with a specific probability for a positive outcome in different treatment modalities.

\subsection{Proposals for Future Research}

Considering prospects for future research, studying patterns of change with GMM in other studies with similar designs can contribute to replicate or not our results. The inclusion of the RGT in new studies regarding treatments for depression could provide with further information about the contribution of their indexes to treatment personalisation. A study aimed at exploring the role of the interventions sequence is necessary to clarify the effect of group therapy on individual therapy and vice versa. Additionally, future studies addressing the effect of fibromyalgia in patients' response may be conducted.

Furthermore, designs controlling and accounting for the effect of different sources of variability at different hierarchical levels should be considered in order to 
identify their role on treatment outcome. Powered enough samples should be collected in order to achieve this aim.

Finally, the implementation of computerised feedback systems in Spanish speaking services needs to be addressed considering that the instruments for ROM are already validated for using them with Spanish speakers patients (Gimeno-Peón, BarrioNespereira, \& Prado-Abril, 2018). The implementation of FIT not only would contribute to enhance treatments for depression (and other mental health problems) but would also contribute to enhance psychotherapists training (Paige Peterson \& Fagan, 2017), and provide researchers with big data systematically collected to conduct psychotherapy research in order to enhance treatments and services. 


\section{Conclusions}

This research aimed to study the differential response patterns (in terms of trajectories) in patients receiving cognitive therapy for depression in two sequential formats: group and individual. Consistent with our hypothesis, we found a differential response pattern to group and individual therapy. Thus, there were patients that responded rapidly to group therapy (group therapy improvers), starting to improve at the beginning of this treatment phase (and even earlier, showing pre-treatment changes), while other patients (individual therapy improvers) needed a second phase of individual therapy to start improving and achieve the same levels of recovery than the first group. A third pattern was found, accounting for patients that did not improve along the two phases of treatment (non-improvers).

Following the objectives that guided the current study, the characteristics that differentiated the patients belonging to each pattern cluster were identified: depression symptoms severity, psychological distress, general functioning, self-ideal discrepancy, perceived social isolation, conflictual construction of the self, and fibromyalgia diagnosis. In this regard, group therapy improvers were the patients who started the treatment with less severe levels of depression and psychological distress, and higher levels of functioning than the other groups. Individual therapy improvers started therapy with medium-to-high levels of depression and psychological distress, and more impairment than group therapy improvers. For individual therapy improvers, their scores at baseline were similar than non-improvers. However, fibromyalgia diagnosis emerged as a significant characteristic presented in this pattern. In terms of outcome, the scores of the measures considered change accordingly. Thus, group and individual therapy improvers changed for the better their scores in depression symptoms severity, psychological distress, general functioning, self-ideal discrepancy, perceived social 
isolation and conflictual construction of the self. Non-improvers did not exhibit significant change in these measures excepting for depression symptoms severity, in which they improved but not as much compared to the other groups. In fact, unlike the other groups, their scores in depression symptoms severity were not in the non-clinical range at any assessment point after treatment.

Considering the prediction of patterns membership from intake characteristics, the measures of depression symptoms severity, psychological distress, and conflictual construction of the self, acted as predictors of the patterns. The inclusion of fibromyalgia diagnosis to the models allow us to establish a better classification and prediction of the patterns. Fibromyalgia diagnosis increased the likelihood of belonging to non-improvers. In this regard, fibromyalgia could be considered a risk factor that can increase the probability of risk failure in psychotherapy for depression.

Finally, the patterns of change identified were predictive of treatment outcome at termination, 3-month and 1-year follow-up assessments. In this regard, group and individual therapy improvers presented the high proportion of patients recovered from depression in the three assessment points after treatment. Therefore, these patterns were related to a specific likelihood of obtaining a different outcome in different treatment modalities. 


\section{References}

Aderka, I. M., Nickerson, A., Bøe, H. J., \& Hofmann, S. G. (2012). Sudden gains during psychological treatments of anxiety and depression: A meta-analysis. Journal of Consulting and Clinical Psychology, 80(1), 93-101. https://doi.org/10.1037/a0026455

Adler, A. D., Strunk, D. R., \& Fazio, R. H. (2015). What Changes in Cognitive Therapy for Depression? An Examination of Cognitive Therapy Skills and Maladaptive Beliefs. Behavior Therapy, 46(1), 96-109. https://doi.org/10.1016/j.beth.2014.09.001

Ægisdóttir, S., White, M. J., Spengler, P. M., Maugherman, A. S., Anderson, L. A., Cook, R. S., ... Rush, J. D. (2006). The Meta-Analysis of Clinical Judgment Project: Fifty-Six Years of Accumulated Research on Clinical Versus Statistical Prediction. The Counseling Psychologist, 34(3), 341-382. https://doi.org/10.1177/0011000005285875

Ahn, H. N., \& Wampold, B. E. (2001). Where oh where are the specific ingredients? A meta-analysis of component studies in counseling and psychotherapy. Journal of Counseling Psychology, 48(3), 251-257. https://doi.org/10.1037/00220167.48.3.251

Álvarez Ariza, M., Atienza Merino, G., Ávila González, M., González García, A., Guitián Rodríguez, D., De las Heras, E., ... Triñanes, Y. (2014). Guía de práctica clínica sobre el manejo de la depresión en el adulto [Clinical guideline about depression management in adults]. Ministerio de Sanidad, Servicios Sociales e Igualdad [Ministry of Health, Social Services, and Equality].

American Psychiatric Association. (2000). Diagnostic and Statistical Manual of Mental 
Disorders, Fourth Edition, Text Revision. Washington, DC: Author.

American Psychiatric Association. (2013). Diagnostic and Statistical Manual of Mental Disorders (5th ed.). Washington, D.C: Author.

American Psychological Association. (2012). Recognition of Psychotherapy

Effectiveness. Washington, D.C. Retrieved from

https://www.apa.org/about/policy/resolution-psychotherapy.aspx

Andrews, G., Issakidis, C., Sanderson, K., Corry, J., \& Lapsley, H. (2004). Utilising survey data to inform public policy: Comparison of the cost-effectiveness of treatment of ten mental disorders. British Journal of Psychiatry, 184(06), 526-533. https://doi.org/10.1192/bjp.184.6.526

Andrews, G., \& Williams, A. D. (2014). Internet psychotherapy and the future of personalized treatment. Depression and Anxiety, 31(11), 912-915. https://doi.org/10.1002/da.22302

Ardito, R. B., \& Rabellino, D. (2011). Therapeutic Alliance and Outcome of Psychotherapy: Historical Excursus, Measurements, and Prospects for Research. Frontiers in Psychology, 2, 270. https://doi.org/10.3389/fpsyg.2011.00270

Baldwin, S. A., Berkeljon, A., Atkins, D. C., Olsen, J. A., \& Nielsen, S. L. (2009). Rates of Change in Naturalistic Psychotherapy: Contrasting Dose-Effect and Good-Enough Level Models of Change. Journal of Consulting and Clinical Psychology, 77(2), 203-211. https://doi.org/10.1037/a0015235

Bar-Kalifa, E., Atzil-Slonim, D., Rafaeli, E., Peri, T., Rubel, J., \& Lutz, W. (2016). Therapist-client agreement in assessments of clients' functioning. Journal of Consulting and Clinical Psychology, 84(12), 1127-1134. 
https://doi.org/10.1037/ccp0000157

Beck, A., Rush, A., Shaw, B., \& Emery, G. (1979). Cognitive Therapy of Depression. New York: Guilford Press.

Beck, A., Steer, R., \& Brown, G. (1996). Manual for the Beck Depression Inventory Second Edition (BDI-II). San Antonio, TX: Psychological Corporation.

Bell, E. C., Marcus, D. K., \& Goodlad, J. K. (2013). Are the parts as good as the whole? A meta-analysis of component treatment studies. Journal of Consulting and Clinical Psychology, 81(4), 722-736. https://doi.org/10.1037/a0033004

Bogner, H. R., Morales, K. H., Reynolds, C. F., Cary, M. S., \& Bruce, M. L. (2012). Prognostic factors, course, and outcome of depression among older primary care patients: The PROSPECT study. Aging \& Mental Health, 16(4), 452-461. https://doi.org/10.1080/13607863.2011.638904

Boritz, T. Z., Bryntwick, E., Angus, L., Greenberg, L. S., \& Constantino, M. J. (2014). Narrative and emotion process in psychotherapy: An empirical test of the Narrative-Emotion Process Coding System (NEPCS). Psychotherapy Research, 24(5), 594-607. https://doi.org/10.1080/10503307.2013.851426

Bortolotti, B., Menchetti, M., Bellini, F., Montaguti, M. B., \& Berardi, D. (2008). Psychological interventions for major depression in primary care: a meta-analytic review of randomized controlled trials. General Hospital Psychiatry, 30(4), 293302. https://doi.org/10.1016/j.genhosppsych.2008.04.001

Boswell, J. F., Kraus, D. R., Miller, S. D., \& Lambert, M. J. (2015). Implementing routine outcome monitoring in clinical practice: Benefits, challenges, and solutions. Psychotherapy Research, 25(1), 6-19. 
https://doi.org/10.1080/10503307.2013.817696

Bower, P., \& Gilbody, S. (2005). Stepped care in psychological therapies: access, effectiveness and efficiency. British Journal of Psychiatry, 186(01), 11-17. https://doi.org/10.1192/bjp.186.1.11

Bower, P., Kontopantelis, E., Sutton, A., Kendrick, T., Richards, D. A., Gilbody, S., ... Liu, E. T.-H. (2013). Influence of initial severity of depression on effectiveness of low intensity interventions: meta-analysis of individual patient data. $B M J$, 346(feb26 2), f540-f540. https://doi.org/10.1136/bmj.f540

Bradford, A., Cully, J., Rhoades, H., Kunik, M., Kraus-Schuman, C., Wilson, N., \& Stanley, M. (2011). Early Response to Psychotherapy and Long-Term Change in Worry Symptoms in Older Adults With Generalized Anxiety Disorder. The American Journal of Geriatric Psychiatry, 19(4), 347-356. https://doi.org/10.1097/JGP.0b013e3181f18061

Braga, C., Ribeiro, A. P., Gonçalves, M. M., Oliveira, J. T., Botelho, A., Ferreira, H., \& Sousa, I. (2018). Ambivalence resolution in brief psychotherapy for depression. Clinical Psychology \& Psychotherapy, 25(3), 369-377. https://doi.org/10.1002/cpp.2169

Braun, J. D., Strunk, D. R., Sasso, K. E., \& Cooper, A. A. (2015). Therapist use of Socratic questioning predicts session-to-session symptom change in cognitive therapy for depression. Behaviour Research and Therapy, 70, 32-37. https://doi.org/10.1016/j.brat.2015.05.004

Bryan, C. J., Corso, M. L., Corso, K. A., Morrow, C. E., Kanzler, K. E., \& RaySannerud, B. (2012). Severity of mental health impairment and trajectories of improvement in an integrated primary care clinic. Journal of Consulting and 
Clinical Psychology, 80(3), 396-403. https://doi.org/10.1037/a0027726

Buckman, J. E. J., Underwood, A., Clarke, K., Saunders, R., Hollon, S. D., Fearon, P., \& Pilling, S. (2018). Risk factors for relapse and recurrence of depression in adults and how they operate: A four-phase systematic review and meta-synthesis. Clinical Psychology Review, 64, 13-38. https://doi.org/10.1016/j.cpr.2018.07.005

Burlingame, G. M., Strauss, B., \& Joyce, A. S. (2013). Change Mechanisms and Effectiveness of Small Group Treatments. In M. J. Lambert (Ed.), Bergin and Garfield's Handbook of Psychotherapy and Behavior Change (6th ed., pp. 640689). New Jersey: John Wiley \& Sons, Inc.

Burns, D. D., \& Nolen-Hoeksema, S. (1991). Coping styles, homework compliance, and the effectiveness of cognitive-behavioral therapy. Journal of Consulting and Clinical Psychology, 59(2), 305-11. Retrieved from http://www.ncbi.nlm.nih.gov/pubmed/2030192

Burns, D. D., \& Spangler, D. L. (2000). Does psychotherapy homework lead to improvements in depression in cognitive-behavioral therapy or does improvement lead to increased homework compliance? Journal of Consulting and Clinical Psychology, 68(1), 46-56. Retrieved from http://www.ncbi.nlm.nih.gov/pubmed/10710839

Burns, D. D., \& Spangler, D. L. (2001). Do changes in dysfunctional attitudes mediate changes in depression and anxiety in cognitive behavioral therapy? Behavior Therapy, 32(2), 337-369. https://doi.org/10.1016/S0005-7894(01)80008-3

Button, E. J. (1983). Construing the anorexic. In J. Adams-Weber \& J. C. Mancuso (Eds.), Applications of Personal Construct Theory (pp. 305-316). Toronto: Academic Press. 
Byrne, B. M. (2012). Structural Equation Modeling with Mplus. Basic concepts, applications, and programming. New York: Routledge.

Caine, T. M., Wijesinghe, O. B. A., \& Winter, D. A. (1981). Personal styles in neurosis: Implications for small group psychotherapy and behavior therapy. London: Routledge \& Kegan Paul.

Callahan, J. L., \& Hynan, M. T. (2005). Models of Psychotherapy Outcome: Are They Applicable in Training Clinics? Psychological Services, 2(1), 65-69. https://doi.org/10.1037/1541-1559.2.1.65

Carlier, I. V. E., Meuldijk, D., Van Vliet, I. M., Van Fenema, E., Van der Wee, N. J. A., \& Zitman, F. G. (2012). Routine outcome monitoring and feedback on physical or mental health status: evidence and theory. Journal of Evaluation in Clinical Practice, 18(1), 104-110. https://doi.org/10.1111/j.1365-2753.2010.01543.x

Carr, J. E. (1974). Perceived therapy outcome as a function of differentiation between and within conceptual dimensions. Journal of Clinical Psychology, 30(3), 282285. https://doi.org/10.1002/1097-4679(197407)30:3<282::AIDJCLP2270300318>3.0.CO;2-N

Carr, J. E., \& Whittenbaugh, J. (1969). Sources of disagreement in the perception of psychotherapy outcomes. Journal of Clinical Psychology, 25(1), 16-21. https://doi.org/10.1002/1097-4679(196901)25:1<16::AIDJCLP2270250104>3.0.CO;2-P

Castonguay, L. G. (2011). Psychotherapy, psychopathology, research and practice: Pathways of connections and integration. Psychotherapy Research, 21(2), 125140. https://doi.org/10.1080/10503307.2011.563250 
Castonguay, L. G., Barkham, M., Lutz, W., \& McAleavey, A. A. (2013). PracticeOriented Research: Approaches and Applications. In M. J. Lambert (Ed.), Bergin and Garfield's Handbook of Psychotherapy and Behavior Change (6th ed., pp. 85133). New Jersey: John Wiley \& Sons, Inc.

Cohen, Z. D., \& DeRubeis, R. J. (2018). Treatment Selection in Depression. Annual Review of Clinical Psychology, 14(1), 209-236. https://doi.org/10.1146/annurevclinpsy-050817-084746

Cohen, Z. D., Kim, T. T., Van, H. L., Dekker, J. J. M., \& Driessen, E. (2019). A demonstration of a multi-method variable selection approach for treatment selection: Recommending cognitive-behavioral versus psychodynamic therapy for mild to moderate adult depression. Psychotherapy Research, O(0), 1-14. https://doi.org/10.1080/10503307.2018.1563312

Comer, J. S., \& Kendall, P. (2013). Methodology, Design, and Evaluation in Psychotherapy Research. In Bergin and Garfield's Handbook of Psychotherapy and Behavior Change (pp. 21-48). New Jersey: John Wiley \& Sons, Inc.

Connolly Gibbons, M. B., Kurtz, J. E., Thompson, D. L., Mack, R. A., Lee, J. K., Rothbard, A., ... Crits-Christoph, P. (2015). The effectiveness of clinician feedback in the treatment of depression in the community mental health system. Journal of Consulting and Clinical Psychology, 83(4), 748-59. https://doi.org/10.1037/a0039302

Constantino, M. J., Marnell, M. E., Haile, A. J., Kanther-Sista, S. N., Wolman, K., Zappert, L., \& Arnow, B. A. (2008). Integrative cognitive therapy for depression: A randomized pilot comparison. Psychotherapy: Theory, Research, Practice, Training, 45(2), 122-134. https://doi.org/10.1037/0033-3204.45.2.122 
Cooper, A. A., \& Conklin, L. R. (2015). Dropout from individual psychotherapy for major depression: A meta-analysis of randomized clinical trials. Clinical Psychology Review, 40, 57-65. https://doi.org/10.1016/j.cpr.2015.05.001

Crits-Christoph, P., Connolly-Gibbons, M.-B., \& Mukberjee, D. (2013). Psychotherapy Process-Outcome Research. In Bergin and Garfield's Handbook of Psychotherapy and Behavior Change2 (pp. 298-340). New Jersey: John Wiley \& Sons, Inc.

Crits-Christoph, P., Gibbons, M. B. C., Temes, C. M., Elkin, I., \& Gallop, R. (2010). Interpersonal accuracy of interventions and the outcome of cognitive and interpersonal therapies for depression. Journal of Consulting and Clinical Psychology, 78(3), 420-428. https://doi.org/10.1037/a0019549

Cui, X., Lyness, J. M., Tang, W., Tu, X., \& Conwell, Y. (2008). Outcomes and Predictors of Late-Life Depression Trajectories in Older Primary Care Patients. American Journal of Geriatric Psychiatry, 16(5), 406-415. https://doi.org/10.1097/JGP.0b013e3181693264

Cuijpers, P., Cristea, I. A., Karyotaki, E., Reijnders, M., \& Hollon, S. D. (2019). Component studies of psychological treatments of adult depression: A systematic review and meta-analysis. Psychotherapy Research, 29(1), 15-29. https://doi.org/10.1080/10503307.2017.1395922

Cuijpers, P., Ebert, D. D., Acarturk, C., Andersson, G., \& Cristea, I. A. (2016). Personalized Psychotherapy for Adult Depression: A Meta-Analytic Review. Behavior Therapy, 47(6), 966-980. https://doi.org/10.1016/j.beth.2016.04.007

Cuijpers, P., Karyotaki, E., Pot, A. M., Park, M., \& Reynolds, C. F. (2014). Managing depression in older age: Psychological interventions. Maturitas, 79(2), 160-169. https://doi.org/10.1016/j.maturitas.2014.05.027.Managing 
Cuijpers, P., Karyotaki, E., Reijnders, M., \& Ebert, D. D. (2018). Was Eysenck right after all? A reassessment of the effects of psychotherapy for adult depression. Epidemiology and Psychiatric Sciences, 1-10. https://doi.org/10.1017/S2045796018000057

Cuijpers, P., Karyotaki, E., Reijnders, M., \& Huibers, M. J. H. (2018). Who benefits from psychotherapies for adult depression? A meta-analytic update of the evidence. Cognitive Behaviour Therapy, 47(2), 91-106. https://doi.org/10.1080/16506073.2017.1420098

Cuijpers, P., Reijnders, M., \& Huibers, M. J. H. (2019). The Role of Common Factors in Psychotherapy Outcomes, 1-25. https://doi.org/10.1146/annurev-clinpsy050718-095424

Cuijpers, P., Reijnders, M., Karyotaki, E., de Wit, L., \& Ebert, D. D. (2018). Negative effects of psychotherapies for adult depression: A meta-analysis of deterioration rates. Journal of Affective Disorders, 239, 138-145. https://doi.org/10.1016/j.jad.2018.05.050

Cuijpers, P., van Lier, P. A. C., van Straten, A., \& Donker, M. (2005). Examining differential effects of psychological treatment of depressive disorder: An application of trajectory analyses. Journal of Affective Disorders, 89(1-3), 137146. https://doi.org/10.1016/j.jad.2005.09.001

Cuijpers, P., van Straten, A., \& Warmerdam, L. (2008). Are individual and group treatments equally effective in the treatment of depression in adults?: A metaanalysis. The European Journal of Psychiatry, 22(1). https://doi.org/10.4321/S0213-61632008000100005

Delgadillo, J., de Jong, K., Lucock, M., Lutz, W., Rubel, J., Gilbody, S., ... McMillan, 
D. (2018). Feedback-informed treatment versus usual psychological treatment for depression and anxiety: a multisite, open-label, cluster randomised controlled trial. The Lancet. Psychiatry, 5(7), 564-572. https://doi.org/10.1016/S22150366(18)30162-7

Delgadillo, J., Moreea, O., \& Lutz, W. (2016). Different people respond differently to therapy: A demonstration using patient profiling and risk stratification. Behaviour Research and Therapy, 79, 15-22. https://doi.org/10.1016/j.brat.2016.02.003

Delgadillo, J., Overend, K., Lucock, M., Groom, M., Kirby, N., McMillan, D., ... de Jong, K. (2017). Improving the efficiency of psychological treatment using outcome feedback technology. Behaviour Research and Therapy, 99, 89-97. https://doi.org/10.1016/j.brat.2017.09.011

DeRubeis, R. J., Cohen, Z. D., Forand, N. R., Fournier, J. C., Gelfand, L. A., \& Lorenzo-Luaces, L. (2014). The Personalized Advantage Index: Translating Research on Prediction into Individualized Treatment Recommendations. A Demonstration. PLoS ONE, 9(1), e83875. https://doi.org/10.1371/journal.pone.0083875

DeRubeis, R. J., \& Feeley, M. (1990). Determinants of change in cognitive therapy for depression. Cognitive Therapy and Research, 14(5), 469-482. https://doi.org/10.1007/BF01172968

DeRubeis, R. J., Gelfand, L. A., German, R. E., Fournier, J. C., \& Forand, N. R. (2014). Understanding processes of change: How some patients reveal more than othersand some groups of therapists less-about what matters in psychotherapy. Psychotherapy Research, 24(3), 419-428. https://doi.org/10.1080/10503307.2013.838654 
Detert, N. B., Llewelyn, S., Hardy, G. E., Barkham, M., \& Stiles, W. B. (2006). Assimilation in good- and poor-outcome cases of very brief psychotherapy for mild depression: An initial comparison. Psychotherapy Research, 16(4), 393-407. https://doi.org/10.1080/10503300500294728

Dew, M. A., Reynolds, C. F., Houck, P. R., Hall, M., Buysse, D. J., Frank, E., \& Kupfer, D. J. (1997). Temporal Profiles of the Course of Depression During Treatment. Archives of General Psychiatry, 54(11), 1016. https://doi.org/10.1001/archpsyc.1997.01830230050007

Dew, M. A., Reynolds, C. F., Mulsant, B., Frank, E., Houck, P. R., Mazumdar, S., ... Kupfer, D. J. (2001). Initial recovery patterns may predict which maintenance therapies for depression will keep older adults well. Journal of Affective Disorders, 65(2), 155-66. Retrieved from http://www.ncbi.nlm.nih.gov/pubmed/11356239

Dimidjian, S., Hollon, S. D., Dobson, K. S., Schmaling, K. B., Kohlenberg, R. J., Addis, M. E., ... Jacobson, N. S. (2006). Randomized trial of behavioral activation, cognitive therapy, and antidepressant medication in the acute treatment of adults with major depression. Journal of Consulting and Clinical Psychology, 74(4), 658670. https://doi.org/10.1037/0022-006X.74.4.658

Driessen, E., Cuijpers, P., Hollon, S. D., \& Dekker, J. J. M. (2010). Does pretreatment severity moderate the efficacy of psychological treatment of adult outpatient depression? A meta-analysis. Journal of Consulting and Clinical Psychology, 78(5), 668-680. https://doi.org/10.1037/a0020570

Duncan, B. L. (2014). On Becoming a Better Therapist. Washington, D.C.: American Psychological Association (APA).

Dunlop, B. W., Kelley, M. E., Aponte-Rivera, V., Mletzko-Crowe, T., Kinkead, B., 
Ritchie, J. C., ... PReDICT Team. (2017). Effects of Patient Preferences on Outcomes in the Predictors of Remission in Depression to Individual and Combined Treatments (PReDICT) Study. American Journal of Psychiatry, 174(6), 546-556. https://doi.org/10.1176/appi.ajp.2016.16050517

Elliott, K., Barker, K. K., \& Hunsley, J. (2015). Dodo Bird Verdict in Psychotherapy. In The Encyclopedia of Clinical Psychology (pp. 1-5). Hoboken, NJ, USA: John Wiley \& Sons, Inc. https://doi.org/10.1002/9781118625392.wbecp053

Evans, C., Mellor-Clark, J., Margison, F., Barkham, M., Audin, K., Connell, J., \& McGrath, G. (2000). CORE: Clinical Outcomes in Routine Evaluation. Journal of Mental Health, 9(3), 247-255. https://doi.org/10.1080/713680250

Eysenck, H. J. (1952). The effects of psychotherapy: An evaluation. Journal of Consulting and Clinical Psychology, 60(5), 659-663. https://doi.org/10.1037//0022-006X.60.5.659

Feeley, M., DeRubeis, R. J., \& Gelfand, L. A. (1999). The temporal relation of adherence and alliance to symptom change in cognitive therapy for depression. Journal of Consulting and Clinical Psychology, 67(4), 578-82. Retrieved from http://www.ncbi.nlm.nih.gov/pubmed/10450629

Feixas, G., Bados, A., García-Grau, E., Montesano, A., Dada, G., Compañ, V., ... Winter, D. (2013). Efficacy of a dilemma-focused intervention for unipolar depression: study protocol for a multicenter randomized controlled trial. Trials, 14(144). https://doi.org/10.1186/1745-6215-14-144

Feixas, G., Bados, A., García-Grau, E., Paz, C., Montesano, A., Compañ, V., ... Lana, F. (2016). A dilemma-focused intervention for depression: A multicenter, randomized controlled trial witha a 3 month follow-up. Depression and Anxiety, 
33(9), 862-869. https://doi.org/10.1002/da.22510

Feixas, G., \& Compañ, V. (2015). Manual de intervención centrada en dilemas para depresión [Manual for the dilemma-focused intervention for depression]. Bilbao: Desclee de Brouwer.

Feixas, G., \& Compañ, V. (2016). Dilemma-focused intervention for unipolar depression: a treatment manual. BMC Psychiatry, 16(235), 1-28. https://doi.org/10.1186/s12888-016-0947-x

Feixas, G., \& Cornejo, J. M. (2002). GRIDCOR: Correspondence analysis for grid data v.4.0 [Computer software and repertory gridmanual]. Retrieved from www.terapiacognitiva.net/record

Feixas, G., De La Fuente, M., \& Soldevila, J. M. (2003). La técnica de rejilla como instrumento de evaluación y formulación de hipótesis clínicas [The Repertory Grid Technique as an Instrument of Assessment and Clinical Hypothesis Formulation]. Revista de Psicopatologla y Psicología Clínica [Journal of Psychopathology and Clinical Psychology], 8(2), 153-172. Retrieved from http://dialnet.unirioja.es/servlet/articulo?codigo=722200\&orden=190740\&info=lin $\mathrm{k}$

Feixas, G., Evans, C., Trujillo, A., Ángel, L., Botella, L., Corbella, S., ... LópezGonzalez, M. A. (2012). La versión española del CORE-om : Clinical Outcomes in Routine Evaluation - Outcome Measure. Revista de Psicoterapia, 23(89), 109-135. Retrieved from http://revistadepsicoterapia.com/catalog/product/view/id/1005/s/laversion-espa-ola-del-core-om-clinical-outcomes-in-routine-evaluation-outcomemeasure/category/3/

Feixas, G., Montesano, A., Compañ, V., Salla, M., Dada, G., Pucurull, O., ... Guàrdia, 
J. (2014). Cognitive conflicts in major depression: Between desired change and personal coherence. British Journal of Clinical Psychology, 53(4), 369-385. https://doi.org/10.1111/bjc. 12050

Feixas, G., Montesano, A., Compañ, V., Salla, M., Hornos, C., Trujillo, A., \& Aguilera, M. (2012). Measuring cognitive conflicts and their relevance for unipolar depression. In Biennial Conference of the International Society Affective Disorders. London.

Feixas, G., Paz, C., García-Grau, E., Montesano, A., Medina, J. C., Bados, A., ... Winter, D. A. (2018). One-year follow-up of a randomized trial with a dilemmafocused intervention for depression: Exploring an alternative to problem-oriented strategies. PLOS ONE, 13(12), e0208245.

https://doi.org/10.1371/journal.pone.0208245

Feixas, G., \& Saúl, L. A. (2004). The Multi-Center Dilemma Project: an investigation on the role of cognitive conflicts in health. The Spanish Journal of Psychology, 7(1), 69-78. https://doi.org/http://dx.doi.org/10.1017/S1138741600004765

Feixas, G., Saúl, L. A., \& Ávila-Espada, A. (2009). Viewing cognitive conflicts as cilemmas: implications for mental health. Journal of Constructivist Psychology, 22(2), 141-169. https://doi.org/10.1080/10720530802675755

Feixas, G., Saul, L. A., Winter, D., \& Watson, S. (2008). Un estudio naturalista sobre el cambio de los conflictos cognitivos durante la psicoterapia [A naturalistic study about change of cognitive conflicts in psychotherapy]. Apuntes de Psicología [Psychology Notes], 26(2), 243-255.

Feixas, G., Saúl, L. Á., Winter, D., \& Watson, S. (2008). Un estudio naturalista sobre el cambio de los conflictos cognitivos durante la psicoterapia [A naturalisti study 
about change in cognitive conflicts during psychotherapy]. Apuntes de Psicología [Psychology Notes], 26(2), 243-255. Retrieved from http://campus.usal.es/ tcp/articulos/un_estudio_nat.pdf

Feixas, G., \& Villegas, M. (2000). Constructivismo y Psicoterapia [Constructivism and Psychotherapy] (3rd ed.). Bilbao: Desclee de Brouwer.

Fernández-Navarro, P., Rosa, C., Sousa, I., Moutinho, V., Antunes, A., Magalhães, C., ... Gonçalves, M. M. (2018). Reconceptualization innovative moments as a predictor of symptomatology improvement in treatment for depression. Clinical Psychology and Psychotherapy, (March), 1-9. https://doi.org/10.1002/cpp.2306

First, M., Spitzer, R., Gibbon, M., \& Williams, J. (1996). Structured Clinical Interview for DSM-IV Axis I Disorders, Clinician Version (SCID-CV). New York: Department of Psychiatry - Columbia University.

Fiske, A., Wetherell, J. L., \& Gatz, M. (2009). Depression in Older Adults. Annual Review of Clinical Psychology, 5, 363-389. https://doi.org/10.1097/01.NAJ.0000422251.65212.4b

Flückiger, C., Del Re, A. C., \& Wampold, B. E. (2015). The sleeper effect: Artifact or phenomenon - A brief comment on Bell et al. (2013). Journal of Consulting and Clinical Psychology, 83(2), 438-442. https://doi.org/10.1037/a0037220

Flückiger, C., Del Re, A. C., Wampold, B. E., \& Horvath, A. O. (2018). The alliance in adult psychotherapy: A meta-analytic synthesis. Psychotherapy. https://doi.org/10.1037/pst0000172

Foa, E. B., Zoellner, L. A., Feeny, N. C., Hembree, E. A., \& Alvarez-Conrad, J. (2002). Does imaginal exposure exacerbate PTSD symptoms? Journal of Consulting and 
Clinical Psychology, 70(4), 1022-8. Retrieved from

http://www.ncbi.nlm.nih.gov/pubmed/12182265

Fransella, F. (1972). Personal Change and Reconstruction. London: Academic Press.

Fransella, F., Bell, R., \& Bannister, D. (2004). A manual for repertory grid technique (2nd ed). Chichester, England: Wiley.

Fransella, F., Bell, R., \& Bannister, D. (2004). A Manual for Repertory Grid Technique (2nd ed.). London: Wiley. Retrieved from https://www.wiley.com/enus/A+Manual+for+Repertory+Grid+Technique\%2C+2nd+Edition-p9780470090800

Fransella, F., \& Button, E. J. (1983). The "construing” of self and body size in relation to the maintenance of weight gain in anorexia nervosa. In P. L. Darby (Ed.), Anorexia Nervosa: Recent de velopments in research (pp. 107-116). New York: Alan R. Liss.

Fried, E. (2017). Moving forward: how depression heterogeneity hinders progress in treatment and research. Expert Review of Neurotherapeutics, 17(5), 423-425. https://doi.org/10.1080/14737175.2017.1307737

Gelo, O., \& Manzo, S. (2015). Quantitative Approaches to Treatment Process, Change Process, and Process-Outcome Research. In O. Gelo, A. Pritz, \& B. Rieken (Eds.), Psychotherapy Research. Foundations, Process, and Outcome2 (pp. 247-278). London: Spinger.

Gelo, O., Pritz, A., \& Rieken, B. (2015). Introduction. In O. Gelo, A. Pritz, \& B. Rieken (Eds.), Psychotherapy Research. Foundations, Process, and Outcome (pp. 1-8). London: Springer. 
Gildengers, A. G., Houck, P. R., Mulsant, B. H., Dew, M. A., Aizenstein, H. J., Jones, B. L., ... Reynolds, C. F. (2005). Trajectories of treatment response in late-life depression: psychosocial and clinical correlates. Journal of Clinical Psychopharmacology, 25(4 Suppl 1), S8-13. Retrieved from http://www.ncbi.nlm.nih.gov/pubmed/16027561

Gimeno-Peón, A., Barrio-Nespereira, A., \& Prado-Abril, J. (2018). Monitorización Sistemática y Feedback en Psicoteapia [Routine Outcome Monitoring and Feedback in Psychotherapy]. Papeles Del Psicólogo [Psychologist Papers], 39(3), 69-83. https://doi.org/10.23923/pap.psicol2018.2872

Gold, C. (2015). Quantitative Psychotherapy Outcome Research: Methodological Issues. In O. Gelo, A. Pritz, \& B. Rieken (Eds.), Psychotherapy Research. Foundations, Process, and Outcome (pp. 537-558). London.

Gonçalves, M. M., Silva, J. R., Mendes, I., Rosa, C., Ribeiro, A. P., Batista, J., ... Fernandes, C. F. (2016). Narrative Changes Predict a Decrease in Symptoms in CBT for Depression: An Exploratory Study. Clinical Psychology \& Psychotherapy. https://doi.org/10.1002/cpp.2048

Greenberg, L. S., Rice, L. N., \& Elliott, R. (1993). Facilitating Emotional Change. The moment-by-moment process. New York: Guilford Press.

Greenberg, L. S., \& Watson, J. C. (2010). Emotion-Focused Therapy for Depression. Washington, D.C.: American Psychological Association (APA).

Gude, T., \& Havik, O. E. (2000). More Than One Way to Change: A Study of Course Heterogeneity During and After Short-term Psychiatric In-patient Treatment. Scandinavian Journal of Psychology, 41(2), 91-100. https://doi.org/10.1111/14679450.00176 
Gunlicks-Stoessel, M., \& Mufson, L. (2011). Early patterns of symptom change signal remission with interpersonal psychotherapy for depressed adolescents. Depression and Anxiety, 28(7), 525-531. https://doi.org/10.1002/da.20849

Haas, E., Hill, R. D., Lambert, M. J., \& Morrell, B. (2002). Do early responders to psychotherapy maintain treatment gains? Journal of Clinical Psychology, 58(9), 1157-1172. https://doi.org/10.1002/jclp.10044

Hahn, T., Marquand, A. F., Ehlis, A. C., Dresler, T., Kittel-Schneider, S., Jarczok, T. A., ... Fallgatter, A. J. (2011). Integrating neurobiological markers of depression. Archives of General Psychiatry, 68(4), 361-368.

https://doi.org/10.1001/archgenpsychiatry.2010.178

Hamilton, M. (1960). A rating scale for depression. Journal of Neurology, Neurosurgery, and Psychiatry, 23, 56-62.

Hannan, C., Lambert, M. J., Harmon, C., Nielsen, S. L., Smart, D. W., Shimokawa, K., \& Sutton, S. W. (2005). A lab test and algorithms for identifying clients at risk for treatment failure. Journal of Clinical Psychology, 61(2), 155-163. https://doi.org/10.1002/jclp.20108

Hardy, G. E., \& Llewelyn, S. (2015). Introduction to Psychotherapy Process Research. In O. Gelo, A. Pritz, \& B. Rieken (Eds.), Psychotherapy Research. Foundations, Process, and Outcome22 (pp. 183-194). London: Springer.

Hayes, A. M., Feldman, G. C., Beevers, C. G., Laurenceau, J.-P., Cardaciotto, L., \& Lewis-Smith, J. (2007). Discontinuities and cognitive changes in an exposurebased cognitive therapy for depression. Journal of Consulting and Clinical Psychology, 75(3), 409-421. https://doi.org/10.1037/0022-006X.75.3.409 
Hayes, A. M., Laurenceau, J.-P., Feldman, G., Strauss, J. L., \& Cardaciotto, L. (2007). Change is not always linear: the study of nonlinear and discontinuous patterns of change in psychotherapy. Clinical Psychology Review, 27(6), 715-23. https://doi.org/10.1016/j.cpr.2007.01.008

Helliwell, J. F., Layard, R., \& Sachs, J. D. (2018). World Happiness Report. New York.

Hollon, S. D., Muñoz, R. F., Barlow, D. H., Beardslee, W. R., Bell, C. C., Bernal, G., ... Sommers, D. (2002). Psychosocial intervention development for the prevention and treatment of depression: promoting innovation and increasing access. Biological Psychiatry, 52(6), 610-630. https://doi.org/10.1016/S00063223(02)01384-7

Howard, K. I., Kopta, S. M., Krause, M. S., \& Orlinsky, D. E. (1986). The Dose-Effect Relationship in Psychotherapy. American Psychologist, 41(2), 159-164. https://doi.org/10.1037/0003-066X.41.2.159

Howard, K. I., Lueger, R. J., Maling, M. S., \& Martinovich, Z. (1993). A phase model of psychotherapy outcome: causal mediation of change. Journal of Consulting and Clinical Psychology, 61(4), 678-85. Retrieved from http://www.ncbi.nlm.nih.gov/pubmed/8370864

Howard, K. I., Moras, K., Brill, P. L., Martinovich, Z., \& Lutz, W. (1996). Evaluation of psychotherapy: Efficacy, effectiveness, and patient progress. American Psychologist, 51(10), 1059-1064. https://doi.org/10.1037/0003-066X.51.10.1059

Hunsley, J., Elliott, K., \& Therrien, Z. (2014). The efficacy and effectiveness of psychological treatments for mood, anxiety, and related disorders. Canadian Psychology/Psychologie Canadienne, 55(3), 161-176.

https://doi.org/10.1037/a0036933 
Huntley, A. L., Araya, R., \& Salisbury, C. (2012). Group psychological therapies for depression in the community: systematic review and meta-analysis. British Journal of Psychiatry, 200(03), 184-190. https://doi.org/10.1192/bjp.bp.111.092049

IBM Corp. (2017). IBM SPSS Statistics for Windows, Version 25.0. Armonk, NY: IBM Corp.

Ilardi, S. S., \& Craighead, W. E. (1994). The Role of Nonspecific Factors in CognitiveBehavior Therapy for Depression. Clinical Psychology: Science and Practice, 1(2), 138-155. https://doi.org/10.1111/j.1468-2850.1994.tb00016.x

Imber, S. D., Pilkonis, P. A., Sotsky, S. M., Elkin, I., Watkins, J. T., Collins, J. F., ... Glass, D. R. (1990). Mode-specific effects among three treatments for depression. Journal of Consulting and Clinical Psychology, 58(3), 352-359. https://doi.org/10.1037/0022-006X.58.3.352

Inserra, A., Rogers, G. B., Licinio, J., \& Wong, M. L. (2018). The MicrobiotaInflammasome Hypothesis of Major Depression. BioEssays, 40(9), 1-11. https://doi.org/10.1002/bies.201800027

Institute for Health Metrics and Education - IHME. (2017). Major depressive disorder, both sexes, all ages, 2016, DALYs per 100,000. Retrieved from http://ihmeuw.org/4cn3

Jacobson, N. S., Dobson, K. S., Truax, P. A., Addis, M. E., Koerner, K., Gollan, J. K., ... Prince, S. E. (1996). A component analysis of cognitive-behavioral treatment for depression. Journal of Consulting and Clinical Psychology, 64(2), 295-304. https://doi.org/10.1037/0022-006X.64.2.295

Jacobson, N. S., \& Truax, P. (1991). Clinical Significance: A Statistical Approach to 
Denning Meaningful Change in Psychotherapy Research. Journal of Consulting and Clinical Psychologv, 59(1), 12-19. https://doi.org/10.1037/0022-006X.59.1.12

Janse, P. D., De Jong, K., Van Dijk, M. K., Hutschemaekers, G. J. M., \& Verbraak, M. J. P. M. (2017). Improving the efficiency of cognitive-behavioural therapy by using formal client feedback. Psychotherapy Research, 27(5), 525-538. https://doi.org/10.1080/10503307.2016.1152408

Johns, R. G., Barkham, M., Kellett, S., \& Saxon, D. (2019). A systematic review of therapist effects: A critical narrative update and refinement to review. Clinical Psychology Review, 67(August 2018), 78-93.

https://doi.org/10.1016/j.cpr.2018.08.004

Karyotaki, E., Smit, Y., Cuijpers, P., Debauche, M., De Keyser, T., Habraken, H., ... Henningsen Holdt, K. (2014). The long-term efficacy of psychotherapy, alone or in combination with antidepressants, in the treatment of adult major depression 2014. KCE Report 230 Good Clinical Practice. Belgium Government, 1-76.

Kazdin, A. E. (2009). Understanding how and why psychotherapy leads to change. Psychotherapy Research, 19(4-5), 418-428. https://doi.org/10.1080/10503300802448899

Kazdin, A. E. (2014). Moderators, mediators and mechanisms of change in psychotherapy. In W. Lutz \& S. Knox (Eds.), Quantitative and Qualitative Methods in Psychotherapy Research. London: Routledge.

Kelley, M. E., Dunlop, B. W., Nemeroff, C. B., Lori, A., Carrillo-Roa, T., Binder, E. B., ... Mayberg, H. S. (2018). Response rate profiles for major depressive disorder: Characterizing early response and longitudinal nonresponse. Depression and Anxiety, 35(10), 992-1000. https://doi.org/10.1002/da.22832 
Kelly, G. (1991/1955). The Psychology of Personal Constructs. Vol. I and II. London: Routledge.

Kendrick, T., El-Gohary, M., Stuart, B., Gilbody, S., Churchill, R., Aiken, L., ... Moore, M. (2016). Routine use of patient reported outcome measures (PROMs) for improving treatment of common mental health disorders in adults. Cochrane Database of Systematic Reviews, 7, CD011119. https://doi.org/10.1002/14651858.CD011119.pub2

Kessler, R. C., van Loo, H. M., Wardenaar, K. J., Bossarte, R. M., Brenner, L. A., Cai, T., ... Zaslavsky, A. M. (2016). Testing a machine-learning algorithm to predict the persistence and severity of major depressive disorder from baseline selfreports. Molecular Psychiatry, 21(10), 1366-1371. https://doi.org/10.1038/mp.2015.198

Kilmer, J. N. (2017). Trajectories of Treatment Change among Patients with Major Depressive Disorder: Predictors and Associations with Outcome. University of North Texas. Retrieved from https://digital.library.unt.edu/ark:/67531/metadc1011764/

Kim, S.-Y. (2014). Determining the Number of Latent Classes in Single- and MultiPhase Growth Mixture Models. Structural Equation Modeling : A Multidisciplinary Journal, 21(2), 263-279. https://doi.org/10.1080/10705511.2014.882690

Knaup, C., Koesters, M., Schoefer, D., Becker, T., \& Puschner, B. (2009). Effect of feedback of treatment outcome in specialist mental healthcare: meta-analysis. British Journal of Psychiatry, 195(01), 15-22. https://doi.org/10.1192/bjp.bp.108.053967 
Koffmann, A. (2017). Has growth mixture modeling improved our understanding of how early change predicts psychotherapy outcome? Psychotherapy Research, 3307, 1-13. https://doi.org/10.1080/10503307.2017.1294771

Kohli, N., Harring, J. R., \& Hancock, G. R. (2013). Piecewise Linear-Linear Latent Growth Mixture Models With Unknown Knots. Educational and Psychological Measurement, 73(6), 935-955. https://doi.org/10.1177/0013164413496812

Kok, R. M., van Baarsen, C., Nolen, W. A., \& Heeren, T. J. (2009). Early response as predictor of final remission in elderly depressed patients. International Journal of Geriatric Psychiatry, 24(11), 1299-1303. https://doi.org/10.1002/gps.2261

Kraemer, H. C., \& Blasey, C. M. (2004). Centring in regression analyses: a strategy to prevent errors in statistical inference. International Journal of Methods in Psychiatry Research, 13(3), 141-151.

Krause, M. (2005). Psicoterapia y Cambio. Una mirada desde la subjetividad [Psychotherapy and Change. An approach from subjetivity]. Santiago de Chile: Pontificia Universidad Católica de Chile.

Lambert, M. J. (2005). Early response in psychotherapy: Further evidence for the importance of common factors rather than "placebo effects." Journal of Clinical Psychology, 61(7), 855-869. https://doi.org/10.1002/jclp.20130

Lambert, M. J. (2013a). Introduction and Historical Overview. In Bergin and Garfield's Handbook of Psychotherapy and Behavior Change (pp. 3-20). New Jersey: John Wiley \& Sons, Inc.

Lambert, M. J. (2013b). The Efficacy and Effectiveness of Psychotherapy. In M. J. Lambert (Ed.), Bergin and Garfield's Handbook of Psychotherapy and Behavior 
Change (pp. 169-218). New Jersey: John Wiley \& Sons, Inc.

Lambert, M. J., \& Barley, D. E. (2001). Research summary on the therapeutic relationship and psychotherapy outcome. Psychotherapy: Theory, Research, Practice, Training, 38(4), 357-361. https://doi.org/10.1037/0033-3204.38.4.357

Lambert, M. J., Hansen, N. B., \& Finch, A. E. (2001). Patient-focused research: using patient outcome data to enhance treatment effects. Journal of Consulting and Clinical Psychology, 69(2), 159-72. Retrieved from http://www.ncbi.nlm.nih.gov/pubmed/11393594

Lambert, M. J., Hansen, N. B., Umphress, V., Lunnen, K., Okiishi, J., \& Burlingame, et al. (1996). Administration and scoring manual for the OQ-45.2. Stevenson, MD: American Professional Credentialing Services.

Lambert, M. J., Whipple, J. L., \& Kleinstäuber, M. (2018). Collecting and delivering progress feedback: A meta-analysis of routine outcome monitoring. Psychotherapy, 55(4), 520-537. https://doi.org/http://dx.doi.org/10.1037/pst0000167

Landfield, W. (1971). Personal construct systems in psychotherapy. Lincoln: University of Nebraska Press.

Landfield, W. (1977). Interpretive man: The en- larged self-image. In Nebraska symposium on motivation. Lincoln: University of Nebraska Press.

Large, R. G. (1985). Prediction of treatment response in pain patients: the illness selfconcept repertory grid and EMG feedback. Pain, 21(3), 279-87. Retrieved from http://www.ncbi.nlm.nih.gov/pubmed/3157913

Lee, Y., Ragguett, R. M., Mansur, R. B., Boutilier, J. J., Rosenblat, J. D., Trevizol, A., 
... McIntyre, R. S. (2018). Applications of machine learning algorithms to predict therapeutic outcomes in depression: A meta-analysis and systematic review. Journal of Affective Disorders, 241(March), 519-532.

https://doi.org/10.1016/j.jad.2018.08.073

Leitner, L. M., \& Grant, C. H. (1982). Obesity, Personal Constructs, and Amount of Weight Loss. Psychological Reports, 50(2), 491-498. https://doi.org/10.2466/pr0.1982.50.2.491

Lemmens, L. H. J. M., Galindo-Garre, F., Arntz, A., Peeters, F., Hollon, S. D., DeRubeis, R. J., \& Huibers, M. J. H. (2017). Exploring mechanisms of change in cognitive therapy and interpersonal psychotherapy for adult depression. Behaviour Research and Therapy, 94(May), 81-92. https://doi.org/10.1016/j.brat.2017.05.005

Liang, J., Xu, X., Quiñones, A. R., Bennett, J. M., \& Ye, W. (2011). Multiple trajectories of depressive symptoms in middle and late life: Racial/ethnic variations. Psychology and Aging, 26(4), 761-777. https://doi.org/10.1037/a0023945

Longmore, R. J., \& Worrell, M. (2007). Do we need to challenge thoughts in cognitive behavior therapy? Clinical Psychology Review, 27(2), 173-187. https://doi.org/10.1016/J.CPR.2006.08.001

Lorenzo-Luaces, L. (2018). Representing the heterogeneity of depression in treatment research. Acta Psychiatrica Scandinavica, (138), 360-362. https://doi.org/10.1111/acps.12914

Lorenzo-Luaces, L., DeRubeis, R. J., van Straten, A., \& Tiemens, B. (2017). A prognostic index $(\mathrm{PI})$ as a moderator of outcomes in the treatment of depression: A proof of concept combining multiple variables to inform risk-stratified stepped 
care models. Journal of Affective Disorders, 213(July 2016), 78-85.

https://doi.org/10.1016/j.jad.2017.02.010

Lutz, W. (2002). Adaptive Modeling of Progress in Outpatient Psychotherapy. Psychotherapy Research, 12(4), 427-443. https://doi.org/10.1093/ptr/12.4.427

Lutz, W. (2003). Efficacy, effectiveness, and expected treatment response in psychotherapy. Journal of Clinical Psychology, 59(7), 745-750. https://doi.org/10.1002/jclp.10169

Lutz, W., Arndt, A., Rubel, J., Berger, T., Schröder, J., Späth, C., ... Moritz, S. (2017). Defining and predicting patterns of early response in a web-based intervention for depression. Journal of Medical Internet Research, 19(6). https://doi.org/10.2196/jmir.7367

Lutz, W., De Jong, K., \& Rubel, J. (2015). Patient-focused and feedback research in psychotherapy: Where are we and where do we want to go? Psychotherapy Research, 25(6), 625-632. https://doi.org/10.1080/10503307.2015.1079661

Lutz, W., Ehrlich, T., Rubel, J., Hallwachs, N., Röttger, M. A., Jorasz, C., ... TschitsazStucki, A. (2013). The ups and downs of psychotherapy: Sudden gains and sudden losses identified with session reports. Psychotherapy Research, 23(1), 14-24. https://doi.org/10.1080/10503307.2012.693837

Lutz, W., Lambert, M. J., Harmon, S. C., Tschitsaz, A., Schürch, E., \& Stulz, N. (2006). The probability of treatment success, failure andn duration - What can be learned from empirical data to support decision making in clinical practice? Clinical Psychology and Psychotherapy, 13(4), 223-232. https://doi.org/10.1002/cpp.496

Lutz, W., Leach, C., Barkham, M., Lucock, M., Stiles, W. B., Evans, C., ... Iveson, S. 
(2005). Predicting change for individual psychotherapy clients on the basis of their nearest neighbors. Journal of Consulting and Clinical Psychology, 73(5), 904-13. https://doi.org/10.1037/0022-006X.73.5.904

Lutz, W., Saunders, S. M., Leon, S. C., Martinovich, Z., Kosfelder, J., Schulte, D., ... Tholen, S. (2006). Empirically and clinically useful decision making in psychotherapy: Differential predictions with treatment response models. Psychological Assessment, 18(2), 133-141. https://doi.org/10.1037/10403590.18.2.133

Lutz, W., Stulz, N., \& Köck, K. (2009). Patterns of early change and their relationship to outcome and follow-up among patients with major depressive disorders. Journal of Affective Disorders, 118(1-3), 60-68. https://doi.org/10.1016/j.jad.2009.01.019

Magnusson, K., Andersson, G., \& Carlbring, P. (2018). The consequences of ignoring therapist effects in trials with longitudinal data: A simulation study. Journal of Consulting and Clinical Psychology, 86(9), 711-725. https://doi.org/10.1037/ccp0000333

Mansur, R. B., Santos, C. M., Rizzo, L. B., Asevedo, E., Cunha, G. R., Noto, M. N., ... Brietzke, E. (2016). Brain-derived neurotrophic factor, impaired glucose metabolism, and bipolar disorder course. Bipolar Disorders, 18(4), 373-378. https://doi.org/10.1111/bdi.12399

McAleavey, A. A., \& Castonguay, L. G. (2015). The Process of Change in Psychotherapy: Common and Unique Factors. In O. Gelo, A. Pritz, \& B. Rieken (Eds.), Psychotherapy Research. Foundations, Process, and Outcome (pp. 293310). Springer.

McIntyre, R. S., Florea, I., Tonnoir, B., Loft, H., Lam, R. W., \& Christensen, M. C. 
(2017). Efficacy of Vortioxetine on Cognitive Functioning in Working Patients

With Major Depressive Disorder. The Journal of Clinical Psychiatry, 78(01), 115-

121. https://doi.org/10.4088/JCP.16m10744

McKain, T. L., Glass, C. R., Arnkoff, D. B., Sydnor-Greenberg, J. M., \& Shea, C. A. (1988). Personal constructs and shyness: The relationship between rep grid data and therapy outcome. International Journal of Personal Construct Psychologyl, 1, $151-167$.

McLaughlin, K. A. (2011). The Public Health Impact of Major Depression: A Call for Interdisciplinary Prevention Efforts. Prevention Science, 12(4), 361-371. https://doi.org/10.1007/s11121-011-0231-8

Meeuwissen, J. A. C., Feenstra, T. L., Smit, F., Blankers, M., Spijker, J., Bockting, C. L. H., ... Buskens, E. (2019). The cost-utility of stepped-care algorithms according to depression guideline recommendations - Results of a state-transition model analysis. Journal of Affective Disorders, 242(July 2018), 244-254. https://doi.org/10.1016/j.jad.2018.08.024

Mendes, I., Rosa, C., Stiles, W. B., Caro Gabalda, I., Gomes, P., Basto, I., \& Salgado, J. (2016). Setbacks in the process of assimilation of problematic experiences in two cases of emotion-focused therapy for depression. Psychotherapy Research, 26(6), 638-652. https://doi.org/10.1080/10503307.2015.1136443

Miller, S. D., Duncan, B. L., \& Sorrell, R. (2006). Using Formal Client Feedback to Improve Retention and Outcome: Making Ongoing, Real-time Assessment Feasible. Journal of Brief Therapy, 5(1), 5-22.

Miller, S. D., Duncan, B. L., Sparks, J. A., \& Claud, D. A. (2003). The Outcome Rating Scale : A Preliminary Study of the Reliability, Validity, and Feasibility of a, 2(2), 
91-100.

Moggia, D., Niño-Robles, N., Miller, S. D., \& Feixas, G. (2018). Psychometric Properties of the Outcome Rating Scale (ORS) in a Spanish Clinical Sample. The Spanish Journal of Psychology, 21(e30), 1-7. https://doi.org/10.1017/sjp.2018.32

Montesano, A., Feixas, G., Caspar, F., \& Winter, D. (2017). Depression and Identity: Are Self-Constructions Negative or Conflictual? Frontiers in Psychology, 8, 877. https://doi.org/10.3389/fpsyg.2017.00877

Montesano, A., Feixas, G., Saúl, L. A., Caicedo, M. I. E., Dada, G., \& Winter, D. (2014). Cognitive conflicts and symptom severity in dysthymia: "I ' d rather be good than happy”. Salud Mental, 37(1), 41-48. Retrieved from http://www.scielo.org.mx/scielo.php?pid=S018533252014000100006\&script=sci_arttext

Montesano, A., López-González, M. A., Saúl, L. Á., \& Feixas, G. (2015). A review of cognitive conflicts research: a meta-analytic study of prevalence and relation to symptoms. Neuropsychiatric Disease and Treatment, 12, 2997-3006. https://doi.org/10.2147/NDT.S91861

Morris, J. B. (1977). Appendix I. The Prediction and Measurement of Change in a Psychotherapy Group Using the Repertory Grid. In F. Fransella \& D. Bannister (Eds.), A Manual for Repertory Grid Technique (pp. 120-148). London: Academic Press.

Müller, V. N. L. S., Boyle, K., Zimmermann, D., Weinmann-Lutz, B., Rubel, J. A., \& Lutz, W. (2018). ¿Qué es la atención personalizada en salud mental? [What is personalised care in mental health? Revista Argentina de Clínica Psicológica [Argetinian Journal of Clinical Psychology], XXVII(II), 157-169. 
https://doi.org/10.24205/03276716.2018.1062

Munder, T., Flückiger, C., Leichsenring, F., Abbass, A. A., Hilsenroth, M. J., Luyten, P., ... Wampold, B. E. (2018). Is psychotherapy effective? A re-analysis of treatments for depression. Epidemiology and Psychiatric Sciences, 1-7. https://doi.org/10.1017/S2045796018000355

Muthén, B. (2004). Latent variable analysis: Growth mixture modeling and related techniques for longitudinal data. In D. Kaplan (Ed.), The SAGE Handbook of Quantitative Methodology for the Social Sciences (pp. 1-24). Newbury Park, CA: Sage. https://doi.org/10.4135/9781412986311.n19

Muthén, B., Brown, C. H., Hunter, A., Cook, I. a, \& Leuchter, a F. (2011). General approaches to analysis of course: Applying growth mixture modeling to randomized trials of depression medication. Causality and Psychopathology: Finding the Determinants of Disorders and Their Cures (Pp, 159-178.

Muthén, L. K., \& Muthén, B. O. (2012). Mplus. Statistical Analysis With Latent Variables. User's Guide. 7th Edition. Los Angeles, CA: Muthén \& Muthén. Retrieved from https://www.statmodel.com/download/usersguide/Mplus user guide Ver_7_r3_web.pdf

National Collaborating Centre for Mental Health. (2011). Generalised Anxiety Disorder in Adults. Generalised Anxiety Disorder in Adults: Management in Primary, Secondary and Community Care. London: Leicester (UK). Retrieved from http://www.ncbi.nlm.nih.gov/pubmed/22536620

National Research Council. (2011). Toward Precision Medicine: Building a Knowledge Network for Biomedical Research and a New Taxonomy of Disease. Washington, D.C.: National Academies Press. https://doi.org/10.17226/13284 
Nazar, B. P., Gregor, L. K., Albano, G., Marchica, A., Coco, G. Lo, Cardi, V., \& Treasure, J. (2017). Early Response to treatment in Eating Disorders: A Systematic Review and a Diagnostic Test Accuracy Meta-Analysis. European Eating Disorders Review, 25(2), 67-79. https://doi.org/10.1002/erv.2495

Neimeyer, G. J. (1993). Constructivist Assessment: A casebook. London: Sage Publications.

Neimeyer, R. A. (2009). Constructivist Psychotherapy. Distinctive features. London: Routledge.

Neimeyer, R. A., \& Feixas, G. (2016). The Role of Homework and Skill Acquisition in the Outcome of Group Cognitive Therapy for Depression - Republished Article. Behavior Therapy, 47(5), 747-754. https://doi.org/10.1016/j.beth.2016.08.013

Neimeyer, R. A., \& Mahoney, M. J. (1995). Constructivism in Psychotherapy. Washington, DC: American Psychological Association.

Neimeyer, R. A., \& Winter, D. A. (2007). Personal Construct Therapy. In Handbook of Homework Assignments in Psychotherapy (pp. 151-171). New York: Springer. https://doi.org/10.1007/978-0-387-29681-4_10

Neimeyer, R., Harter, S., \& Alexander, P. (1991). Group Perceptions as Predictors of Outcome in the Treatment of Incest Survivors. Psychotherapy Research, 1(2), 148-158. https://doi.org/10.1080/10503309112331335571

Norcross, J. C., \& Lambert, M. J. (2018). Psychotherapy relationships that work III. Psychotherapy, 55(4), 303-315. https://doi.org/10.1037/pst0000193

Norcross, J. C., \& Wampold, B. E. (2011a). Evidence-Based Therapy Relationships: Research Conclusions and Clinical Practices. Psychotherapy, 48(1), 98-102. 
https://doi.org/10.1037/a0022161

Norcross, J. C., \& Wampold, B. E. (2011b). What works for whom: Tailoring psychotherapy to the person. Journal of Clinical Psychology, 67(2), 127-132. https://doi.org/10.1002/jclp.20764

Nylund, K. L., Asparouhov, T., \& Muthén, B. O. (2007). Deciding on the Number of Classes in Latent Class Analysis and Growth Mixture Modeling: A Monte Carlo Simulation Study. Structural Equation Modeling: A Multidisciplinary Journal, 14(4), 535-569. https://doi.org/10.1080/10705510701575396

Oei, T. P. S., \& Free, M. . (1995). Do cognitive behaviour therapies validate cognitive models of mood disorders? A review of the empirical evidence. International Journal of Psychology, 30, 145-179.

Okumura, Y., \& Ichikura, K. (2014). Efficacy and acceptability of group cognitive behavioral therapy for depression: A systematic review and meta-analysis. Journal of Affective Disorders, 164, 155-164. https://doi.org/10.1016/j.jad.2014.04.023

Orford, J. (1974). Simplistic thinking about other people as a predictor of early drop-out at an alcoholism halfway house. British Journal of Medical Psychology, 47(1), 5362. https://doi.org/10.1111/j.2044-8341.1974.tb02271.x

Owen, J., Adelson, J., Budge, S., Wampold, B., Kopta, M., Minami, T., \& Miller, S. (2015). Trajectories of Change in Psychotherapy. Journal of Clinical Psychology, 71(9), 817-827. https://doi.org/10.1002/jclp.22191

Paige Peterson, A., \& Fagan, C. (2017). Training the next generation in routine outcome monitoring: Current practices in psychology training clinics. Training and Education in Professional Psychology, 11(3), 182-189. 
https://doi.org/10.1037/tep0000148

Parikh, S. V., Quilty, L. C., Ravitz, P., Rosenbluth, M., Pavlova, B., Grigoriadis, S., ... Uher, R. (2016). Canadian Network for Mood and Anxiety Treatments (CANMAT) 2016 Clinical Guidelines for the Management of Adults with Major Depressive Disorder. The Canadian Journal of Psychiatry, 61(9), 524-539. https://doi.org/10.1177/0706743716659418

Paul, G. L. (1967). Strategy of outcome research in psychotherapy. Journal of Consulting Psychology, 31(2), 109-118. https://doi.org/10.1037/h0024436

Paz, C. (2016). Change in cognitive conflicts and the construction of the self in two modalities of cognitive therapy for depression. Universitat de Barcelona.

Paz, C., Montesano, A., Winter, D., \& Feixas, G. (2019). Cognitive conflict resolution during psychotherapy: Its impact on depressive symptoms and psychological distress. Psychotherapy Research, 29(1), 45-57. https://doi.org/10.1080/10503307.2017.1405172

Prescott, D. S., Maeschalck, C., \& Miller, S. D. (2017). Feedback-Informed Treatment in Clinical Practice. Washington, D.C.: American Psychological Association (APA).

Pucurull, O. (2015). Psicoterapia breve con un enfoque cognitivo constructivista en la atención primaria: Cambios sintomáticos y cognitivos. Universitat de Barcelona.

Ram, N., \& Grimm, K. J. (2009). Growth Mixture Modeling: A Method for Identifying Differences in Longitudinal Change Among Unobserved Groups. International Journal of Behavioural Development, 33(6), 565-576. https://doi.org/10.1177/0165025409343765.Growth 
Reese, R. J., Norsworthy, L., \& Rowlands, S. (2009). Does continuous feedback system improve psychotherapy outcome? Psychotherapy: Theory Research \& Practice, $46,418-431$.

Ribeiro, E., Cunha, C., Teixeira, A. S., Stiles, W. B., Pires, N., Santos, B., ... Salgado, J. (2016). Therapeutic collaboration and the assimilation of problematic experiences in emotion-focused therapy for depression: Comparison of two cases. Psychotherapy Research, 26(6), 665-680.

https://doi.org/10.1080/10503307.2016.1208853

Rouco, V., Paz, C., Winter, D., \& Feixas, G. (2018). On the Measurement of Implicative Dilemmas. Journal of Constructivist Psychology, 1-16. https://doi.org/10.1080/10720537.2018.1499159

Rubel, J., Lutz, W., Kopta, S. M., Köck, K., Minami, T., Saunders, S. M., \& Zimmermann, D. (2014). Psychological Assessment Defining Early Positive Response to Psychotherapy: An Change Criteria and Growth Mixture Modeling Defining Early Positive Response to Psychotherapy: An Empirical Comparison Between Clinically Significant Change Criteria and Grow. Psychological Assessment, 27(2), 478-488. Retrieved from http://dx.doi.org/10.1037/pas0000060

Rubel, J., Lutz, W., \& Schulte, D. (2015). Patterns of Change in Different Phases of Outpatient Psychotherapy: A Stage-Sequential Pattern Analysis of Change in Session Reports. Clinical Psychology and Psychotherapy, 22(1), 1-14. https://doi.org/10.1002/cpp.1868

Sakurai, H., Uchida, H., Abe, T., Nakajima, S., Suzuki, T., Pollock, B. G., ... Mimura, M. (2013). Trajectories of individual symptoms in remitters versus non-remitters with depression. Journal of Affective Disorders, 151(2), 506-13. 
https://doi.org/10.1016/j.jad.2013.06.035

Sanz, J. (2013). 50 Años de los Inventarios de Depresion de Beck. Consejos para la utilizacion de la adaptacion espanola del BDI-II en la practica clinica. [50 years of Beck's depression inventories. Advices for the utilisation of the BDI-II in the clinical practice]. Papeles Del Psicologo, 34(3), 161-168. Retrieved from http://www.papelesdelpsicologo.es/pdf/2275.pdf

Sasso, K. E., Strunk, D. R., Braun, J. D., DeRubeis, R. J., \& Brotman, M. A. (2015). Identifying moderators of the adherence-outcome relation in cognitive therapy for depression. Journal of Consulting and Clinical Psychology, 83(5), 976-984. https://doi.org/10.1037/ccp0000045

Saxon, D., Delgadillo, J., Barkham, M., \& Firth, N. (2018). La evidencia basada en la práctica y la ley de la variabilidad en el tratamiento psicológico [Practice-based evidence and the law of variability in psyhcological treatments]. Revista Argentina De Clinica Psicologica, XXVII, 115-125. https://doi.org/10.24205/03276716.2018.1059

Schiefele, A.-K., Lutz, W., Barkham, M., Rubel, J., Böhnke, J., Delgadillo, J., ... Lambert, M. J. (2017). Reliability of Therapist Effects in Practice-Based Psychotherapy Research: A Guide for the Planning of Future Studies. Administration and Policy in Mental Health and Mental Health Services Research, 44(5), 598-613. https://doi.org/10.1007/s10488-016-0736-3

Schlagert, H., \& Hiller, W. (2015). Häufigkeit und prädiktiver Wert von Early Response in naturalistischen Psychotherapien [Frequency and predictive value of early response in naturalistic psychotherapy]. Zeitschrift Für Klinische Psychologie Und Psychotherapie [Journal of Clinical Psychology and Psychotherapy], 44(3), 159- 
168. https://doi.org/10.1026/1616-3443/a000314

Schlagert, H., \& Hiller, W. (2017). The predictive value of early response in patients with depressive disorders. Psychotherapy Research, 27(4), 488-500. https://doi.org/10.1080/10503307.2015.1119329

Shimokawa, K., Lambert, M. J., \& Smart, D. W. (2010). Enhancing treatment outcome of patients at risk of treatment failure: Meta-analytic and mega-analytic review of a psychotherapy quality assurance system. Journal of Consulting and Clinical Psychology, 78(3), 298-311. https://doi.org/10.1037/a0019247

Silverstone, P. H., Rittenbach, K., Suen, V. Y. M., Moretzsohn, A., Cribben, I., Bercov, M., ... Trew, M. (2017). Depression outcomes in adults attending family practice were not improved by screening, stepped-care, or online CBT during a 12-week study when compared to controls in a randomized trial. Frontiers in Psychiatry, 8(MAR), 1-10. https://doi.org/10.3389/fpsyt.2017.00032

Söchting, I., Wilson, C., \& De Gagné, T. (2010). Cognitive Behavioural Group Therapy (CBGT): capitalizing on efficiency and humanity. In J. Bennett-Levy, D. A. Richards, P. Farrand, H. Christensen, K. M. Griffiths, D. J. Kavanagh, ... C. Williams (Eds.), Oxford Guide to Low Intensity CBT Interventions (pp. 323-330). Oxford: Oxford University Press.

Soriano-Mas, C., Hernández-Ribas, R., Pujol, J., Urretavizcaya, M., Deus, J., Harrison, B. J., ... Cardoner, N. (2011). Cross-Sectional and Longitudinal Assessment of Structural Brain Alterations in Melancholic Depression. Biological Psychiatry, 69(4), 318-325. https://doi.org/10.1016/j.biopsych.2010.07.029

Stewart, J. W., Quitkin, F. M., McGrath, P. J., Amsterdam, J., Fava, M., Fawcett, J., ... Roback, P. (1998). Use of Pattern Analysis to Predict Differential Relapse of 
Remitted Patients With Major Depression During 1 Year of Treatment With Fluoxetine or Placebo. Archives of General Psychiatry, 55(4), 334-343. https://doi.org/10.1001/archpsyc.55.4.334

Strawbridge, R., Arnone, D., Danese, A., Papadopoulos, A., Herane Vives, A., \& Cleare, A. J. (2015). Inflammation and clinical response to treatment in depression: A meta-analysis. European Neuropsychopharmacology, 25(10), 1532-1543. https://doi.org/10.1016/j.euroneuro.2015.06.007

Strunk, D. R., Cooper, A. A., Ryan, E. T., DeRubeis, R. J., \& Hollon, S. D. (2012). The process of change in cognitive therapy for depression when combined with antidepressant medication: Predictors of early intersession symptom gains. Journal of Consulting and Clinical Psychology, 80(5), 730-738.

https://doi.org/10.1037/a0029281

Stulz, N., \& Lutz, W. (2007). Multidimensional patterns of change in outpatient psychotherapy: The phase model revisited. Journal of Clinical Psychology, 63(9), 817-833. https://doi.org/10.1002/jclp.20397

Stulz, N., Lutz, W., Leach, C., Lucock, M., \& Barkham, M. (2007). Shapes of Early Change in Psychotherapy Under Routine Outpatient Conditions. Journal of Consulting and Clinical Psychology, 75(6), 864-874. https://doi.org/10.1037/0022006X.75.6.864

Stulz, N., Thase, M. E., Klein, D. N., Manber, R., \& Crits-Christoph, P. (2010). Differential effects of treatments for chronic depression: A latent growth model reanalysis. Journal of Consulting and Clinical Psychology, 78(3), 409-419. https://doi.org/10.1037/a0019267

Swift, J. K., \& Callahan, J. L. (2009). The impact of client treatment preferences on 
outcome: a meta-analysis. Journal of Clinical Psychology, 65(4), 368-381.

https://doi.org/10.1002/jclp.20553

Tamayo-Sarver, J. H., Albert, J. M., Tamayo-Sarver, M., \& Cydulka, R. K. (2005).

Advanced Statistics: How to Determine Whether Your Intervention Is Different, At Least As Effective As, or Equivalent: A Basic Introduction. Academic Emergency Medicine, 12(6), 536-542. https://doi.org/10.1197/j.aem.2005.01.010

Tang, T. Z., \& DeRubeis, R. J. (1999). Reconsidering Rapid Early Response in Cognitive Behavioral Therapy for Depression. Clinical Psychology: Science and Practice, 6(3), 283-288. https://doi.org/10.1093/clipsy.6.3.283

Thase, M. E., Greenhouse, J. B., Frank, E., Reynolds, C. F., Pilkonis, P. A., Hurley, K., ... Kupfer, D. J. (1997). Treatment of major depression with psychotherapy or psychotherapy-pharmacotherapy combinations. Archives of General Psychiatry, 54(11), 1009-15. Retrieved from http://www.ncbi.nlm.nih.gov/pubmed/9366657

The National Institute for Health and Care Excellence - NICE. (2018). Depression in Adults: Treatment and management. Draft for second consultation. NICE. London, UK. Retrieved from http://www.nice.org.uk/guidance/cg90/resources/guidancedepression-in-adults-pdf.

Thibodeau, M. A., Quilty, L. C., De Fruyt, F., De Bolle, M., Rouillon, F., \& Bagby, R. M. (2015). Latent classes of nonresponders, rapid responders, and gradual responders in depressed outpatients receiving antidepressant medication and psychotherapy. Depression and Anxiety, 32(3), 213-220. https://doi.org/10.1002/da.22293

Trujillo, A. (2016). Técnica de la rejilla interpersonal: Un estudio de validación en población comunitaria [The Interpersonal Repertory Grid Technique. A validation 
study in communitary population]. Universitat de Barcelona. Unpblished Thesis.

Trujillo, A., Feixas, G., Bados, A., García-Grau, E., Salla, M., Medina, J. C., ... Evans, C. (2016). Psychometric properties of the Spanish version of the Clinical Outcomes in Routine Evaluation - Outcome Measure. Neuropsychiatric Disease and Treatment, 12, 1457-66. Retrieved from https://www.dovepress.com/psychometric-properties-of-the-spanish-version-ofthe-clinical-outcome-peer-reviewed-article-NDT

Van, H. L., Schoevers, R. A., Kool, S., Hendriksen, M., Peen, J., \& Dekker, J. (2008). Does early response predict outcome in psychotherapy and combined therapy for major depression? Journal of Affective Disorders, 105(1-3), 261-265. https://doi.org/10.1016/j.jad.2007.04.016

Vittengl, J. R., Clark, L. A., Dunn, T. W., \& Jarrett, R. B. (2007). Reducing relapse and recurrence in unipolar depression: A comparative meta-analysis of cognitivebehavioral therapy's effects. Journal of Consulting and Clinical Psychology, 75(3), 475-488. https://doi.org/10.1037/0022-006X.75.3.475

Vittengl, J. R., Clark, L. A., Thase, M. E., \& Jarrett, R. B. (2013). Nomothetic and idiographic symptom change trajectories in acute-phase cognitive therapy for recurrent depression. Journal of Consulting and Clinical Psychology, 81(4), 615626. https://doi.org/10.1037/a0032879

Wampold, B. E. (2015). How important are the common factors in psychotherapy? An update. World Psychiatry: Official Journal of the World Psychiatric Association (WPA), 14(3), 270-7. https://doi.org/10.1002/wps.20238

Wampold, B. E., \& Imel, Z. E. (2015). The great psychotherapy debate. The evidence for what makes psychotherapy work (2nd ed.). New York: Routledge. 
Wardenaar, K. J., Conradi, H.-J., \& de Jonge, P. (2014). Data-driven course trajectories in primary care patients with major depressive disorder. Depression and Anxiety, 31(9), 778-786. https://doi.org/10.1002/da.22228

Webb, C. A., DeRubeis, R. J., Amsterdam, J. D., Shelton, R. C., Hollon, S. D., \& Dimidjian, S. (2011). Two aspects of the therapeutic alliance: Differential relations with depressive symptom change. Journal of Consulting and Clinical Psychology, 79(3), 279-283. https://doi.org/10.1037/a0023252

Webb, C. A., DeRubeis, R. J., \& Barber, J. P. (2010). Therapist adherence/competence and treatment outcome: A meta-analytic review. Journal of Consulting and Clinical Psychology, 78(2), 200-211. https://doi.org/10.1037/a0018912

Webb, C. A., DeRubeis, R. J., Dimidjian, S., Hollon, S. D., Amsterdam, J. D., \& Shelton, R. C. (2012). Predictors of patient cognitive therapy skills and symptom change in two randomized clinical trials: The role of therapist adherence and the therapeutic alliance. Journal of Consulting and Clinical Psychology, 80(3), 373381. https://doi.org/10.1037/a0027663

Wickrama, K. A. S., Lee, T. K., O’Neal, C. W., \& Lorenz, F. O. (2016). Higher-order growth curves and mixture modeling with Mplus: A practical guide. London: Routledge.

Winter, D. A. (1983). Logical inconsistency in construct relationships: Conflict or complexity? British Journal of Medical Psychology, 56(1), 79-87. https://doi.org/10.1111/j.2044-8341.1983.tb01534.x

Winter, D. A. (1988). Constructions in social skills training. In F. Fransella \& L. Thomas (Eds.), Experimenting with Personal Construct Psychology (pp. 342-356). London: Routledge. 
Winter, D. A. (2003). Repertory Grid Technique as a Psychotherapy Research Measure. Psychotherapy Research, 13(1), 25-42. https://doi.org/10.1093/ptr/kpg005

Winter, D. A., \& Viney, L. (2005). Personal Construct Psychotherapy: Advances in Theory, Practice and Research. London, England: Whurr Publishers Ltd. https://doi.org/10.1002/9780470713686

Winter, D., Goggins, S., Baker, M., \& Metcalfe, C. (1996). Into the community or back to the ward? Clients' construing as a predictor of the outcome of psychiatric rehabilitation. In B. M. Walker, J. Costigan, L. L. Viney, \& B. Warren (Eds.), Personal construct theory: A psychology for the future (pp. 253-270). Australian Psychological Society.

Winter, D., \& Gournay, K. (1987). Construction and constriction in agoraphobia. British Journal of Medical Psychology, 60(3), 233-244. https://doi.org/10.1111/j.2044-8341.1987.tb02736.x

Winter, D., \& Procter, H. (2014). Formulation in personal and relational construct psychology: seeing the world through clients' eyes. In Formulation in Psychology and Psychotherapy. Making sense of people's problems (2nd ed., pp. 145-171). London: Routledge.

Winter, S. E., \& Barber, J. P. (2013). Should treatment for depression be based more on patient preference? Patient Preference and Adherence, 7, 1047-57. https://doi.org/10.2147/PPA.S52746

Wise, T., Radua, J., Via, E., Cardoner, N., Abe, O., Adams, T. M., ... Arnone, D. (2017). Common and distinct patterns of grey-matter volume alteration in major depression and bipolar disorder: Evidence from voxel-based meta-analysis. Molecular Psychiatry, 22(10), 1455-1463. https://doi.org/10.1038/mp.2016.72 
World Health Organisation. (2018a). Depression. Retrieved from

http://www.who.int/en/news-room/fact-sheets/detail/depression

World Health Organisation. (2018b). International Classification of Diseases. Geneva: Author.

Yalom, I. D., \& Leszcz, M. (2005). The Theory and Practice of Group Psychotherapy (5th ed.). New York: Basic Books. 